
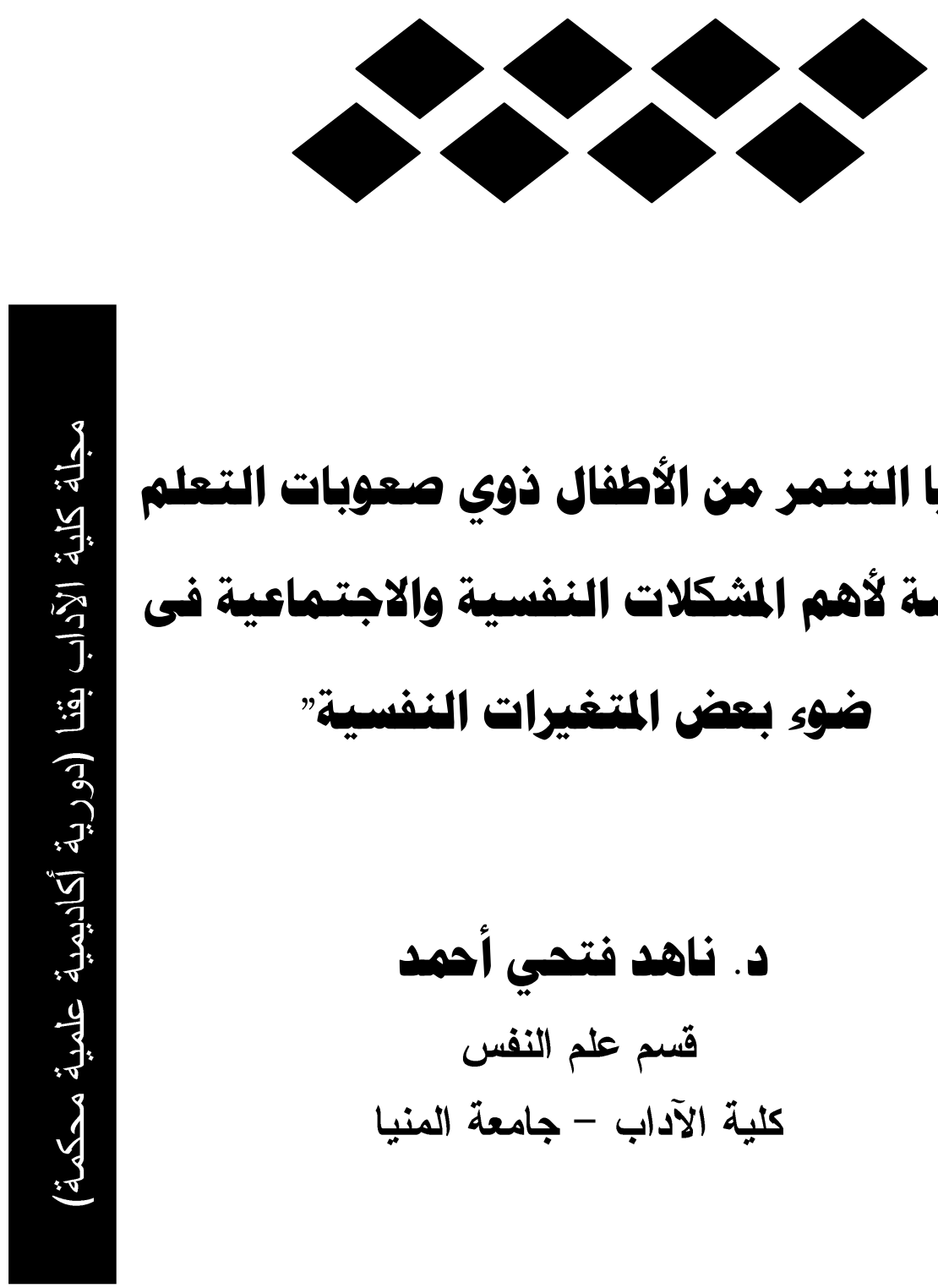

ضمايا التنـهر هن الأطفال ذوي صموبات التملم

"دراسة لأهم الاشكلات النفهية والاجتماعية فى

ضوs بهض المتغيزات النفهية"

$$
\text { د. ناهد فتحي أحمد }
$$

كلية الآداب - جامعة المنيا

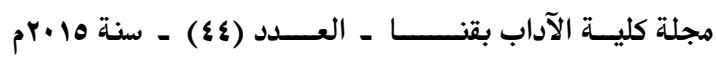


د. ناهد فتحي أحمد

$-\varepsilon \vee \varepsilon-$ 
ضحايا التنمر من الأطفال ذوي صعوبات التعلم "دراسة لأهم المشكلات النفسية والاجتماعية فى ضوء بعض المتغيرات النفسية" -

$$
\text { ضحايا التنمر من الأطفال ذوي صعوبات التعلم }
$$

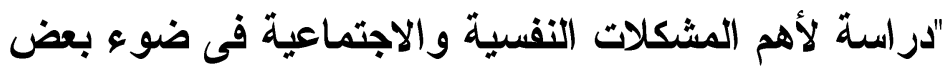

المتغير ات النفسية" ولاتهاع

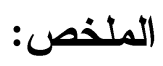

الأهداف: استهدفت الدراسة الراهنة التعرف على أهم المشكلات النفسية والاجتماعية

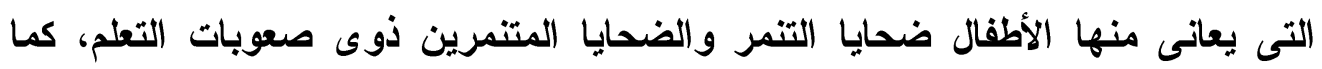

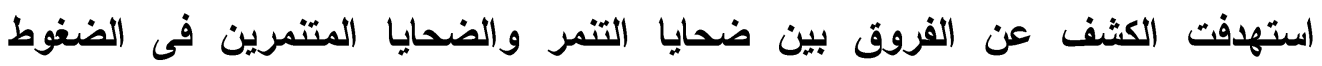

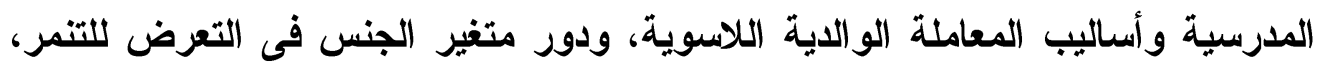

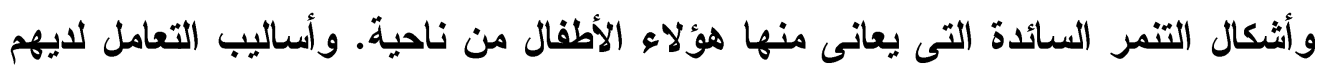

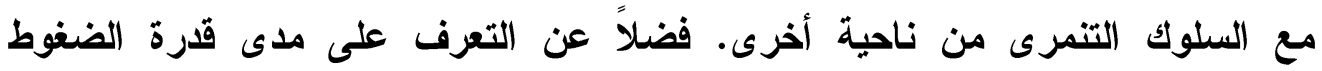

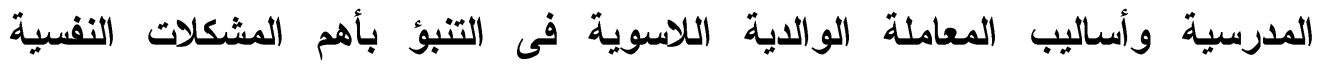
والاجتماعية لدى هؤلاء الأطفال ضحايا التنمر والضحايا المتنمرين ذوى صعوبات التهاته التعلم.

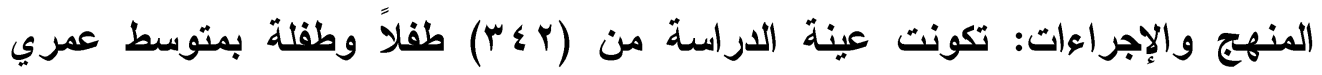

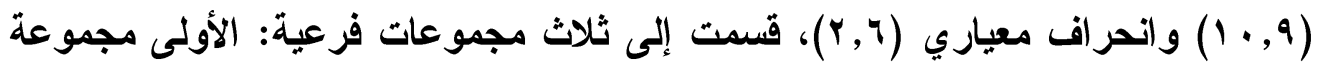

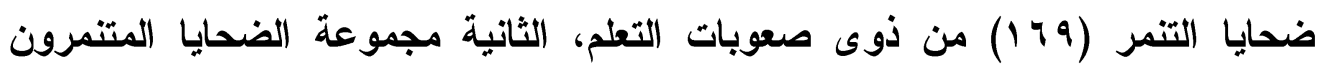
(IVT)

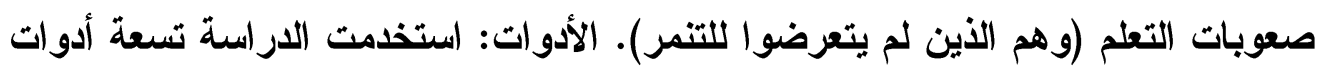
هي: استمارة البيانات الأساسية، مقياس المتنمر/ الضحية، مقياس المشكلات الحياتية

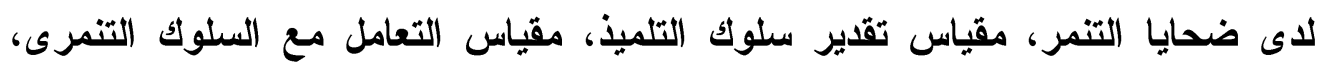

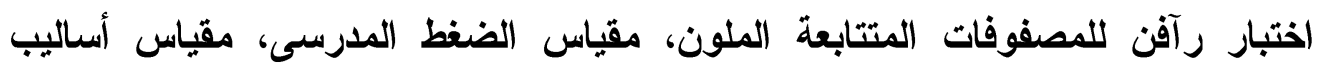

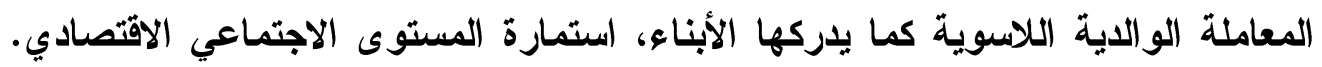

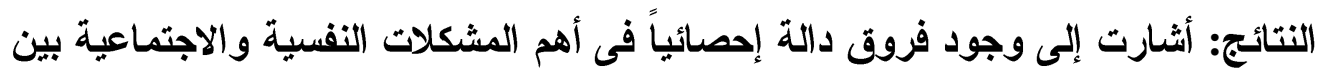

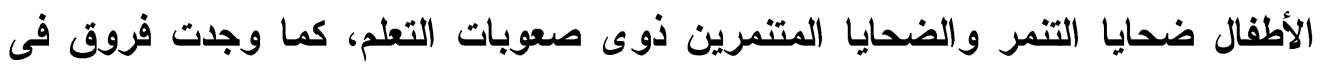

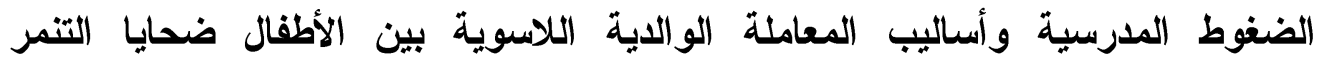
و الضحايا المتنمرين، وكذلك فى أثنكال التنمر السائدة، وفى أساليب التعامل مع السلوك لوكاله

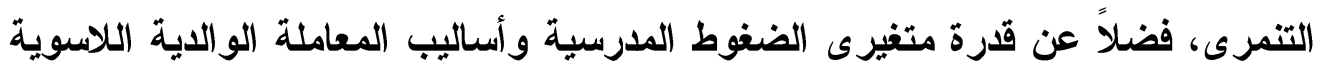

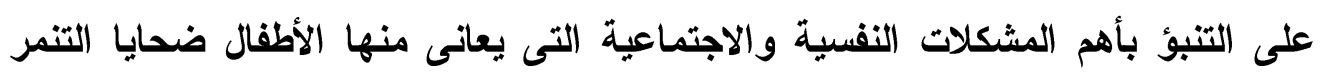
و الضحايا المتنمرين ذوى صعوبات التعلم. 
د. ناهد فتحي أحمد

مقدمة:

أصبح التنمر اليوم مشكلة شائعة وخطيرة في المدارس، وتؤكد الأبحاث مدى الآثار السلبية التي تبقى في ذاكرة الطفل وتؤثر في صحته النفسية على المدى البعيد نتيجة تعرضه للتنمر، وتثبير الأرقام إلى تعرض نصف الأطفال في مرحلة ما من حياتهم

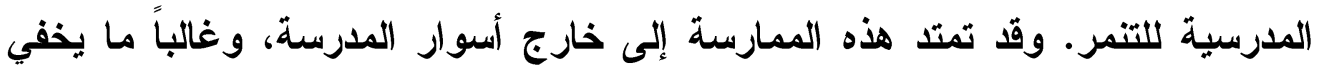
الأطفال عن الأهل معاناتهم بسبب شعورهم بالخجل فهم لا يريدون أن يوصفوا بالضعف. هذه المشكلة أو هذه القضية تنمو وتستمر بخفية تامة في ظل إهمال من الوالدين و إهمال

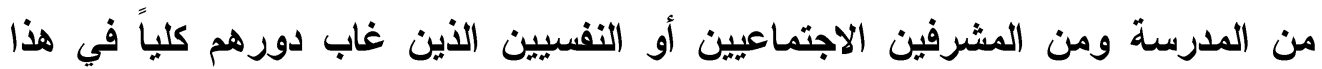

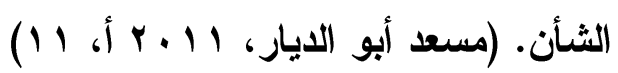
لقد حظيت دراسة التنمر باهتمام الباحثين منذ مطلع السبعينات من القرن السابق

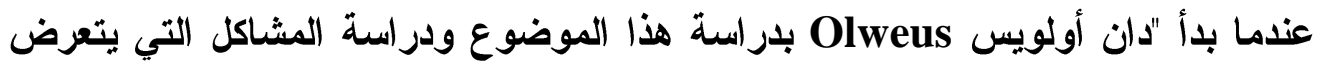

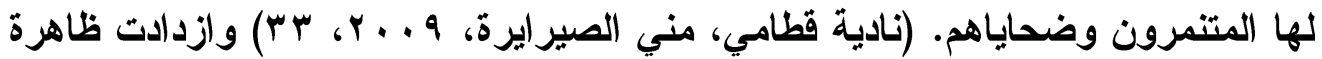
التنمر بشكل ملحوظ في الآونة الأخيرة محلياً وعالمياً حتى أصبحت قضية سلوكية التهية عامة تنتشر في كل المجتمعات وتتجاوز حدود الفروق بين الثقافات وتأخذ صيغاً متباينة بين

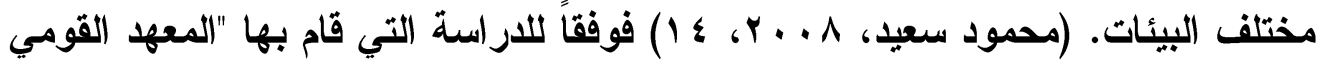

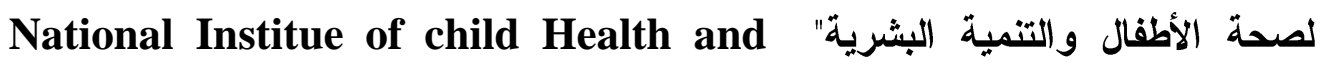
Human Development الولايات المتحدة يمارسون التنمر سواء كانوا ضحايا أو متنمرين، كما وجد أن أكثر من من من لمن

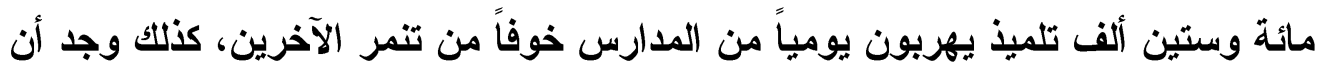
ثلث الأطفال ما بين 11 11 11 سنة قد واجهوا بعض أثنكال التنمر في أثناء وجودهم بالمدرسة. (Hillsberg \& spak, 2006) وفي دراسة مسحية لفون وبيترمانن (Von \& peterman, 2010) بألمانيا كثفت

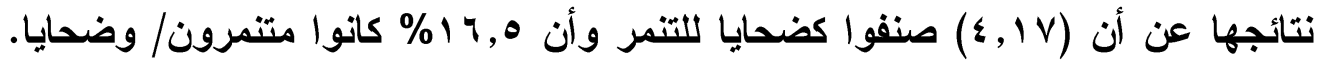

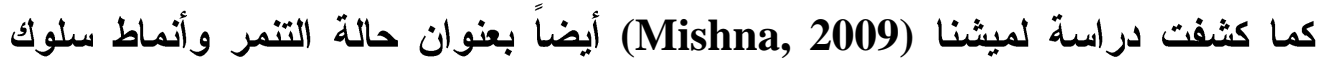

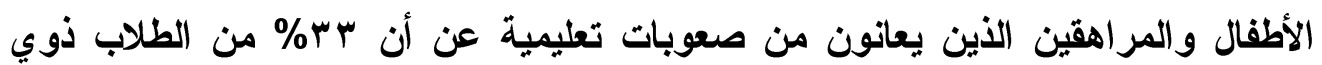


ضحايا التنمر من الأطفال ذوي صعوبات التعلم "دراسة لأهم المشكلات النفسية والاجتماعية فى ضوء بعض المتغيرات النفسية" ـ صعوبات التعلم كانوا ضحايا مقابل 9\% من العاديين، وأن حوالي ه \% من الطلاب ذوي صعوبات التعلم كانوا متنمرين/ ضحايا مقابل ؛ \% من العاديين. وفي دراسة لكاررول ليند وكيرني (Carrol-Lind \& Kearney, 2004) أجريت في نيوزيلندا اتضح أن حوالي بـ\% من الطلاب قد تعرضوا لشكل أو آخر من ممارسات

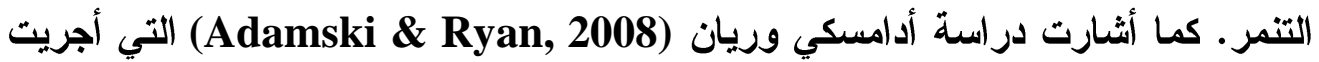

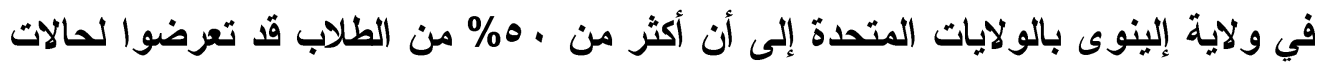

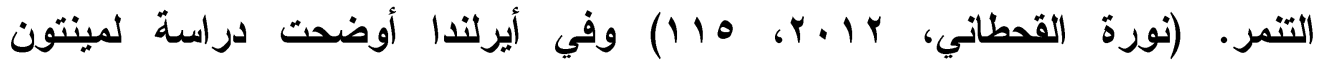
أن ه广\% من طلاب المرحلة الابتدائية قد تعرضوا لمشكلات التنمر (Minton, 2010) في مقابل \&, צس من طلاب المرحلة المتوسطة. كما أظهرت دراسة "يانغ وآخرون" فى مدارس كوريا الجنوبية الأساسية انتشار التنمر بين الطلبة (Yang et al., 2006)

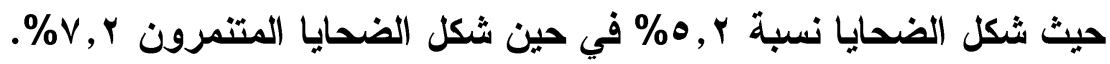
أمسا فى الدول العربية لم تحظ ظاهرة التنمر باهتمام يذكر من الباحثين، وبالتالى فئإن النسب الحقيقية لانتشار هذه الظاهرة تكاد تكون معدومة، ويرى مسعد أبو الديار

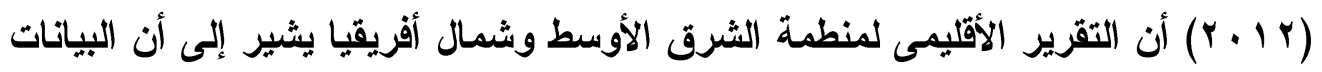

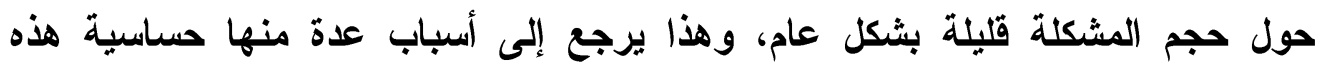

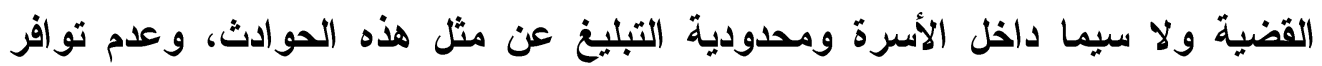

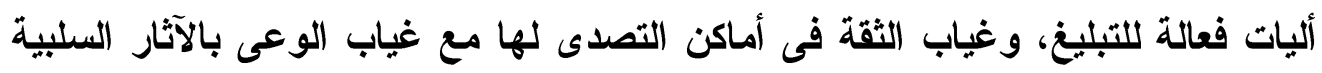

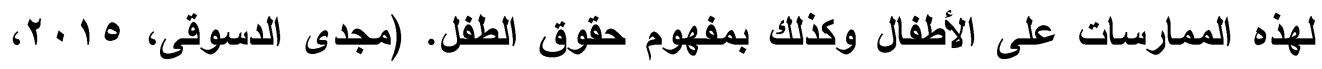

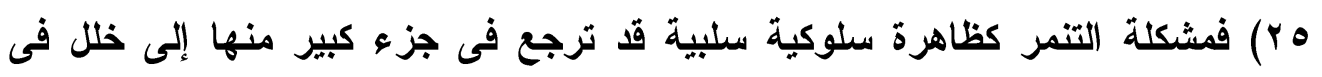

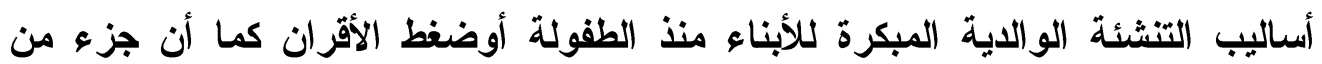
المسئولية يعود إلى ضعف دور المؤسسات التعليمية فى التربية النفسية للطلاب.

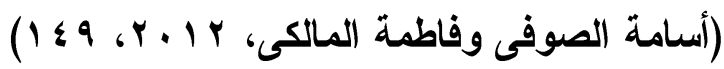

وللتنمر وخاصة التنمر المدرسي العديد من الآثار السلبية على الصحة النفسية سواءواء

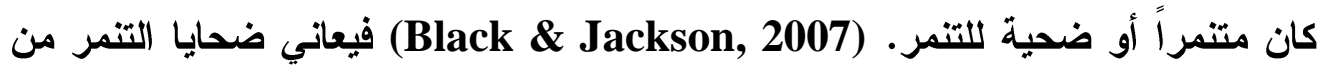
تكيف نفسي سيء، ومن الصعب عليهم إقامة صداقات وهم يميلون إلى الوحدة والإنعزال

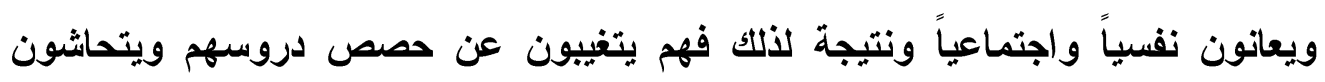




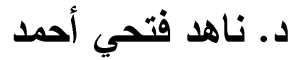

المدرسة. كما أن ضحايا التنمر المزمن في الغالب هم عرضة لغطر حدوث مشاكل بعيدة المدى في أواقات لاحقة. ومن ثم يعانون من ارتفاع معدلات النفور الاجتماعى وهم أكثر

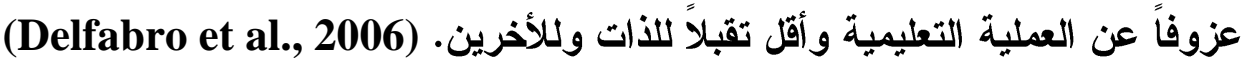
لذا تهدف الاراسة الراهنة إلى استكثاف مدى الآثار أو المشكلات النفسية والاجتماعية التى يعاني منها هؤلاء الأطفال ضحايا التنمر والتى تؤثر في حياتهر التها وسلوكهم وفي أدائهم الأكاديمي. واستكشاف مدي معاناتهم وتأثير الضغوط المداء المدرسية وأساليب المعاملة الو الدية اللاسوية.

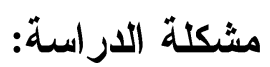
يعد التنمر بين طلاب المدارس من الأطفال والمراهقين مشكلة متز ايدة في العديد من

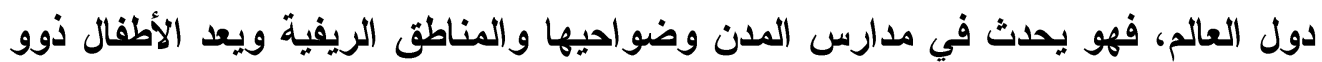
صعوبات التعلم أو اضطراب نقص الاتتباه هم أكثر عرضة لمشكلات التنمر. (مسعد أبو

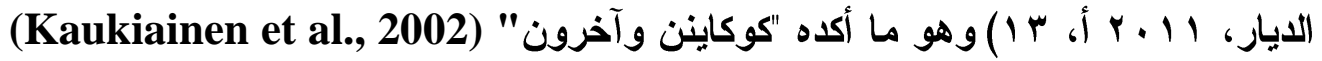
من خلال دراستهم من أن التنمر ينتشر عند الطلبة الذين يعانون من صعوبات في التعلم.

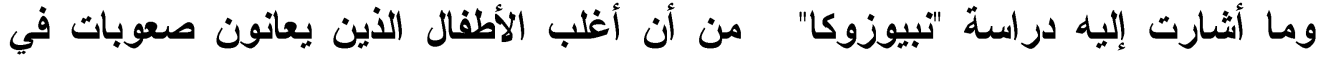

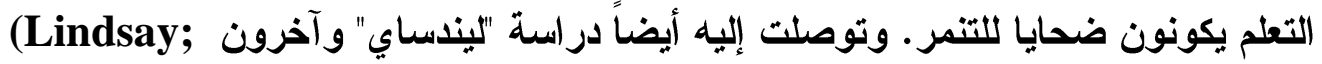
Dockrell \& Mackie, 2008) العاديين والأطفال ذوي صعوبات التعلم في السلوك التنمري في اتجاه ذوي صعوبات

وتحاول الدراسة الراهنة الإجابة عن التساؤلات الآتية:

1- ما هى أهم المشكلات النفسية والاجتماعية التى يعانى منها الأطفال ذوى صعوبات

التعلم ضحايا التنمر والضحايا المتنمرين ؟ فائ

r- هل توجد فروق بين الأطفال ذوى صعوبات التعلم (ضحايا التنمر/ الضحايا

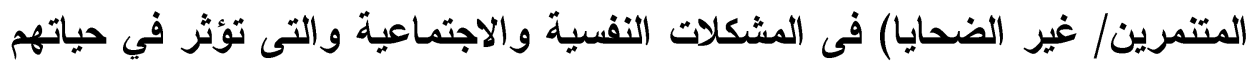

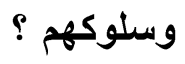

r- هل يعانى الأطفال ذوى صعوبات التعلم ضحايا التنمر والضحايا المتنمرين من

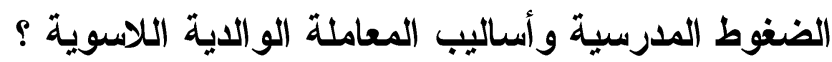


ضحايا التنمر من الأطفال ذوي صعوبات التعلم "دراسة لأهم المشكلات النفسية والاجتماعية فى ضوء بعض المتغيرات النفسية" ـ ع - هل توجد فروق فى المشكلات النفسية والاجتماعية بين الأطفال ذوى صعوبات التعلم

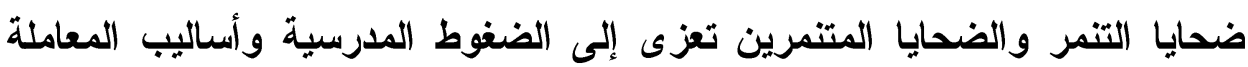

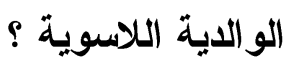

ه- هل تتباين المشكلات النفسية والاجتماعية التى يعانى منها ضحايا التنمر والضحايا

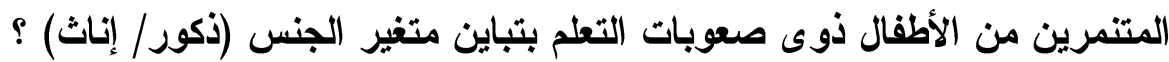

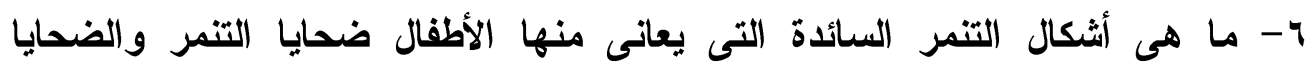
المتنمرين ذوى صعوبات التعلم ؟ - Vيف يتعامل الأطفال ضحايا التنمر والضحايا المتنمرون ذوو صعوبات التعلم مع

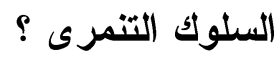
1- هل يمكن التنبؤ بالمشكلات النفسية والاجتماعية لاى الأطفال ذوى صعوبات التعلم

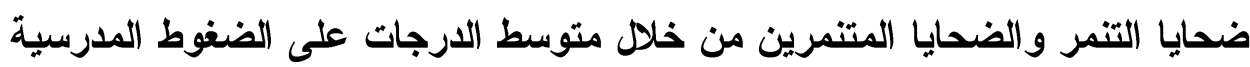
وأساليب المعاملة الو الاية اللاسوية ؟ أهمية الار اسة: 1- تبدو أهمية الاراسة الراهنة من ارتفاع نسب ضحايا التنمر لدى الأطفال ذوي

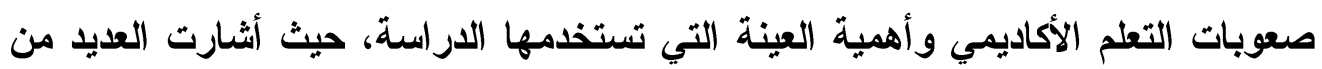
الاراسات ومنها دراسة مكنمارا وآخرين \&cNamara, Vervaeke \& التى أثشارت إلى ارتفاع نسب ضحايا التنمر لدى الأطفال ذوي صعوبات التعلم الأكاديمي، ومنها دراسة نابيوزوكا (Nabuzoka, 2003) التى أثثارت إلى أن أغلب الأطفال الذين يعانون صعوبات في التعلم (LD) يكونون ضحايا للتنمر . كما أثشارت دراسة نورويتش وكيلى (Norwich \& Kelly, 2004) إلى ارتفاع نسبة التنمر في مدارس صعوبات التعلم مقارنة بالمدارس العادية. وما أثنارت إليه نتائج دراسة (Luciano \& Savage, 2007) من أن الأطفال ذوي صعوبات التعلم في مدارس الامبج التي تطبق عليهم سياسة عدم الفصل ما يزالون يواجهون سلوك التنمر مواجهة كبيرة.

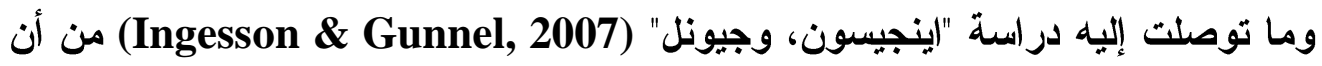

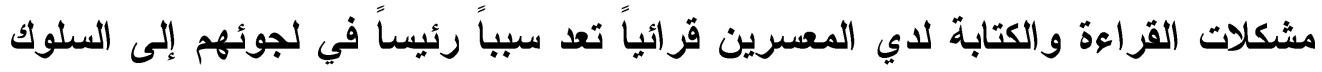

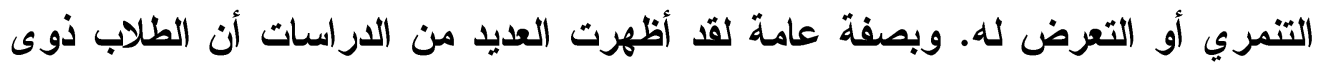


الإعاقات هم أكثر احتمال لأن يكونوا ضحايا للتنمر مقارنة بمن هم ليسوا من ذوى (Farmer et al., 2010; Rose, Espelage \& Monda-Amaya, . الإعاقات. 2009; Rose, Monda-Amaya, \& Espelage, 2011; Turner et al., 2011; Bear et al., 2015) r- لاحظ شاو وآخرون (Shaw et al., 2013) أن السلوكيات المتعلقة بالتنمر تزداد فى

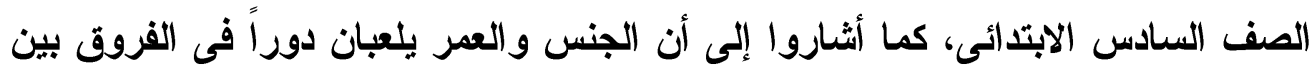

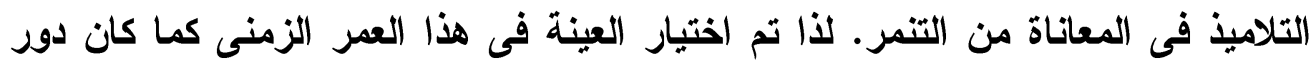
النوع هو أحد اهتمامـات هذه الدراسة. r- يرى بيانى (Beane, 1999) أن المتنمرين والضحايا يعانون من مشكلات وصعوبات نفسية وجسمية تؤثر على حياتهم ونموهم، وأن التدخل المبكر وإثارة الوعي ضروريان

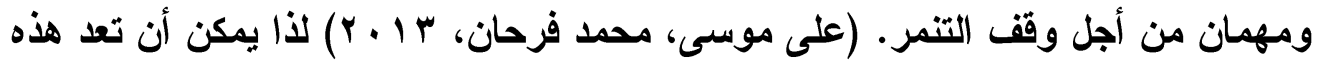

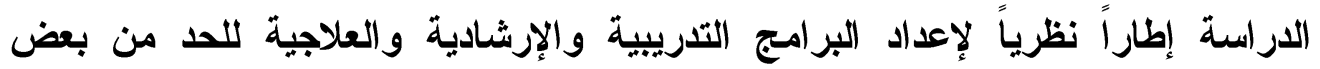
المشكلات النفسية والاجتماعية لاى ضحايا التنمر أو المتنمرين الضحايا أنفسهم. خاصة فى ظل ندرة الدراسات العربية والمصرية بثكل خاص على ضحايا التنمر ذوي صعوبات

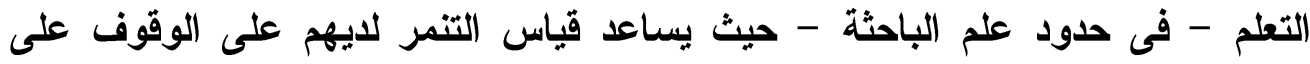
مصادره، وأثكاله السائدة وهو ما يمكن أن يساعد المتخصصين في وضع استراتيجيات

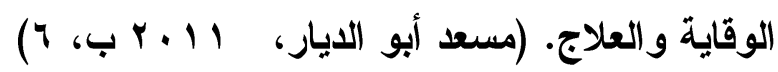
مفاهيم الار اسة:

1- مفهوم التنمر: Bullying Concept يرى دان أولويس النرويجي (Olweus, 1993, 9) وهو من أوائل من درسوا وعرفوا هذا المفهوم أن التنمر "هو شكل من أثنكال العنف الثائعة جداً بين الأطفال

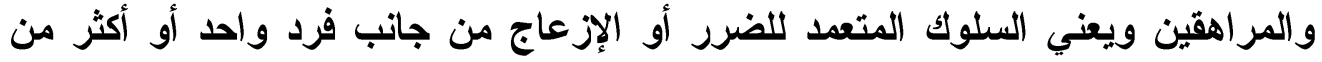

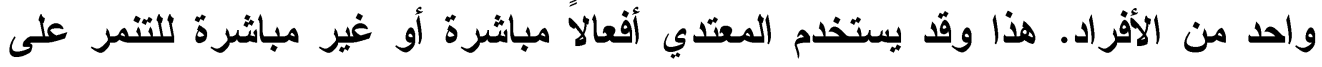
الآخرين، والتنمر المباشر هو يتم على الآخرين من خلال العدوان اللفظي أو الجسمي،

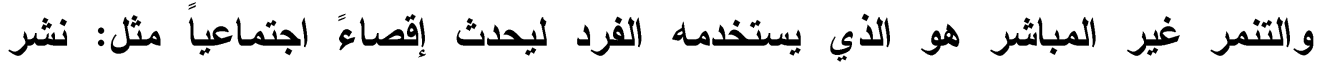
الثائعات، ويمكن أن يكون التنمر غير المباشر ضار جداً على أداء الفرد مثله مثل التنمر

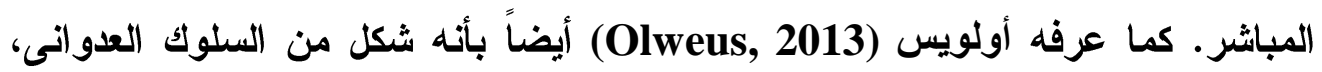


ضحايا التنمر من الأطفال ذوي صعوبات التعلم "دراسة لأهم المشكلات النفسية والاجتماعية فى ضوء بعض المتغيرات النفسية" ـ

بحيث يكون متعد ومتكرر، ويسبب الأذى والألم أو الإزعاج لشخص أخر. وهو ما أثثار

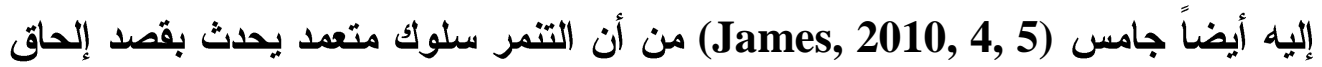

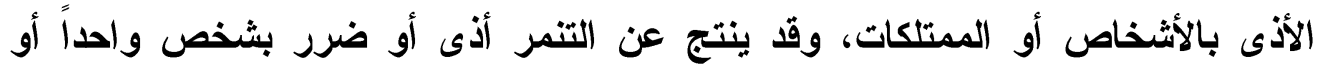

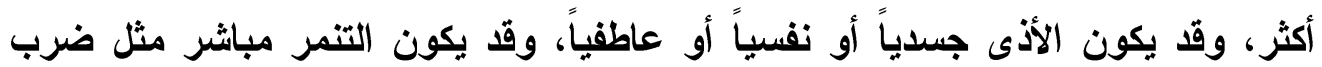

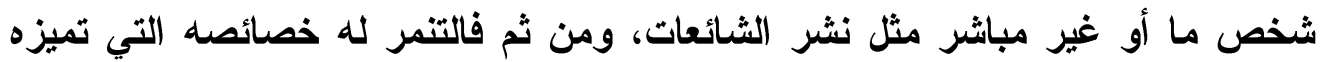
عن غيره من السلوكيات العدوانية.

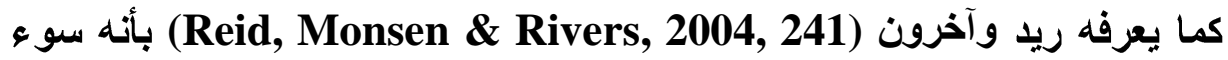
استخدام ممنهج بثكل منتظم للقوة ميع التكرار والتعدد والأذى للآخرين. فالتنمر ريما يكون بثكل فردي أو في جماعة ويكون التفاعل سلبى حيث يسلك الفرد المسيطر سلوكاً

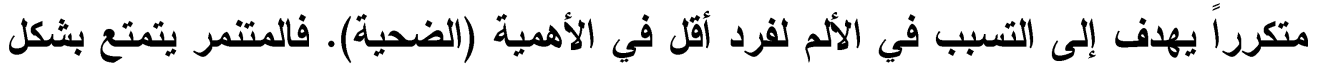

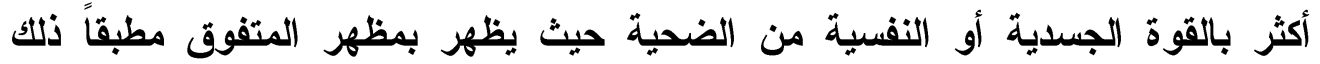

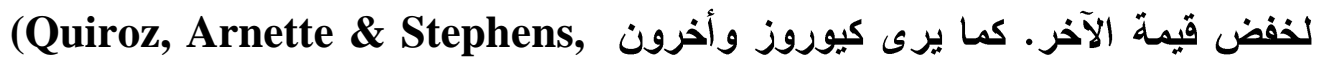

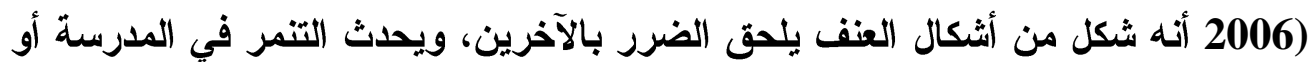

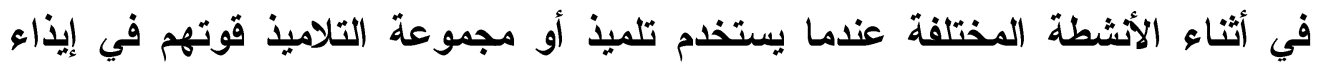

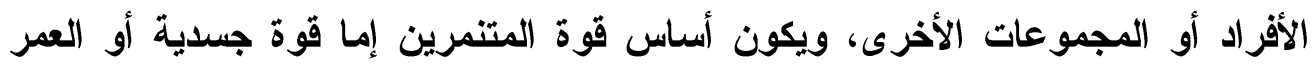

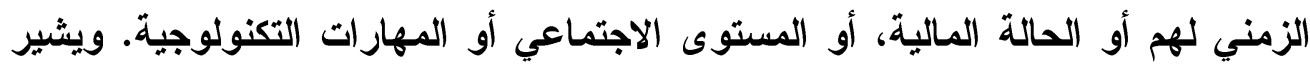
إلبه كلا من كريستينسين وسميث (Kristensen \& Smith, 2003) على أنه فعل سلبي تجاه طقل أو أكثر بثكل مقصود، من أجل الضرر به والإساءة إليه، بحيث لا يكون هناك توازن بينهم.

كما عرفه آدمس Admas بأنه عبارة عن استغلال بعض الأطفال لقوتهم الجسدية

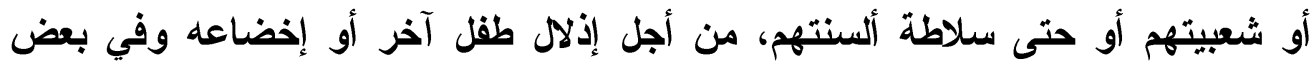

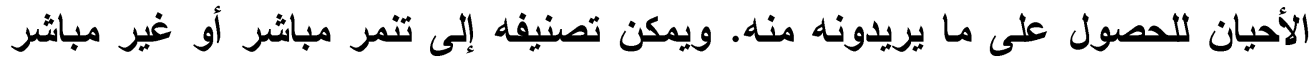

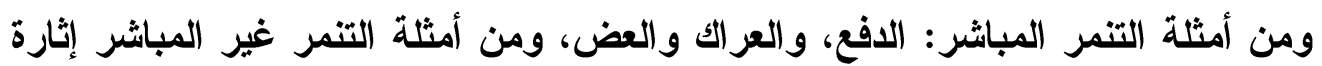

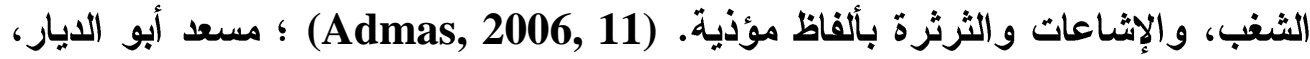

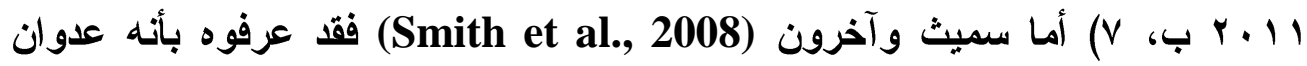
متكرر سواء بصورة لفظية أو نفسية أو جسدية يصدر من فرد أو مجموعة أفراد ضد 
د. ناهد فتحي أحمد

ويعد التنمر المدرسي شكلاً من أثكال التفاعل العدواني غير المتوازن وهو يحدث

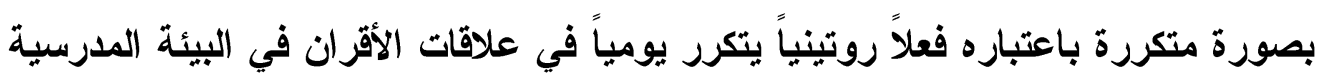

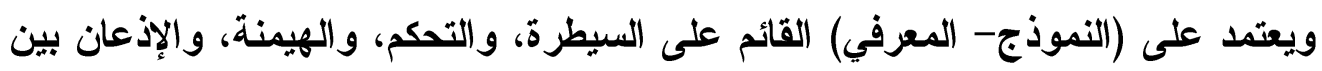

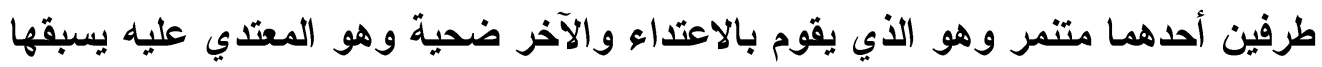

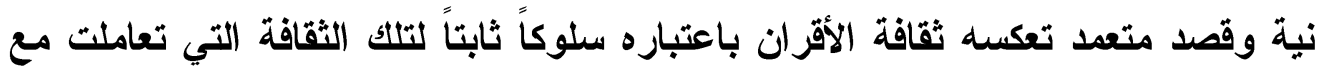

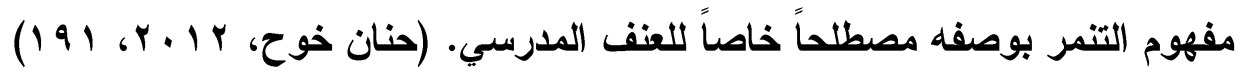
كما يعرف أولويس (Olweus \& Sue, 2002, 8) التمر المدرسي بأنه "أفعال سلبية متعدة من قبل تلميذ أو أكثر لإلحاق الأذى بتلميذ آخر، تتم بشكل متكرر وطوال

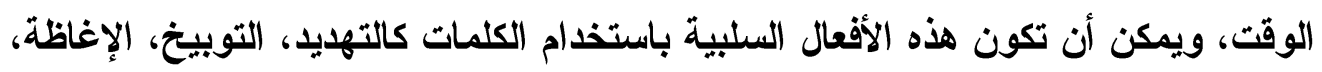

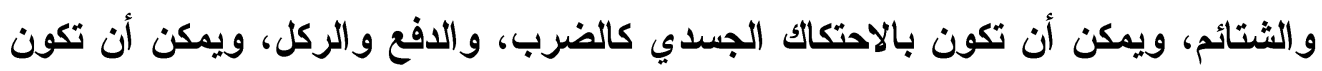

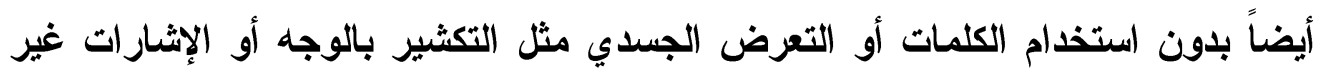

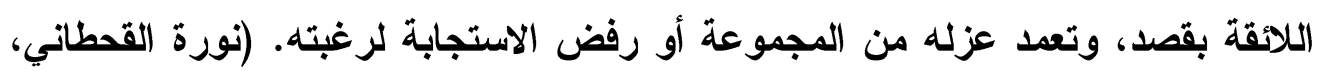

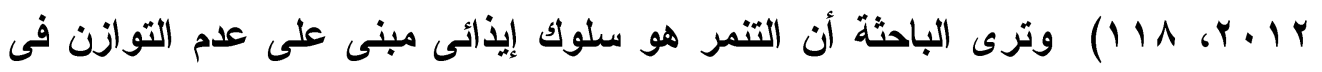

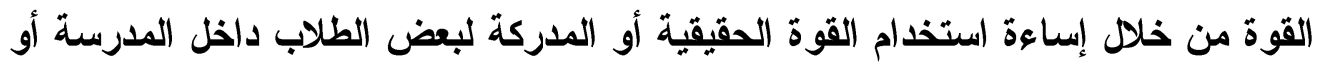

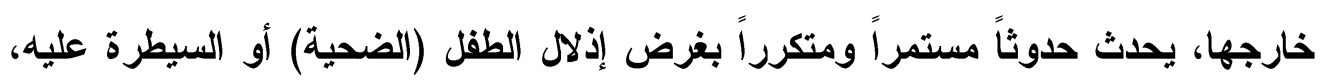
وهو إما أن يكون لفظياً أو جسدياً أو عاطفياً أو جنسياً أو عنصرياً أو عبر الإنترنت الون.

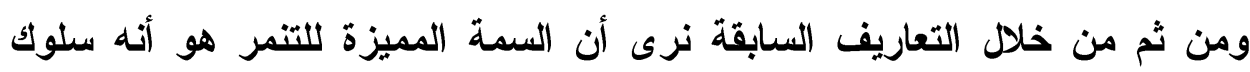

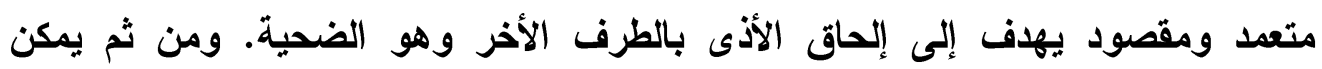

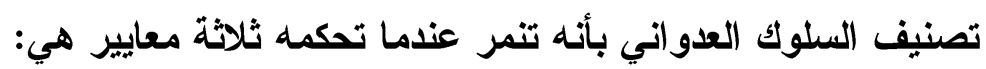

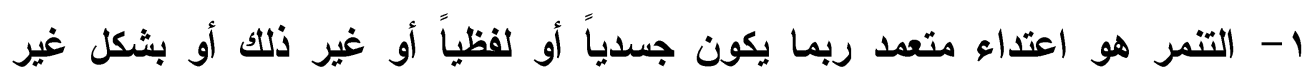

$$
\text { مباشر (التعمد). }
$$

r- التنمر يعرض الضحايا لاعتداعات متكررة وخلال فترات عديدة من الوقت (التكرار).

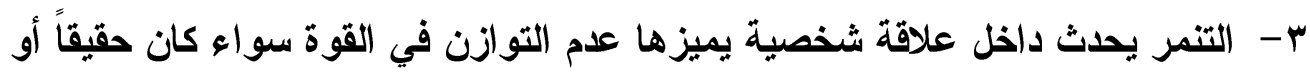
معنوياً؛ وهذه القوة تنبع من منطلق القوة الجسمانية (القوة). (نورة القحطاني،

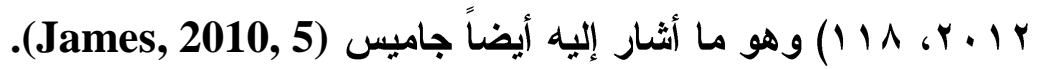

Y rictm Bullying : مفهوم ضحايا التنمر 
ضحايا التنمر من الأطفال ذوي صعوبات التعلم "دراسة لأهم المشكلات النفسية والاجتماعية فى ضوء بعض المتغيرات النفسية" يشير إليهم مينارد وجوزيف (Mynard \& Joseph, 1997) بأنهم هم الأطفال

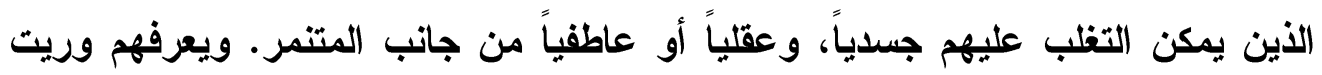
(Wright, 2004) خلال عدم الدفاع عن أنفسهم أو بإعطاء جزء من مصروفهم أو كله للمتنمرين. كما

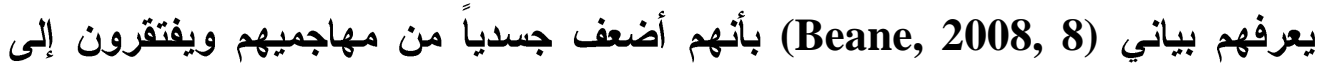

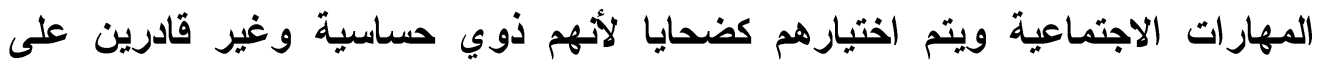

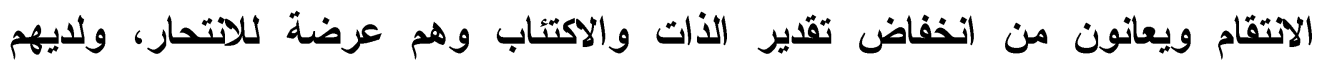
مشكلات أخرى.

ويمكن تصنيفهم إلى نوعين وفقاً لما أشار إليه مينارد وجوزيف Mynard \&) Joseph, 1997)

(1)

سلبيين أو مذعنيين وغير حازمين، ولا يردون إذا تعرضوا لهجوم أو إهانة، وغالباً ما يكون هؤلاء الضحايا ضعاف الجسم عن معظم زملاء الفصل ويتجنبون العنف ولايهم

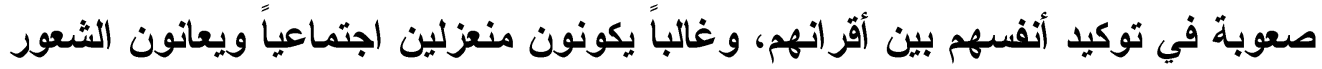

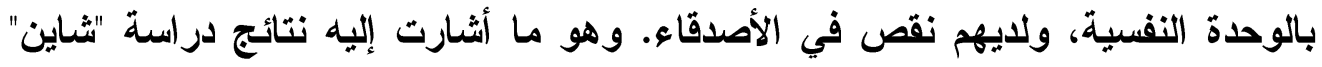
(Shin, 2010)

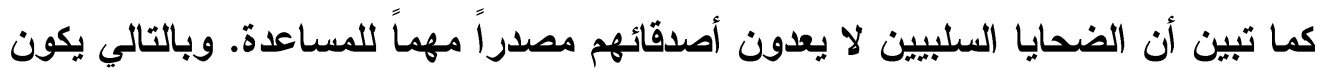
من السهل وقوعهم فريسة للتنمر، كما أنهم يشعرون بعدم الأمن ويهاجمون باستمرار، أنهارئ ويفشلون في الافاع عن أنفسهم، ويستجيب هؤلاء الضحايا للتنمر من خلا لل التجنب والأسحاب والهروب، حيث يتجنبون الأماكن المدرسية التي يقع فيها التنمر، ويتجنبون الأنشطة المدرسية ويبكون بسهولة، وينهارون سريعاً عندما يتعرضون للتنمر .

$$
\text { (Y) (Y) ضحايا متنمرون: }
$$

ويظل هذا النوع ضحية فترة معينة من الزمن، ثم لاحقاً يميل إلى التنمر مع الأطفال

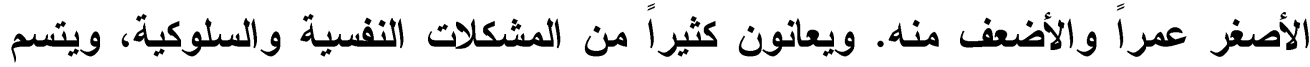
هذا النوع من الضحايا بالعدوان والنشاط الزائد، وهو ما يستفز زملاءهم في الفصل

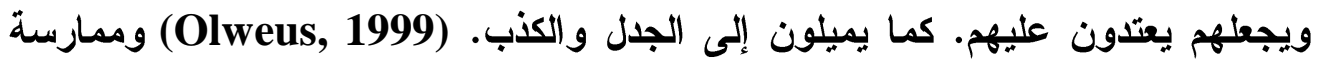
التنمر على غيرهم، مما يجعهم متنمرين وضحايا في الوقت نفسه لمتنمرين آخرين، 
وهذا نوع من الضحايا يصعب التعامل معه لأنهم يظهرون سلوكاً عدوانياً لكنهم أيضاً يكونون عرضه للمتنمرين ولأنهم يميلون إلى التنمر، فمن الصعب التعاطف معهم عندما لآنها

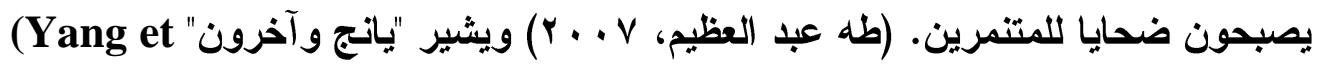
al., 2006)

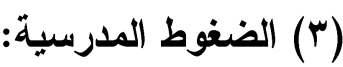
يعرف (لطفي عبد الباسط، 9 . . r، r) الضغط المدرسي بأنه "ظاهرة سيكولوجية متعددة الأبعاد تتنج عن مختلف العلاقات النفس اجتماعية والظروف البيئية التي يتفاعل معها

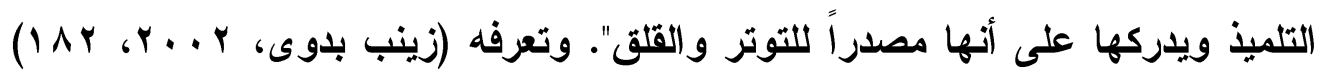

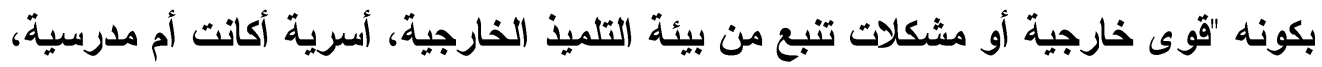

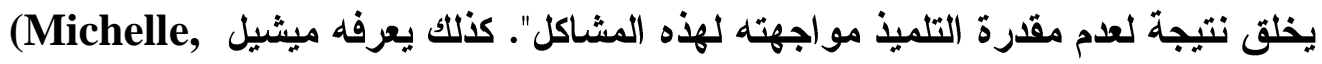
2001,21) بأنه "المتغيرات الخارجية التى تحيط بالتلميذ ويتفاعل معها ويدركها على أنها

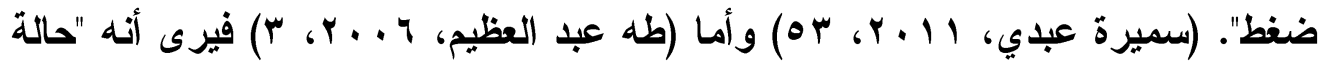
من عدم التوازن، وتنشأ لاى التلميذ عندما يقارن بين المواقف البيئية التى يتعرض لها،

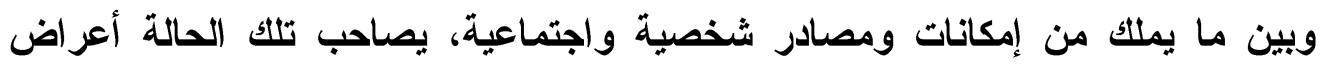

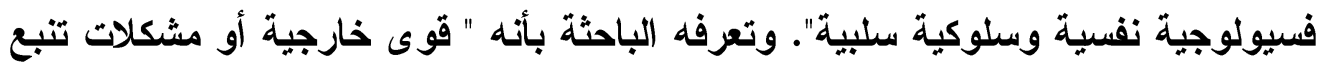
من بيئة التلميذ الخارجية، أسرية أكانت أم مدرسية من شأنها أن تهدد تكيفه أو تتجاوز قدراته على المواجهة وتثير القلق والتوتر، مما يترتب عليها العديد من الاضطرابات و المشكلات النفسية والاجتماعية لايهة". (؛ ) أساليب المعاملة الوالدية النلاسوية:

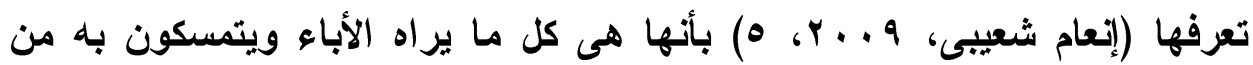
أساليب فى معاملة وتنشئة الأبناء فى مختلف المواقف الحياتية، وتتضمن أساليب المعاملة الو الدية كل من أساليب (التسلط، الحماية الزائدة، الإهمال، التدليل، القسوة، إثارة الألم،

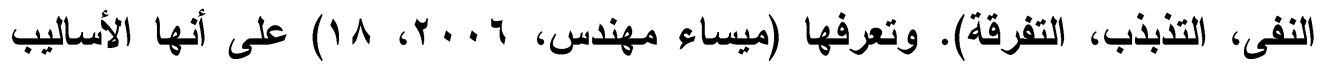

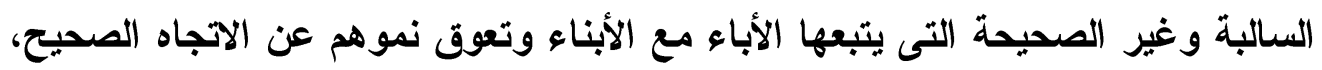
وبحيث تؤدى إلى الانحراف فى مختلف جوانب حياتهم المختلفة وبذلك لا تكون لايهر

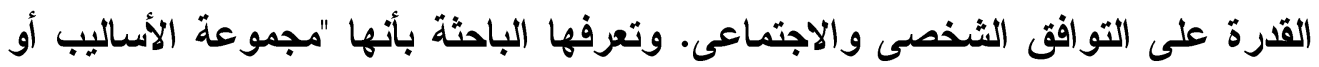


ضحايا التنمر من الأطفال ذوي صعوبات التعلم "دراسة لأهم المشكلات النفسية والاجتماعية فى ضوء بعض المتغيرات النفسية" ـ السلوليات السلبية وغير الصحيحة (الرفض، الإهمال، الحماية الزائدة، التسلط، القسوة،

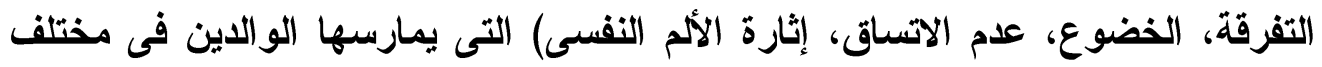

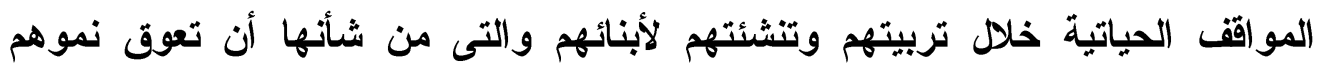
وتنعكس بالسلب على شخصية الأبناء".

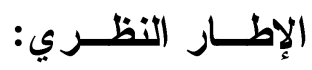
أولاً: التنمر:

يعد التنمر المدرسي شكلًا من أثنكال التفاعل العدواني غير المتوازن وهو يحدث بصورة متكررة باعتباره فعلاً روتينياً يتكرر يومياً في علاقات الأقران في البئئة المدرسية. (Smorti, Ortega \& Ortega, 2006) ويختلف التنمر عن العدوان والصراع والعنف من خلال طبيعته المتكررة أو من خلال الاحتمال الأكبر لتكراره، ومن خلال احتوائه على تفاعل دينامكى بين شخصين على الأقل. :Gladden et al., 2014) Juvonen \& Graham, 2014; Marsh et al., 2011) فالتنمر ظاهرة قديمة موجودة في جميع المجتمعات منذ زمن بعيد وهي موجودة في

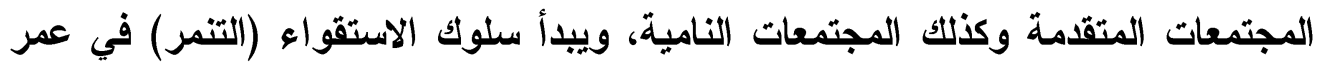
مبكر من الطفولة حتى أن بعضهم يراه يبدأ في عمر السنتين حيث يبدأ الطفل بتثكيل

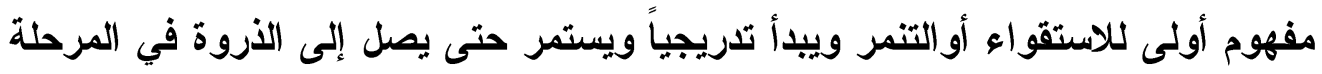
الأساسية المتوسطة (الرابع، الخامس، السادس) ثم يستمر في المرحلة الأساسية العليا، ثم يبدأ في الهبوط في المرحلة الثانوية وقلما يكون في المرحلة الجامعية. ومن ثم يمثل ئل التنمر وضحاياه مشكلات خطيرة فى المدارس بسبب ارتفاع معدلات حدوثه ويحتمل أن فئه

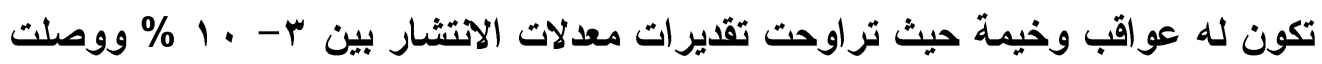
Kokkinos \& Panayiotou, إلى \% لأى الأطفال فى العدارس اللابتدائية. (2004) وللتنمر أثنكالاً متعددة وهى:

Physical Bullying التنمر الجسدي (البنني) كالضرب أو الصفع، القرص، الرفس، الإيقاع أرضاً، السحب، الإجبار على فعل شيء،

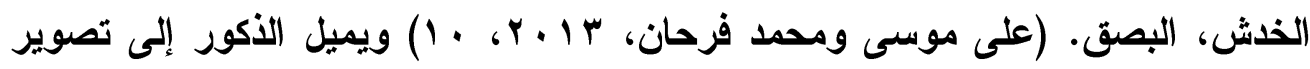

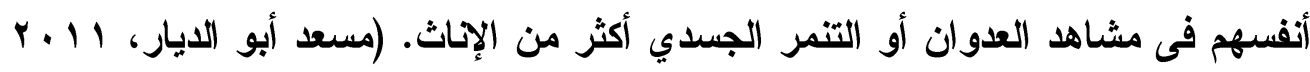
ب، 01؛ (Andreou \& Bonoti, 2010. وهو ما أثشارت إليه دراسة فارجاس الإس 


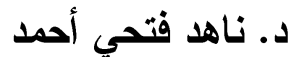

وأخرون (varjas; Henrich \& Meyers, 2009) من أن الذكور قـ أبلغوا عن وقوعهم ضحايا للتنمر البذني أكثر من التنمر اللفظي.

r- التنمر اللفظي: Andreou \& Bonoti, 2010) Verbal Bullying ويعد التنمر اللفظي أكثر أنواع التنمر انتشاراً. (Spade, 2007) ويمكن تعريفه بأنه" أي هجوم أو تهايد من الثخص يقصد به الأذى عن طريق السخرية، والتقليل من شأن

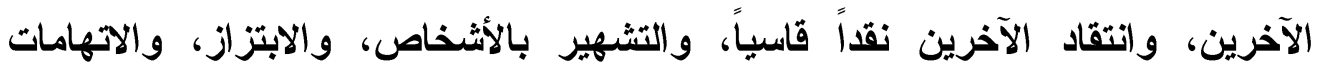

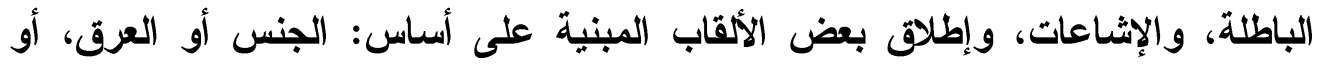

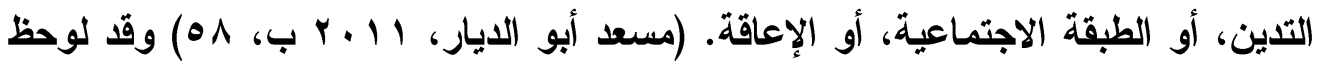
وجود فروق في التنمر اللفظي في اتجاه الإناث. (Andreou \& Bonoti, 2010) كما أظهرت الاراسات أن التنمر اللفظي ربما يكون من أكثر (Tom et al., 2010) التأثيرات السلبية الممتدة الأثر على الضحية. (Campbell, 2005, 3) r- التنمر الجنسي: Sexual Bullying ويشمل التعليقات المخجلة على الآخرين والتحرش الجنسي بهم (Smith, 2001) أو

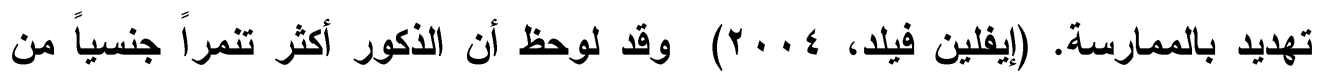
الإناث، ولكن تبين أن الإناث والأكور متساوون على مقياس ضحايا التنمر الجنسي،

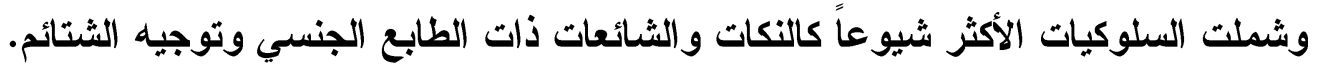
(Young et al., 2008) צ - التنمر الاجتماعى: Social Bullying ويعني وضع المتنمر قواعد قاسية تحول دون مشاركة الضحية فى الأشطة المختلفة، وعدم تقديم أية مساعدة له، والابتعاد عنه، وفرض السيطرة عليه بالقوة. (مجدى

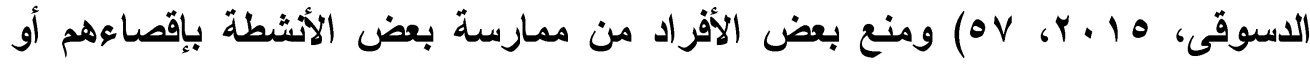
رفض صداقتهر. (Wolke et al., 2002) والتقليل من شأن الضحية، وتخفيض درجة

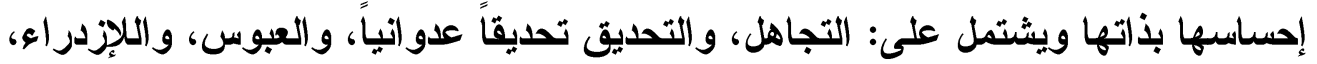
واستخدام لغة الجسد العدوانية، ويعد التنمر الانفعالى من أكثر أنواع التنمر أضراراً وتأثيراً، حيث يحدث أذى انفعالي لا يلاحظه المعلمون والكبار كما يعد شكلاً من أثنكال

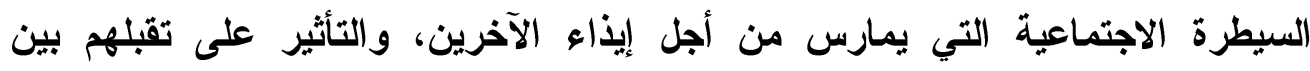


ضحايا التنمر من الأطفال ذوي صعوبات التعلم "دراسة لأهم المشكلات النفسية والاجتماعية فى ضوء بعض المتغيرات النفسية" ـ أقرانهم، وتخفض من إحساس الضحية بذاتها وتقديرها لها. (مسعد أبو الديار، II بـ

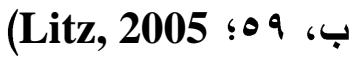

ه- التنمر عبر الاتترنت (الإلكتروني): Cyber Bullying (Zacchili \& Valerio, يعد التنمر عبر الاتترنت نوع جديد من أثنكال التنمر:

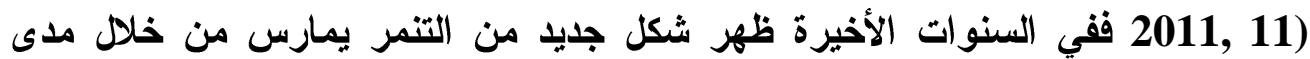
واسع ومتنوع من التكنولوجيا المتاحة الآن وهو التنمر الإكتروني الذي أصبح ظاهرة واضحة. حيث يقدم الأطفال والمراهقون على استخدامها بثكل متزايد لإلحاق الأذى الأى

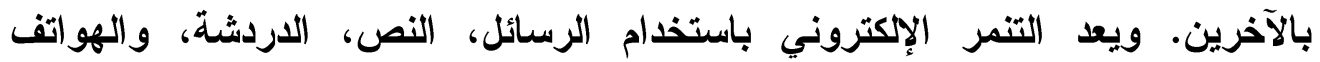
المحمولة، كاميرات الهواتف، والمواقع على شبكة الانترنت وسيلة جديدة وحديثة بالئة

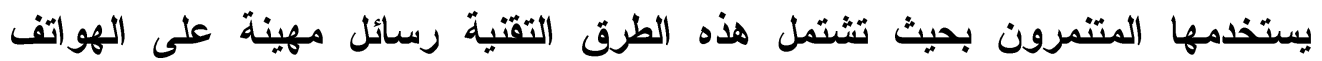
المحمولة يتم إرسالها إلى هو اتف الآخرين مثلما يتم إرسالها للضحية الهدف. أى إرسال

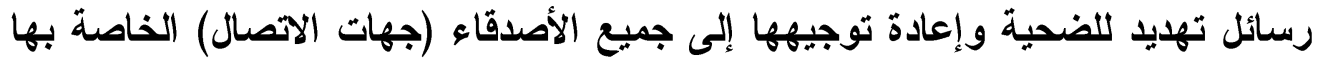

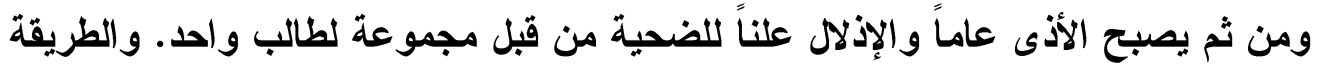

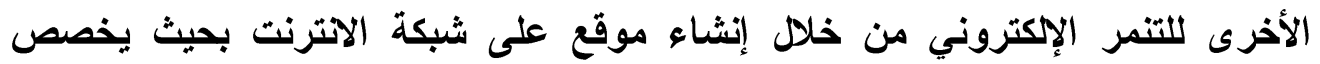
للطالب المستهدف ثم يتم دعوة الآخرين لإبداء تعليقاتهم أو التصويت مثلاً على أكبر مهوس أو أفضل فتاة في المدرسة. (Campbell, 2005, 2) ويرى "فارجاس وآخرون" (Varjas; Henrich \& Meyers, 2009) أن التنمر على شبكة المعلومات قد يمثل شكلاً فريداً للوقوع ضحية للتنمر مقارنة بالأشكال الأخرى التي تتم في المدرسة، وأن التنمر على شبكة المعلومات وما يتعلق به سلوك لث لم يكن

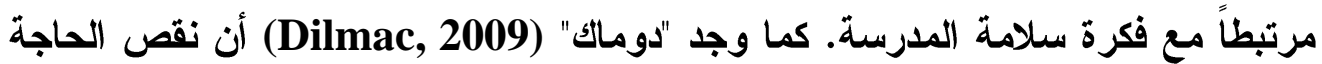

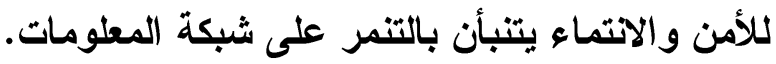
؟-التنمر العنصري: Racial Bulling وهذا النوع من التنمر يكون بدافع الكراهية والتحيز تجاه شخص أو مجموعة

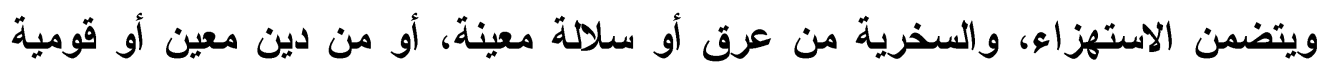

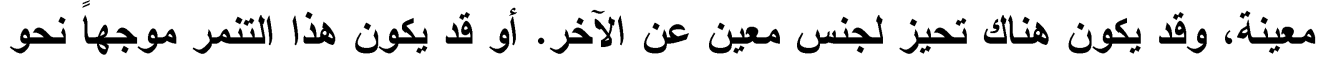

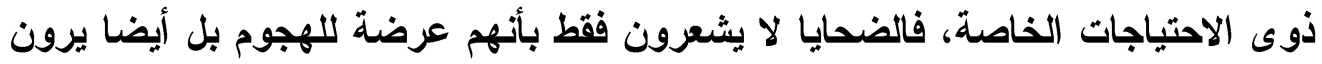




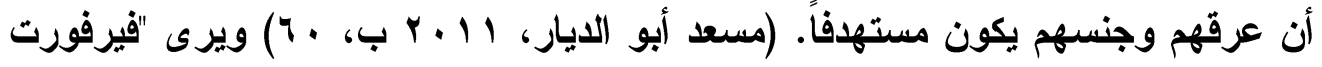

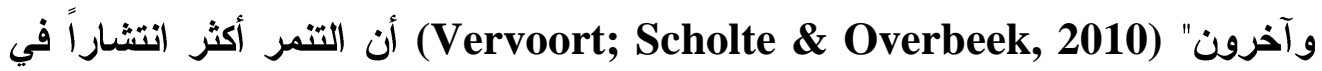
الصفوف غير المتجانسة عرقياً.

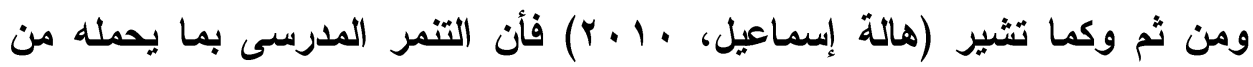

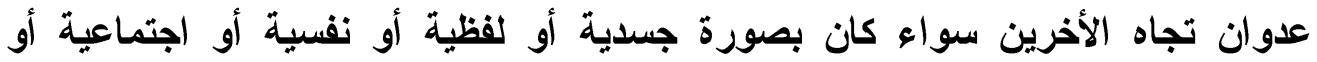
إلكترونية من المشكلات التى لها آثار سلبية على القائم بالتنمر أو على المتنمر عليه

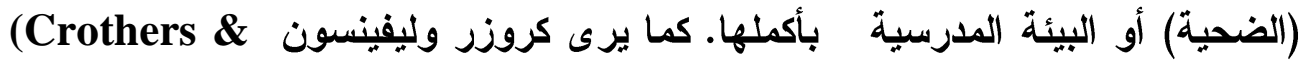
(أن كل أثكال التنمر هذه يمكن قياسها باستخدام أساليب متنوعة (الملاحظة، المقابلة، مقاييس القياس الاجتماعى، الاستخبارات) وباستخدام مصادر مختلفة (التقارير الأتية، الوالدين، المدرسين، الأثران).

وبالنسبة لأماكن حدث التنمر يرى "كيوروز وأخرون" \&uiroz, Arnette \& Stephens, 2006) يحدث التنمر بعيداً عن الكبار كما في: مسجد المدرسة، الحصص، دورات المياه، في المداخل، في انتظار الحافلات، في حافلة المدرسة، في الطريق للمدرسة أو إلى البيت.

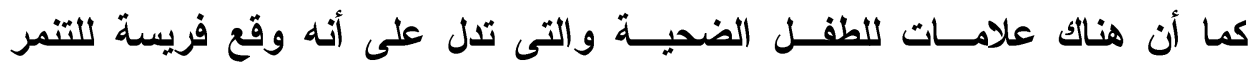
غالباً ما نر اه يثكو ويتذمر من المدرسة، يدعى المرض لعدم الأهاب إلى فصله، يعود إلى الى

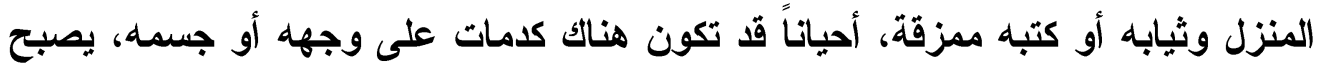

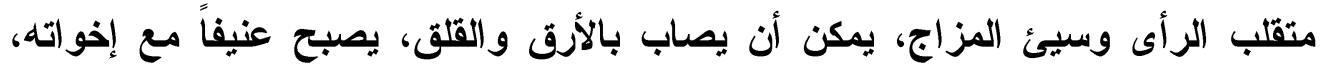

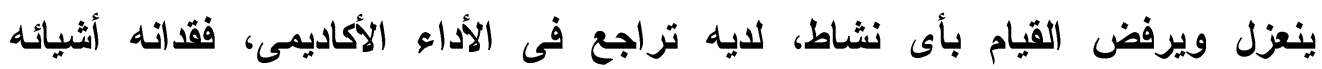

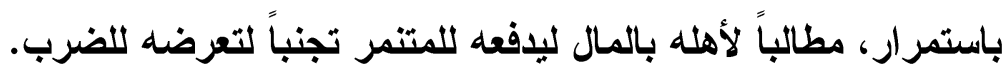

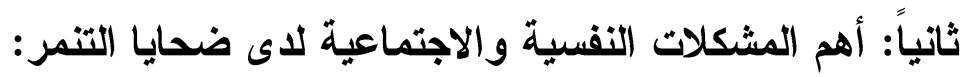
يرى "ثوارتز وآخرون" (Schwart et al., 2002) أن التعرض للتنمر يرتبط بقلة التوافق الأكاديمي، إذ إن الطلبة ذوي التحصيل الدراسي المنخفض يتكرر تعرضهم للتنمر

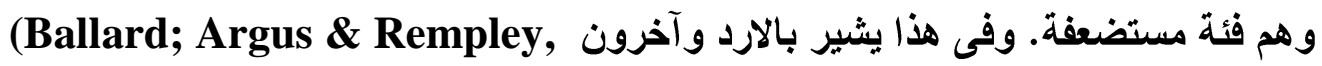
1999, 40) 
ضحايا التنمر من الأطفال ذوي صعوبات التعلم "دراسة لأهم المشكلات النفسية والاجتماعية فى ضوء بعض المتغيرات النفسية" ـ ا - قابلية السقوط (فالضحية سريعة الانذاع، ولا تستطيع أن تدافع عن نفسها، ولها خصائص جسدية ونفسية تجعلها عرضة لأن تكون ضحية). r- غياب الدعم (فالضحية تثعر بالعزلة والضعف، وأحياناً لا تذكر الضحية المتنمر لونه عليها خوفاً من انتقام المتنمر).

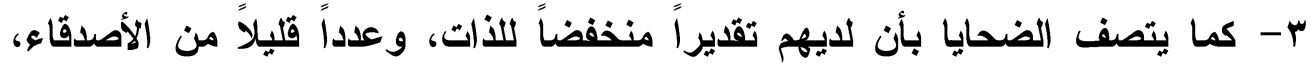

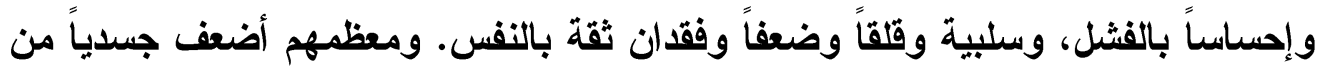
أقرانهم مما يجعله عرضه لهجمات المتنمرين، ولأهه عاجزين عن تكوين علاقات مع أقرانهم فهم يميلون للعزلة في المدرسة، مما يجعلهم يشعرون بالوحدة والإهمال. كما

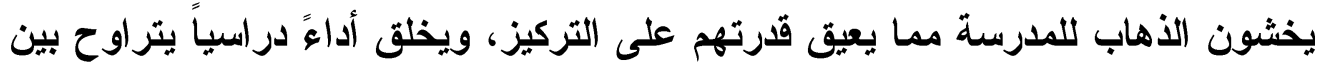
الهامشية والضعف، مع الوجود الدائم للتهايد والعنف مما يشعرهم بالافتقار إلى الأمان

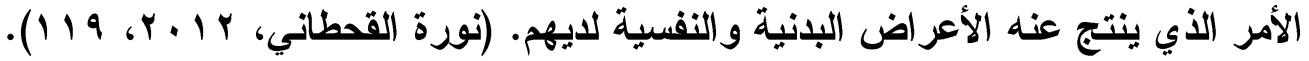
في الإجمال، يختار المتنمر الطقل الضعيف، الأي يسهل تهليده أو ليس لايه أصدقاء

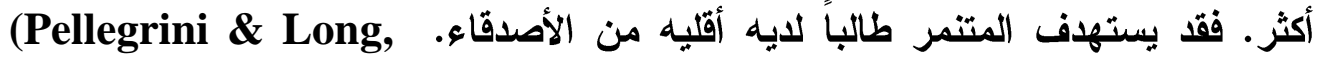
(2002 أو الطقل الذي يكون أصغر أو أقصر ويعاني صعوبة في الدفاع عن ذاته. ويشير "وينكي" وآخرون (Wienke, et al., 2009) من خلا نقارير المعلمين و التقدير الذاتي للطالب إلى ارتفاع معدلات التنمر لدى ذوي صعوبات التعلم (المتنمرين، و الضحايا، والمتنمر/ الضحية). وارتباطه إيجابياً بالمشكلات النفسية والتحصيلية لديهم. كما يعانى هؤلاء الأطفال أيضاً من العديد من المشكلات الاجتماعية وهو ما أثثارت إليه

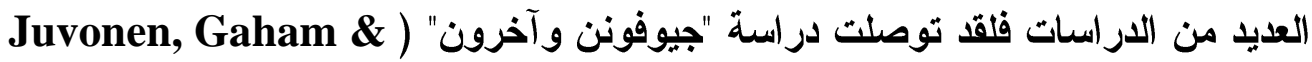
(Schuster 2003 إلى أن الطلبة ضحايا التنمر يعانون من الألم العاطفى والنبذ الاجتماعى وانخفاض مكانتهم الاجتماعية، كما كانوا أكثر اضطر اباً حيث كانوا أكثر الذين الأنين ينبذهم أقرانهم، وأكثرهم ميلاً لإظهار المشكلات السلوكية ويعانون من مستويات مرتفعة مurner et ( من الاكتئاب والوحدة النفسية. وهو ما أثشار إليه أيضاً "تورنز وآخرونه

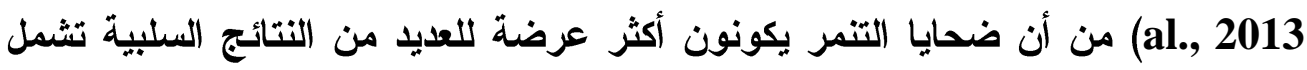
درجة مرتفعة من الاكتئاب و التفكير فى الانتحار. 
د. ناهد فتحي أحمد

كما حصل المتنمرون والضحايا على درجات أعلى على مقياس الإحباط مقارنة بالعاديين. (Seals \& Young, 2003) كما وجدت علاقة سلبية بين التنمر وتقدير الذات لاى المتنمرين وضحاياهم. (Spade, 2007) كنلك لوحظ وجود ارتباط موجب بين صعوبات التعلم ورفض الأقران وبين السلوك التنمري في مدارس الامج. \& Luciano

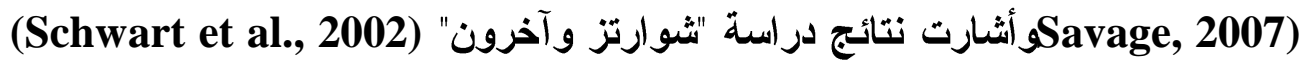
إلى أن التعرض للتنمر يرتبط بانخفاض السلوك الاجتماعي والإحساس بالوحدة والعدوانية والاتعزالية. وهو ما توصلت إليه دراسة "ميشنا" (Mishna, 2009) من أن الأطفال ضحايا التنمر ذوي صعوبات التعلم يميلون إلى العزلة، ويعانون ضعفاً في المهارات الاجتماعية مقارنة بالعاديين. وما أثنار إليه "تبيوزوكا" (Nabuzoka, 2003) من أن أغلب الأطفال الذين يعانون صعوبات في التعلم يكونون ضحايا للتنمر ولايهم شعور بالخجل والتوتر • وهو ما توصلت إليه أيضاً دراسة "تابوزوكا وسميث" ل

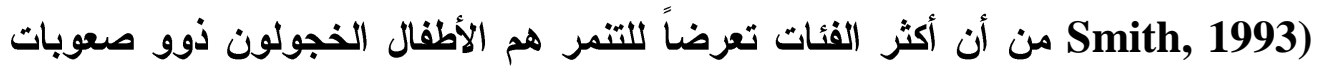

كما يعانى ضحايا التنمر من انخفاض مستوى الأكاء الاجتماعي ومفهوم الذات

(Kuakiainen et al., 2002) al., 2003 ولديهم أعراض القلق المرتفع والاكتئاب الثديد. (Kerryn, 2001) ولديهم مستوى مرتفع من القلق الاجتماعى ومستوى منذفض من تقدير الذات ويعانون من

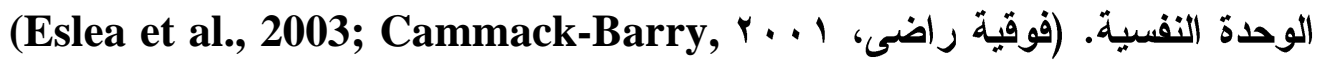
2005; Grills \& Ollendick, 2002) الأنشطة المدرسية أو الهروب من المدرسة. (Health, Dyches \& Prater, 2013)

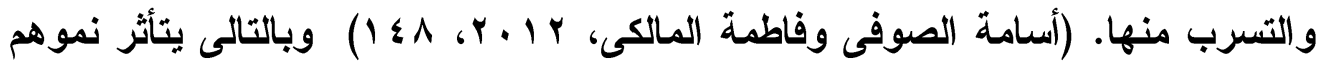
(لنفسى والاجتماعى. (Hillsbereg \& Spak, 2006)

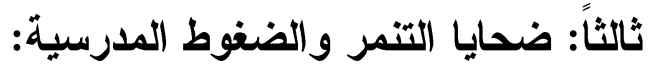
شغل موضوع الضغوط المدرسية التي يعيشها التلاميذ داخل المؤسسات التربوية أذهان المختصين في علم النفس وعلوم التربية، ذلك لإدراكهم للمعاناة التي يعاني منها هؤلاء التلاميذ والمتمثة في التوتر والضيق نتيجة الأعباء الاراسية المتلاحقة، التي 
ضحايا التنمر من الأطفال ذوي صعوبات التعلم "دراسة لأهم المشكلات النفسية والاجتماعية فى ضوء بعض المتغيرات النفسية" ـ تتجاوز قدراتهم وطاقاتهم في بعض الأحيان، ككثرة الواجبات المدرسية والكثافة فى

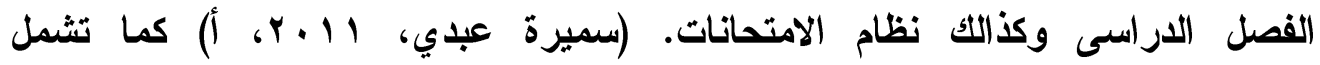
الممارسات الاستفزازية الخاطئة من بعض المدرسين، وضعف التحصيل الاراسى للتلاميذ، والتأثير السلبى لجماعة الرفاق، والخصائص النفسية غير السوية، وضعف العلاقة بين المدرسة وأولياء الأمور، والظروف والعوامل الأسرية والمعيشية للتلاميذ، وضعف ولفيه

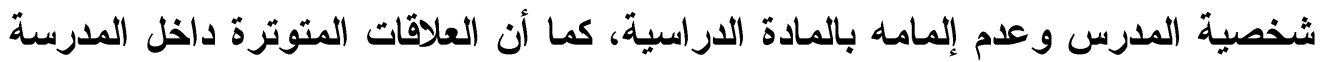
والاحباط والقمع للتلاميذ، وأسلوب التدريس غير الفعال كل هذه عوامل تؤدى إلى الاحباط

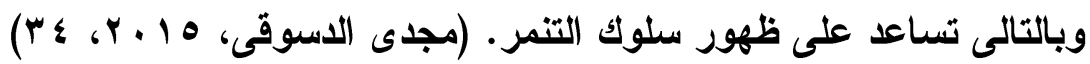

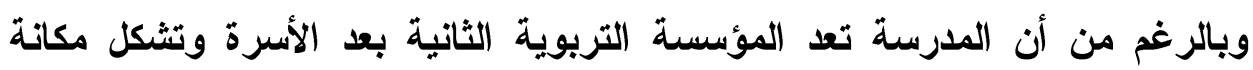
متميزة عند التلاميذ، إلا أنها في الوقت ذاته يمكن أن تمثل مصدراً للضغوط المدأ المدرسية.

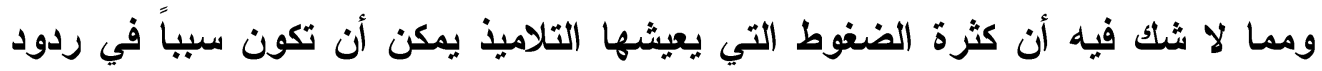
أفعال نفسية وسلوكية، كظاهرة العنف المدرسي، التي تثكل تحدياً لجميع المنتسبين

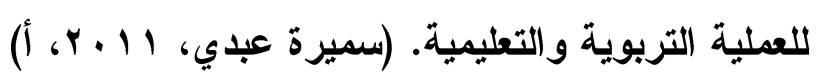
وفى هذا يشير "كارلسون وآخرون" (Carlson; Flannery \& Kral, 2005) إلى وئ وجود فروق دالة بين الطلاب العاديين وذوي صعوبات التعلم في مستويات التقارير الذاتية

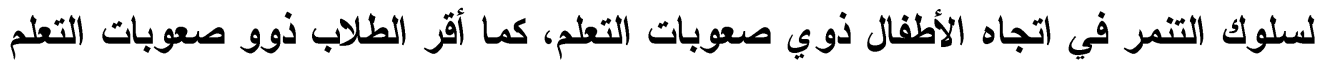
عدم توافر مداخل وقائية لمنع التنمر في المدرسة، ووجد ارتباط سالب دال بين حب التبات الطلاب للمدرسة ورغبتهم في تكوين الأصدقاء وتعرضهم للتنمر. كما يشير "منتون" (Minton, 2010)

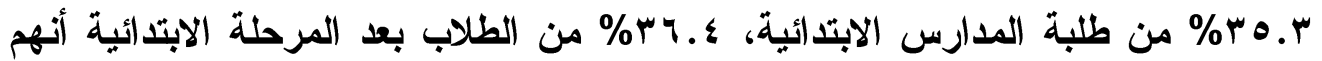
تعرضو السلوك التنمر . ت من ويمكن تفسير ذلكت فى ضوء ما أثشارا إليه كلا من "وودز ووللك" (Woods \& Wolk, 2003) عكسية بين التنمر ونقص السياسات الددرسية الجيدة. وفى هذا تثير نتائج دراسة ورئ "خوري كسابري" (Khoury-Kassabri, 2009) إلى أن الطلاب المتنمرين، والضحايا،

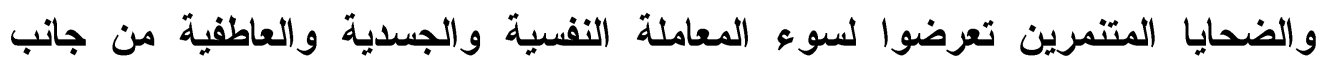


موظفى المدرسة أكثر من تعرضهم لسوء المعاملة من جاتب الطلاب. وهو ما توصل إليه

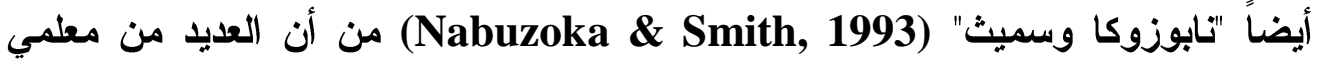

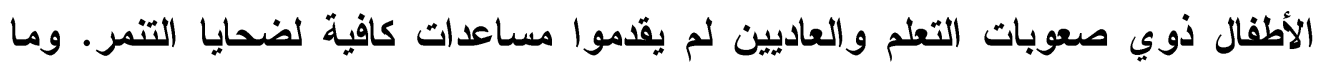
أثشارا إليه "كيلباترك وكريس" (Kilpatrick \& Kerres, 2003) من أن الطلبة المتنمرين، والضحايا المتنمرين يحصلون على دعم اجتماعي أقل من قبل المعلمين والأقران من الطلاب العاديين غير المشاركين في التنمر (العاديين) ومجموعة الضحايا. كما شكلت العلاقات السلبية بين المديرين والمعلمين في كثير من المدارس من جهة وبين الطلاب من جهة أخرى عاملاً آخر هام حيث أسفرت دراسة "آوبرنن وآخرين" من هين (O'Brennan; Bradshaw \& Sawyer, 2009) المديرين والمعلمين والمتنمرين و الضحايا بالمدارس الابتدائية، والمتوسطة والثانوية عن وجود علاقات سلبية بين المديرين والمعلمين في كثير من المدارس، وكذلك بين المديرين و المعلمين وبين الطلاب، كما أكد أغلب أفر اد العينة أنهم يتعرضون فئن للتنمر تعرضاً متكرراً. وهو ما أثثارا إليه أيضاً كلا من "مارتلو وهيدسون" (Martlew \& Hodson, 1991)

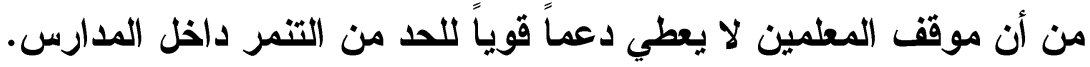

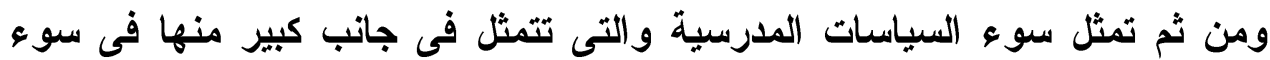
المعاملة النفسية والجسدية و العاطفية من جاتب موظفى المدرسة، والعلاقات السلبية بين المديرين والمعلمين في بعض المدارس من جهة، وبين المديرين والمعلمين وبين الطلاب ضحايا التنمر من جهة أخرى، وقلة الدعم الاجتماعي من قبل المعلمين والأقران، فضلاً

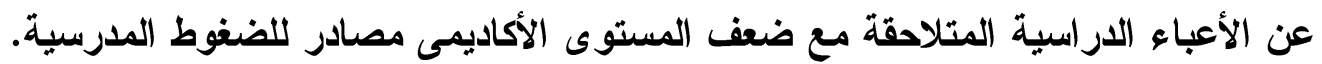
لذا يرى "المكتب الوطنى للأطفال" (NCB, 2007, 3) أنه لابد من وجود سياسات مكافحة للتنمر فى جميع المدارس تثمل الخطوات التى ستقوم المدرسة باتخاذها إزاء حوادث الثن التنمر والتى تكون معروفة لهيئة التدريس والأباء والأطفال والتى ينبغى أن تكون متاحة

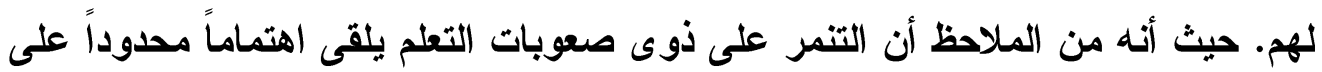
المستوى الدولى و المحلى. 
ضحايا التنمر من الأطفال ذوي صعوبات التعلم "دراسة لأهم المشكلات النفسية والاجتماعية فى ضوء بعض المتغيرات النفسية" ـ رابعاً: ضحايا التنمر وأساليب المعاملة الو الدية اللاسوية: يرى يونيفير (Unnever, 2005) أن للحياة الأسرية دور كبير في سلوك التنمر، فكل من المتنمرين وضحاياهم يواجهون مشكلات مع أسرهم.

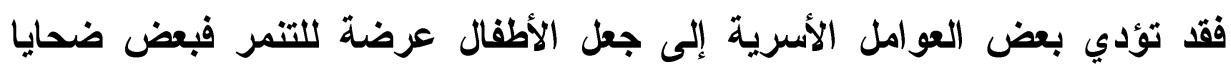

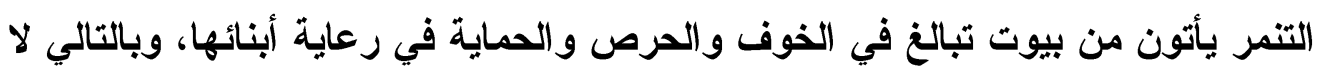

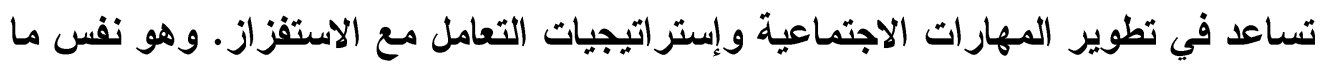
أثشار إليه راجبي وآخرون (Rigby; slee \& Cunningham, 1999) من أن معظم ضحايا سلوك التمر ينتمون إلى أسر تمارس الحماية الزائدة في تعاملها مي أبنائها

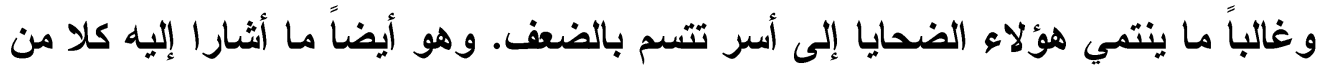

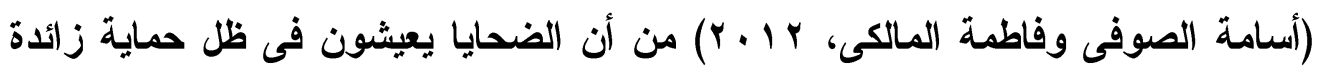

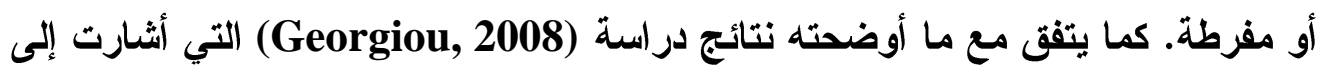
أن الحماية الزائدة من قبل الأمهات من شأنها أن تؤدي إلى أطفال ضحايا للتنمر .

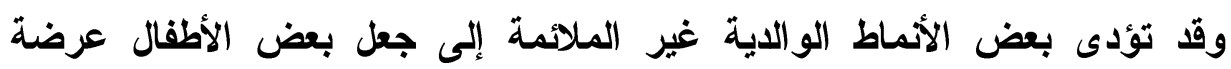

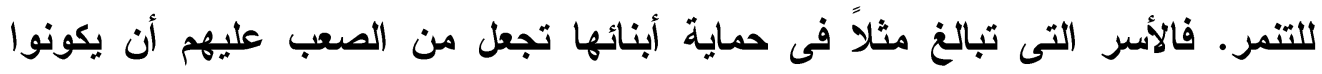
حازمين فى قراراتهم وبالتالى يشعرون بقلق أكبر وعدم استقرار فى مجموعات الأقران.

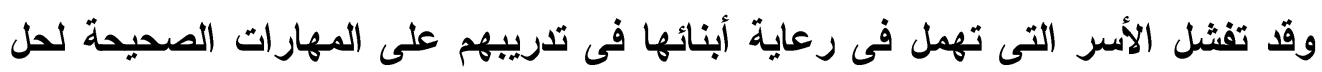

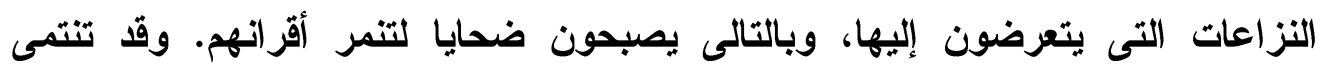

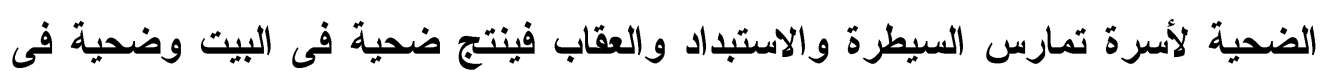

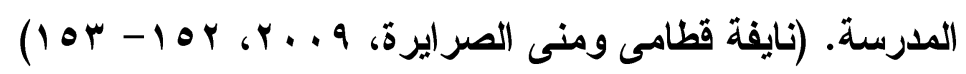

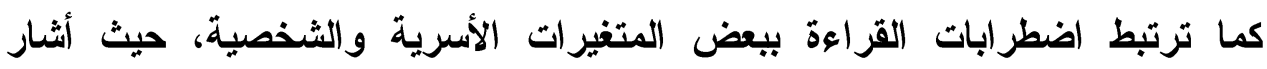
لفينسون (Levinson, 2003, 239) إلى أن أهم أسباب اضطر اب القراعة إنما يعود إلى الى

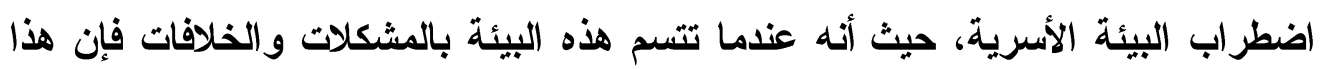
ينعكس على شعور الطقل بالأمن فيشعر بنقص الأمن كما يقلل قدرته على التركيز

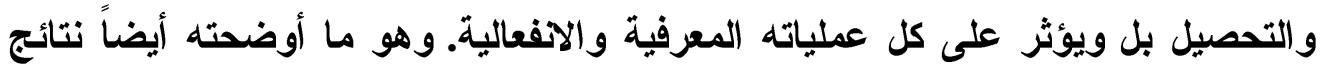

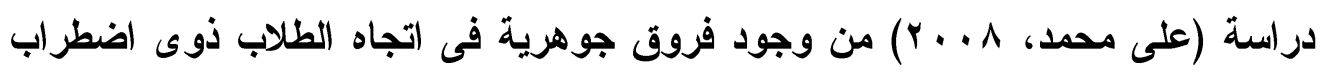

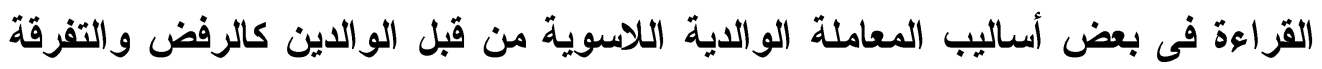




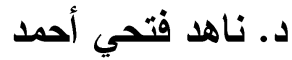

في المعاملة والتحكم والقسوة والحماية الزائدة والتذبذ. كما ارتبطت هذه الأساليب الخاطئة بأبعاد الثخصية السلبية (التقدير السلبى للأت، نقص الكفاية الثخصية، نقص الثبات الافعالى، الاعتمادية، العداء، العدوان، النظرة السلبية للحياة، نقص التجاوب الانفعالى) لاى ذوى اضطر اب القراعة. وهو ما أثنار أليه أيضاً "ريبل"(Ruble, 1978) من أن أساليب المعاملة الوالدية كالإيذاء الجسدي والإهمال والحرمان والقسوة والتوان والتدل الز ائد والإذلال والرفض والتفرقة في المعاملة، هي أساليب خاطئة من شأنها أن تؤدي إلى اضطراب الثخصية وتجعل الأبناء يشعرون بعدم القيمة وعدم الكفاية وعندما يواجهون الضغوط سيتوقعون الفشل وعدم القدرة على المواجهة. وفى هذا الصدد أجرى"سميث، وتويملو، وهوفر " Smith; Twemlow \& (Hoover, 1999) المتنمرون وضحاياهم وأنماط التربية الوالدية وأثشارت نتائج الدراسة إلى أن المتنمرين وضحاياهم يأتون من أسر يسودها الانفصال أو الطلاق أو التفكك أو الفوضوية. كما

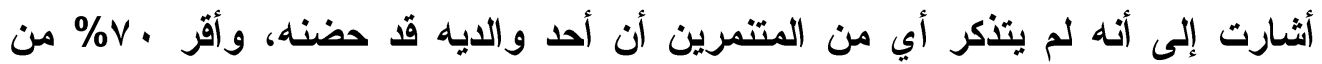

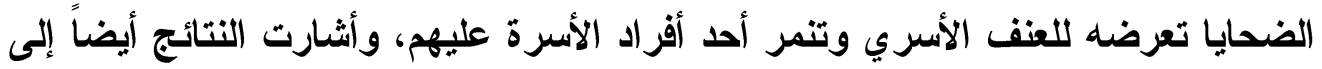
أن كلا من الضحايا والمتنمرين قد ذكروا أن العلاقات السلبية أو غير المرغوب فئه فيها هي

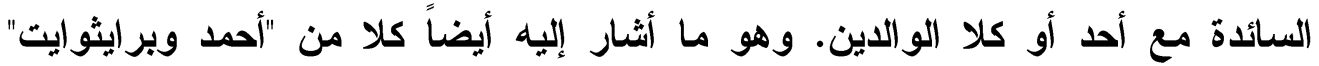
(Ahmed \& Braithwaite, 2004) وضحاياهم والعاديين في نمط الرعاية الوالاية والتفكث الأسري. من أن أسر الطلبة ضحايا

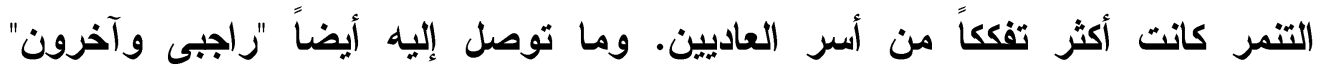
(Rigby; slee \& Cunningham,1999) الو الاية لاى الطالب المتنمر والطالب الضحية. وتثثير بعض الاراسات إلى أهمية الاعم الوالدى وأثره فى انخفاض التعرض للتنمر،

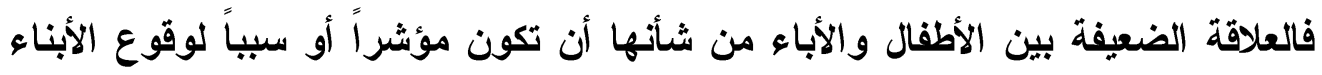

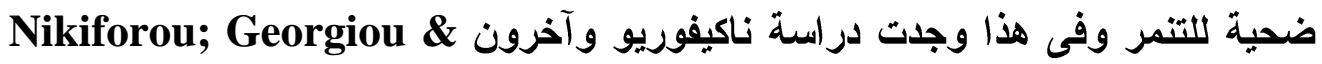
(Stavrinides, 2013) وبضحايا التنمر. وومن ثم فالدعم من الوالدين خاصة من الأم من شأنه أن يكون عاملاً 
ضحايا التنمر من الأطفال ذوي صعوبات التعلم "دراسة لأهم المشكلات النفسية والاجتماعية فى ضوء بعض المتغيرات النفسية" ـ مؤثراً وهو ما بحثته دراسة "كلوميك وآخرون" (Klomek et al., 2015) بثأن العلاقة بين ضحية التنمر والتعلق بكل من الوالدين والمدرسين بين الطلاب ذوى صعوبات التعلم

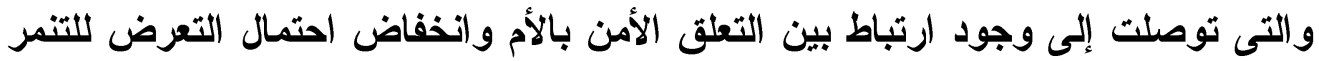
أو الإيذاء.

كما بحثت "هولت وآخرون" (Holt; Kantor, \& Finkelhor, 2009) الخصائص الأسرية المرتبطة بارتكاب سلوكيات التنمر وأوضحت أن منازل الضحايا وجه إليها العديد

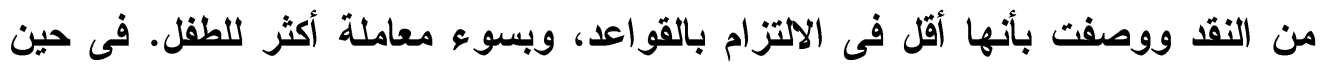
وصفت منازل المتنمرين بمستوى ضعيف من الإثراف عليهز وسوء معاملة الأطفال وتعرضهم للعنف الأسرى.

كما درس "كيلباترك وكريس" (Kilpatrick \& Kerres, 2003) الدعم الاجتماعي المقدم من الآباء إلى الطلبة المتنمرين والضحايا/ المتنمرين، ووجد أن الطلبة المتنمرين والضحايا المتنمرين قد حصلوا على دعم والدي أقل من العاديين والضحايا. وهو نفس ما أثشارت إليه أيضاً دراسة "كونوز - بيرو وآخرون" (Conners-Burrow)

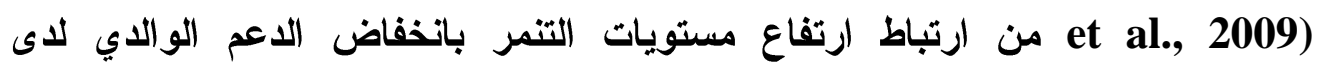

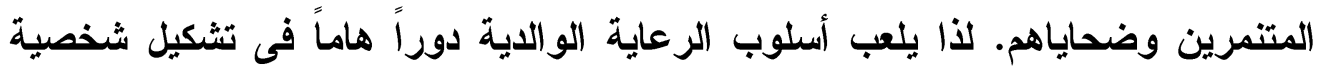

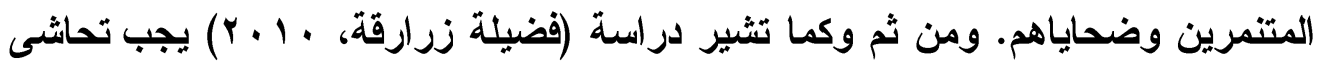
الممارسات اللاسوية في تربية الطقل ومنها : النبذ والرفض، التذبذب، التفرقة، القسوة،

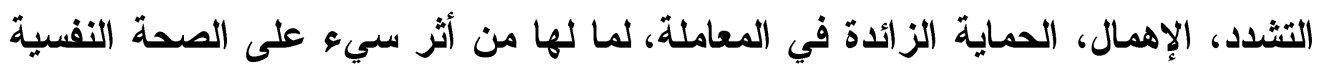
للطقل. در اســات سابة لــةهة: تعرض الباحثة فى هذا الصدد لبعض الدراسات التى تثير إلى العديد من الآثار

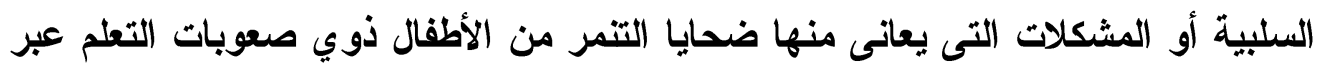

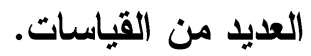
اجرى كلا من "مارتلو وهيدسون" (Martlew, \& Hodson, 1991) دراسة لمقارنة الأطفال الذين يعانون صعوبات في التعلم في المدارس الحكومية والخاصة في هلي

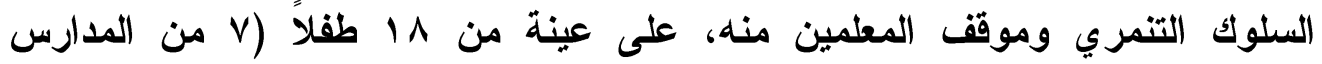

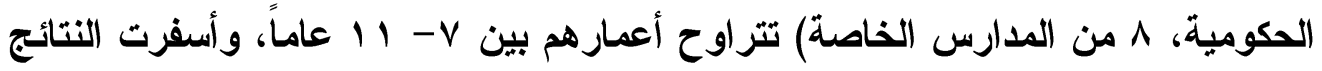


عن أن موقف المعلمين لا يعطي دعماً قوياً للحد من التنمر داخل المدارس، كما لوحظ أن

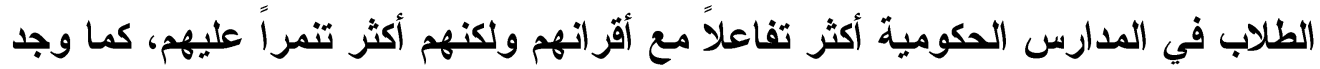

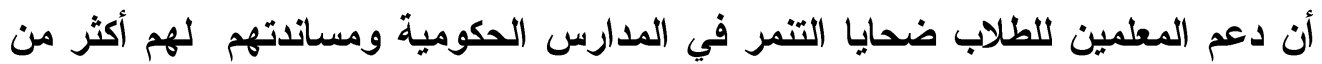
دعم أقر انهم في المدارس الخاصة. وعن تقييم سلوكيات التنمر للأطفال العاديين وأقرانهم ذوي صعوبات التعلم (LD) توصلت دراسة "تابوزوكا وسميث" (Nabuzoka \& Smith, 1993) التى أجريت على ونى

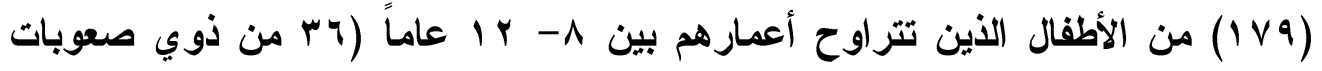

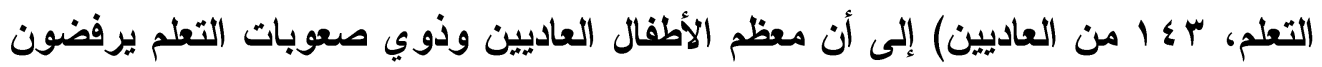

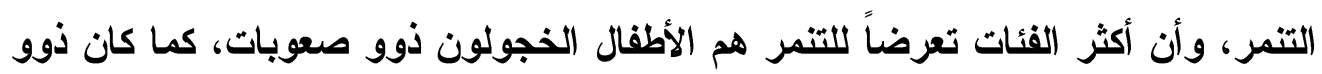

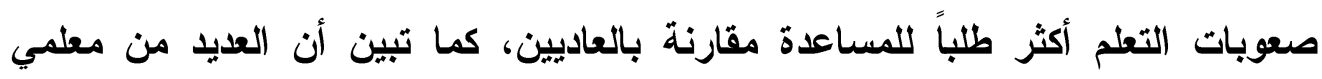
الأطفال ذوي صعوبات التعلم والعاديين لم يقدموا مساعدات كافية لضحايا التنمر .

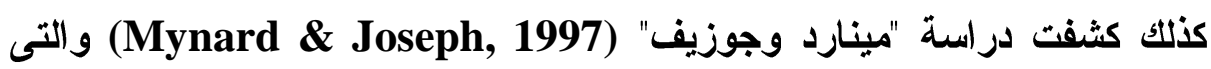

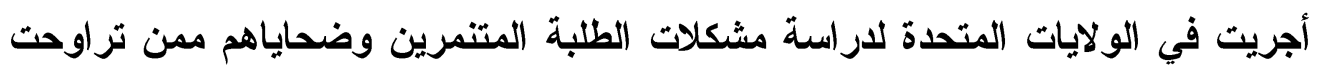

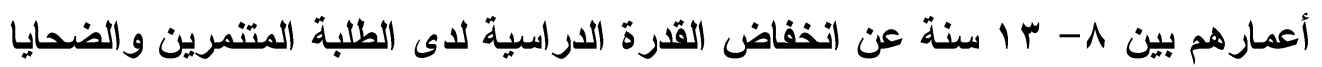
مقارنة بالطلبة العاديين

وبحثت دراسة "نانسل وآخرون" (Nansel et al., 2001) انخفاض مستوى تحصيل الطلبة المتنمرين وضحاياهم من خلال استعراض نتائج الاراسات التي بحثت في التحصيل الاراسي لاى الطلاب المتنمرين وضحاياهم، توصلت نتائج بعض الاراسات إلى عنى عدم وجود

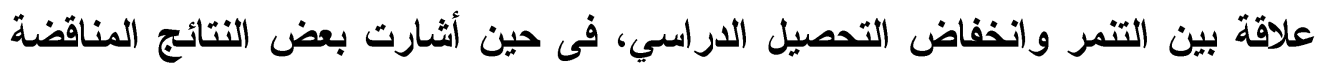
إلى انخفاض القدرة الاراسية لاى كل من المتنمرين والضحايا. وركز "كوكاينن وآخرون" (Kaukiainen et al., 2002) على العلاقة بين ونين مشكلات الضحايا المتنمرين ذوى صعوبات التعلم والأكاء الاجتماعي ومفهوم الأات على

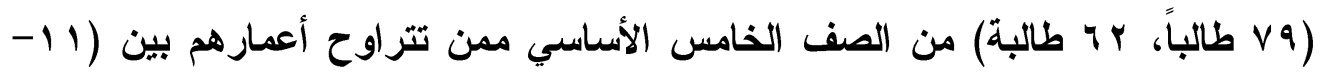

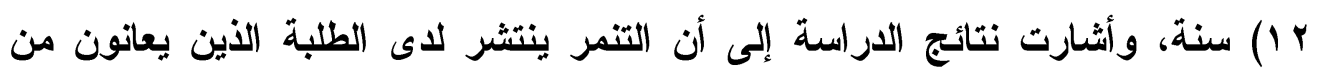

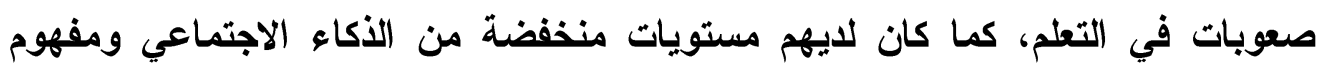
الأات. كما ارتبط الأكاء الاجتماعي بمهار في ات لات التعلم. 
ضحايا التنمر من الأطفال ذوي صعوبات التعلم "دراسة لأهم المشكلات النفسية والاجتماعية فى ضوء بعض المتغيرات النفسية" ـ وأثشارت دراسة شوارتز وآخرون" (Schwartet al., 2002) التى بحثت العلاقة بين الاستضعاف (كون الثخص ضحية لسلوك التنمر) والعوامل الأكاديمية والسلوكية

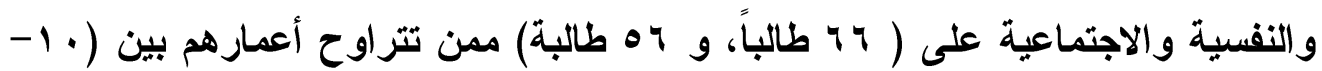

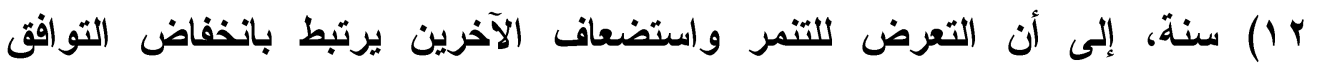
الأكاديمي، إذ إن الطلبة ذوي التحصيل الاراسي المنخفض يتكرر تعرضهم للتنمر وهم فئة

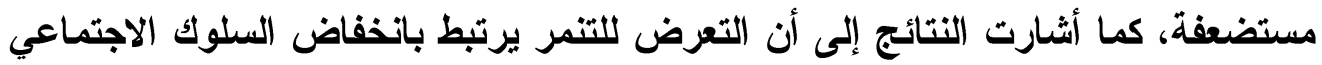
والإحساس بالوحدة و العدوانية والاتعز الية.

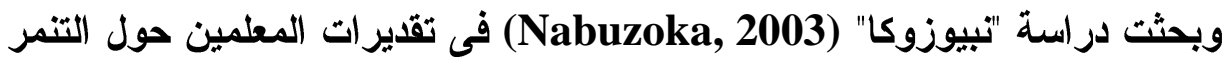

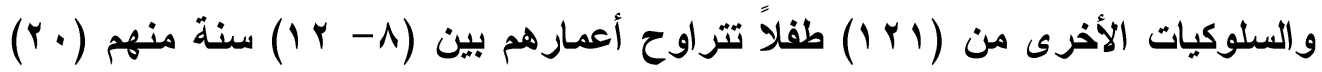
طفلاً ممن يعانون صعوبات في التعلم (LD)، وأسفرت النتائج عن أن أغلب الأطفال الذين يعانون صعوبات في التعلم يكونون ضحايا للتنمر ولايهم شعور بالخجل والتوتر، بينما

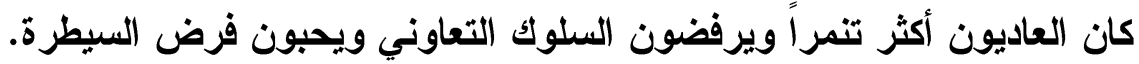

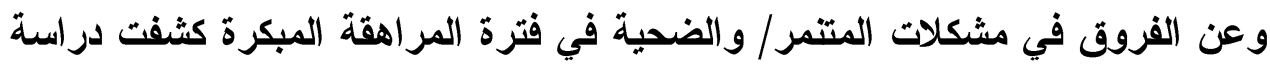

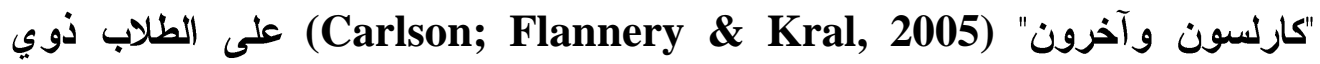

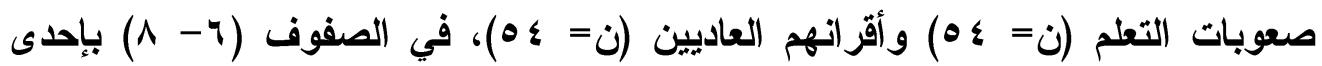
المدارس المتوسطة في ضواحي ولاية مينيسوتا، عن وجود فروق دالة بين الطلاب العاديين وذوي صعوبات التعلم في مستويات التقارير الأتية لسلوك التنمر في اتجاه الأطفال ذوي صعوبات التعلم، كما أقر الطلاب ذوو صعوبات التعلم عدم توافر مداخل وقائية لمنع التنمر في المدرسة، كما تبين وجود ارتباط سالب دال بين حب الطلاب للمدرسة ورغبتهم في تكوين الأصدقاء وتعرضهم للتنمر .

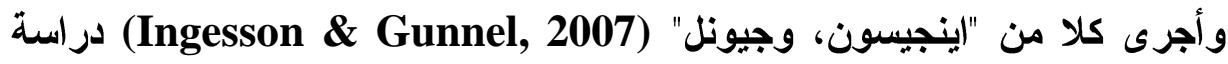
للتعرف على علاقة تقدير الأات والتحصيل الاراسي والمهارات الاجتماعية بالسلوك وندئ التنمري على (V0) من الطلاب المراهقين المعسرين قرائياً في بعض المدارس الثانوية المشتركة، وأقر أفراد العينة أن مشكلات القراعة والكتابة لديهم تعد سبياً رئيساً في لجوئهم إلى السلوك التنمري أو التعرض لهـ له. 
ووجدت دراسة "لوتثيانو وسافاج" (Luciano \& Savage, 2007) و التى اهتمت بالكثف عن النواحي المعرفية والتصور الذاتي والعوامل المرتبطة بتقارير الإيذاء من وناع جانب الأقران على عينة مكونة من (r I) من طلاب الصف الخامس من ذوي صعويات

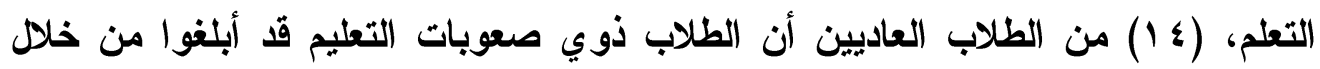
التقارير الذاتية عن حوادث أكثر وأقروا بتعرضهم للتنمر مقارنة بالطلاب الذين لا يعانون

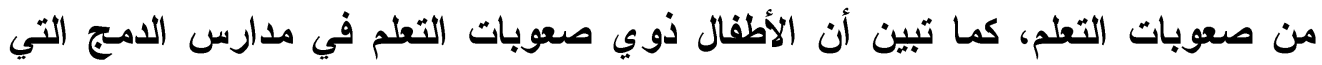

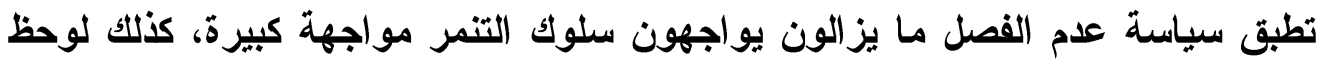
وجود ارتباط موجب بين صعوبات التعلم ورفض الأقران وبين السلوك التنمري في بوني مدارس الامجج. وأثــارت دراسة "مكنمارا وآخـرون" \&cNamara, Vervaeke ) Willoughby, 2008) لاى المراهقين، وكذلك دراسة العلاقة بين الحالة الاجتماعية والسلوك التنمري على عينة

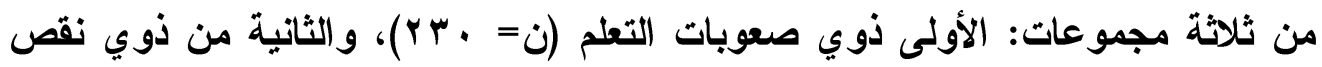

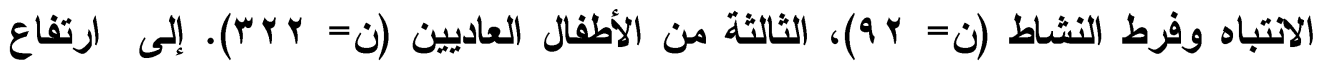

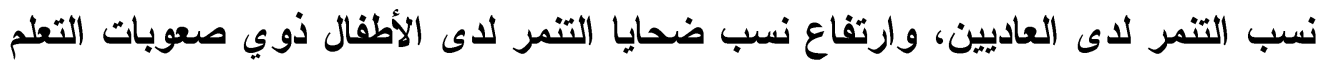

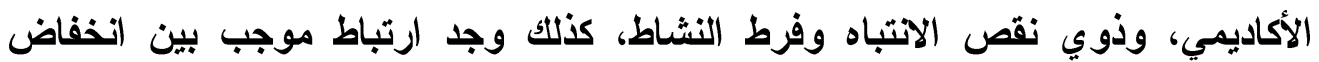
الحالة الاجتماعية وسلوك التنمر لاى المجموعات الثلاث. وناقثت دراسة "ميشنا" (Mishna, 2009) التنمر وأنماط سلوك لوكو الأطفال و المراهقين الذين يعانون صعوبات تعليمية على عينة من ع Y بواقع (YV) من الذكور

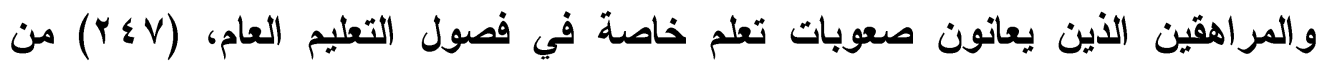
العاديين. وتوصلت النتائج إلى أن ابون مات من الطلاب ذوي صعوبات التعلم والعاديين

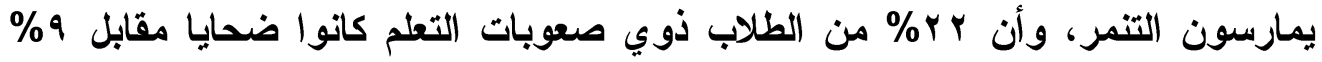
من العاديين، وأن ه 1\% من الطلاب ذوي صعوبات التعلم كانوا ضحايا متنمرين مقابل ٪\% من العاديين، كما تبين أن المتنمرين يميلون إلى النشاط المفرط، بينما يميل الضحايا إلى العزلة، كما تبين أن الأطفال ذوي صعوبات التعلم يعانون ضعفاً في المهارات الاجتماعية مقارنة بالعاديين. 
ضحايا التنمر من الأطفال ذوي صعوبات التعلم "دراسة لأهم المشكلات النفسية والاجتماعية فى ضوء بعض المتغيرات النفسية" ـ واستهدفت دراسة "وينكي وآخرون" (Wienke et al., 2009) إلى التقييم النفسي و السلوكي والأكاديمي المرتبط بالتنمر والإيذاء في المدارس المتوسطة وكان عدد العينة

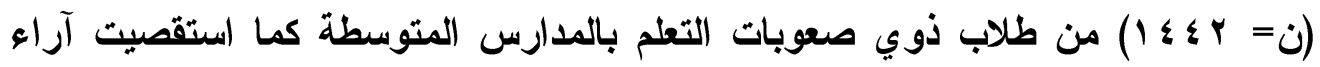

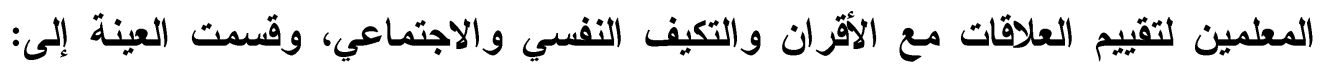

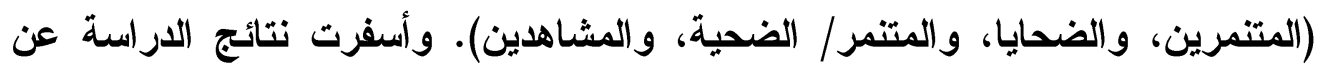
وجود ارتباط سالب بين التقييم النفسي والسلوكي والأكاديمي للمعلمين وبين صعوبات التعلم، كما تبين من تقارير المعلمين والتقدير الذاتي للطالب عن ارتفاع معدلات التنمر

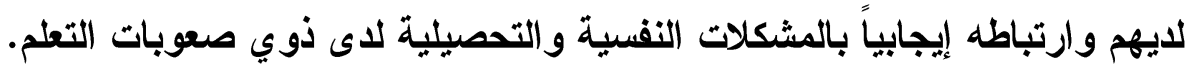
وللوقوف على واقع سلوك التنمر لاى الأطفال ذوي صعوبات التعلم باستخدام تحليل (المضمون أجريت دراسة "يونج وآخرون" (Young; Ne'eman \& Gelser, 2011) وتوصلت إلى العديد من الأثار المترتبة على التعرض لتهن للتنمر والتى تتفق مع ما حدادته

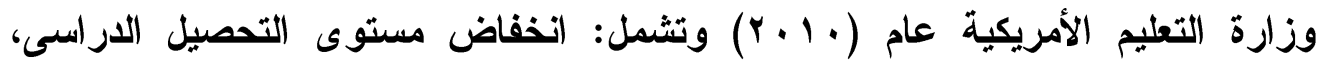
انخفاض تطلعات الطلاب، ازدياد القلق، انخفاض تقدير الذات والثقة، الاكتئاب، ضغوط ما بعد الصدمة، تدهور الصحة الجسمية، إلحاق الأذى بالذات والتفكير بالاتتحار، وأحياناً

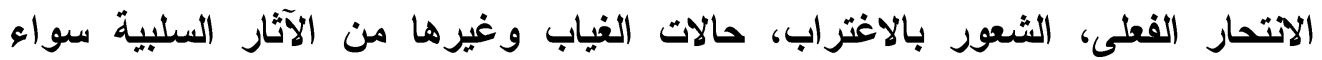

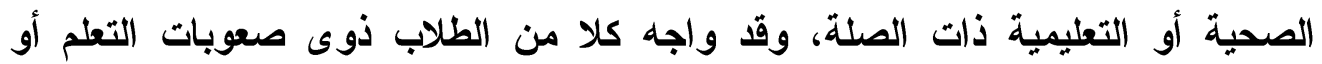
العاديين معاً هذه الآثار وما تنطوى عليه من مشكلات.

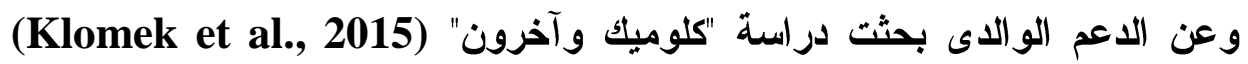
العلاقة بين ضحية التنمر والتعلق بكل من الوالدين والمدرسين بين الطلاب ذوى صعوبات

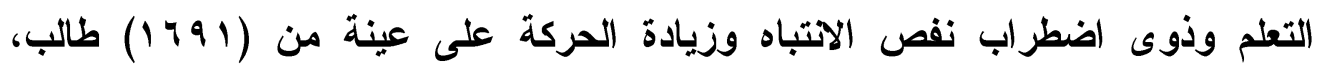
وتوصلت الاراسة إلى أن الطلاب ذوى صعوبات التعلم وذوى اضطراب نفص الانتباه وزيادة الحركة هم أكثر عرضة لمرات الإيذاء (التنمر) مقارنة بالطلاب العاديين، كما ارتبط التعلق الأمن بالأم بانخفاض احتمال التعرض للتنمر فى حين لم يكن هناك ارتباط جوهرى الإبـ بين التعلق بالأب أو المدرس والتعرض للإيذاء من قبل أعضاء مجموعة الضحية. كذلك فئك تبين أن إدراك الأطفال للاعم والتعلق بالأم كان وراء تجاوزههم لتشخيصهم على أنهم من من فئ

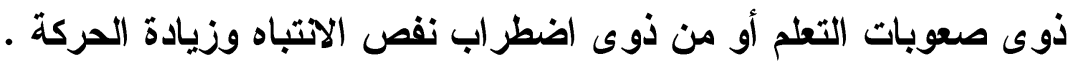


تعقيب على الار اسات السابقة:

في ضوء ما سبق يمكنتا الوقوف على الأتي:

1- لوحظ ندرة في توجهات الدراسات العربية وخاصة المصرية التي اهتمت مباشرة

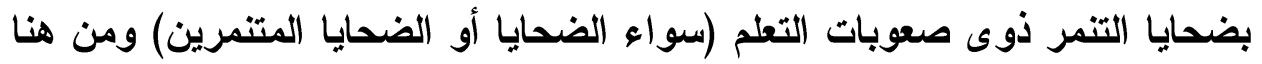
تبرز أهمية هذه الدراسة في تركيزها المباشر على دراسة بعض مشكلاتهم خاصة فى الميات

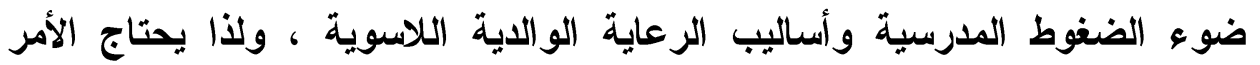
لمزيد من البحوث المستقبلية.

r- أثثارت مجمل الدراسات الأجنبية السابقة التى عنيت بالآثار السلبية أو المشكلات

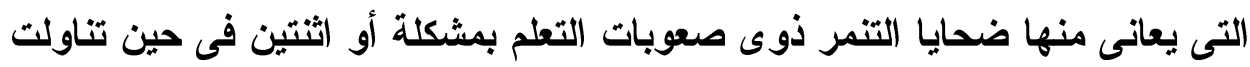
الاراسة الراهنة المثكلات النفسية السلوكية والانفعالية والدراسية والمثكلات الاجتماعية.

r- أن معظم ضحايا التنمر يأتون من أسر يسودها نمط الحماية المفرطة في حين يأتي

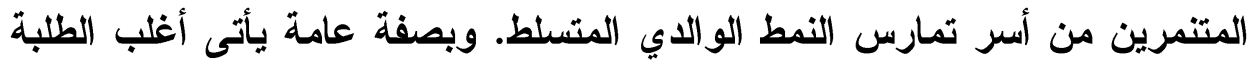

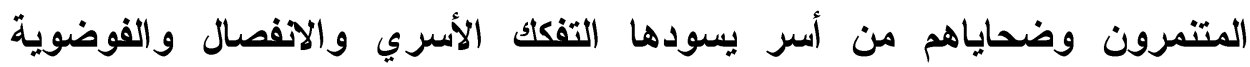

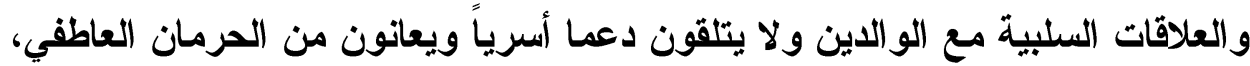
ويتعرضون إلى العنف الأسري، أو يتنمر عليهم أحد أفراد أسرهم.

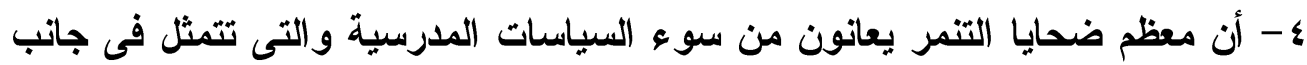
كبير منها فى سوء المعاملة النفسية والجسدية والعاطفية من جانب موظفى المدرسة دوسة

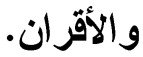
ه- أن أكثر الفئات التعليمية تعرضاً للتنمر هم الأطفال الخجولون ذوو صعوبات التعلم.

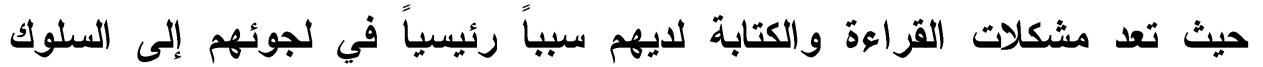

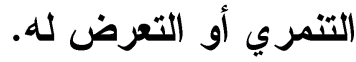

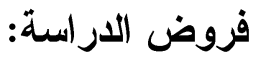
ا - توجد العديد من المثكلات النفسية والاجتماعية التى يعانى منها الأطفال ذوى صعوبات التعلم ضحايا التنمر والضحايا المتنمرين. 
ضحايا التنمر من الأطفال ذوي صعوبات التعلم "دراسة لأهم المشكلات النفسية والاجتماعية فى ضوء بعض المتغيرات النفسية" r- توجد فروق ذات دلالة إحصائية بين الأطفال ذوى صعوبات التعلم ضحايا التنمر والضحايا المتنمرين فى العديد من المشكلات النفسية والاجتماعية مقارنة بالأطفال ذوى صعوبات التعلم غير الضحايا. r- توجد فروق ذات دلالة إحصائية بين الأطفال ذوى صعوبات التعلم ضحايا التنمر والضحايا المتنمرين فى الضغوط المدرسية وأساليب المعاملة الوالدية دالية اللاسوية. ع - توجد فروق ذات دلالة إحصائية فى المشكلات النفسية والاجتماعية بين الأطفال

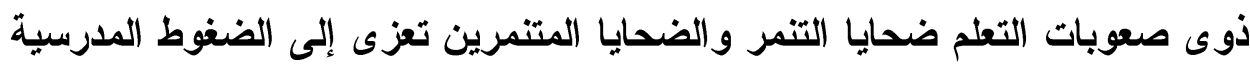
وأساليب المعاملة الو الاية اللاسوية. ه - تتباين المشكلات النفسية والاجتماعية التى يتعرض لها الأطفال ذوى صعوبات التعلم ضحايا التنمر والضحايا المتنمرين بتباين متغير الجنس (ذكور / إناث). צ- توجد العديد من أثكال التنمر السائدة التى يعانى منها الأطفال ضحايا التنمر لهرئ و الضحايا المتنمرين ذوى صعوبات التعلم. V- توجد فروق بين الأطفال ذوى صعوبات التعلم ضحايا التنمر والضحايا المتنمرين فى صى

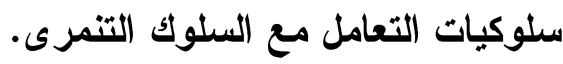
^- يمكن التنبؤ بالمشكلات النفسية والاجتماعية لاى الأطفال ذوى صعوبات التعلم ضحايا

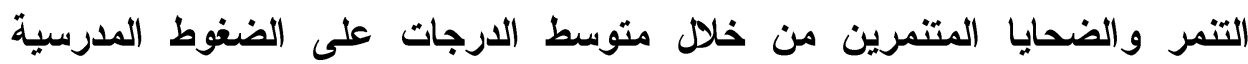
وأساليب المعاملة الوالاية اللاسوية. 


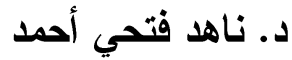

$$
\text { منهج الاراسة و إجراء|تها: }
$$

أولاً: المنهج:

استخدمت الدراسة الراهنة المنهج الوصفى الارتباطى المقارن، وذلك للكثف عن التباين في المشكلات النفسية والاجتماعية لاى الأطفال ذوى صعوبات التعلم.

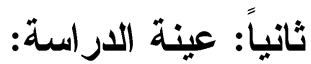

تكونت عينة الاراسة النهائية من (r ع ب) طفلاً وطفلة، في المدى العمرى ما بين

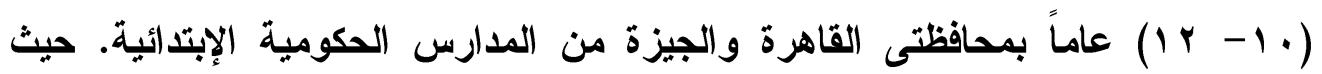
أثشارت دراسة (Sarzen, 2002) إلى أن الأطفال فى المرحلة المتوسطة هم الأكثر تنمراً

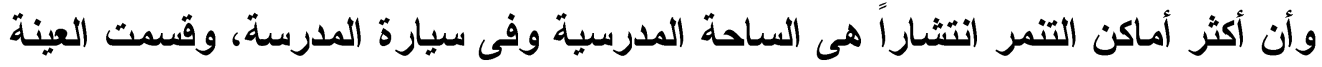
إلى ثلاث مجموعات فرعية: الأولى مجموعة ضحايا التنمر من ذوى صعوبات منيات التعلم

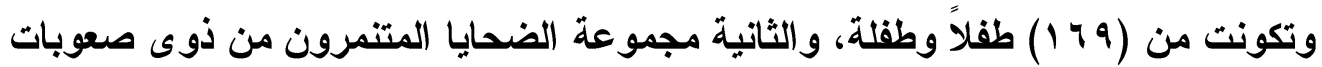
التعلم وتكونت من (IVT) طفلاً وطفلة، و الثالثة مجموعة غير الضحايا من ذوى صعوبات

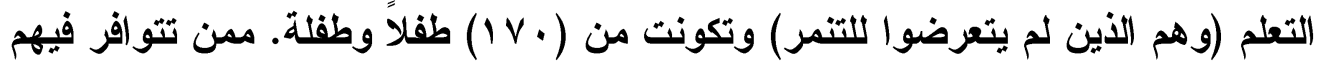
الشروط الأتية:

1 - أن تكون العينة من ذوى صعوبات التعلم الأكاديمى (القراءة)

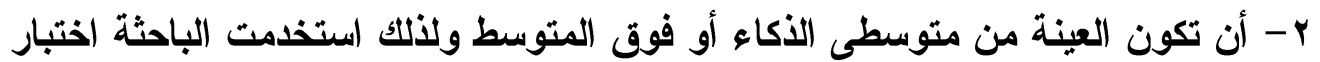

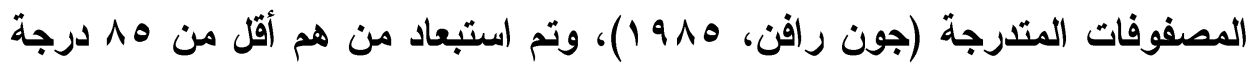
فى نسبة الذكاء العامة وكان عددهم (^) أطفال. r- أن تكون العينة من مستوى اجتماعي اقتصادي ثقافى متوسط ولذلك استخدمت واءت الباحثة استمارة المستوى الاجتماعي الاقتصادي الثقافى من اعدئ مادئ الباحثة.

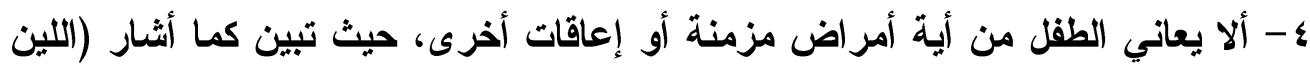
بين، ه . . ب) أن الأطفال ذوى الحالات المرضية والإعاقات هم من بين الأطفال الأكثر عرضة ليكونوا ضحايا للتنمر ومن ثم تم استبعاد (؛ (أطفال. ه- أن يعيش الطقل مع الأبوين معاً. 
ضحايا التنمر من الأطفال ذوي صعوبات التعلم "دراسة لأهم المشكلات النفسية والاجتماعية فى ضوء بعض المتغيرات النفسية" والجدول التالي رقم (1) يوضح خصائص العينة الكلية وخصائص المجموعات الفرعية:

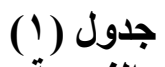

خصائص العينة الكلية والفرعية من حيث الجنس والعمر

\begin{tabular}{|c|c|c|c|c|c|}
\hline \multicolumn{2}{|c|}{ العمر } & \multicolumn{3}{|c|}{ الجنس } & المتغي \\
\hline$\varepsilon$ & $p$ & مج & إناث & ذكور & \\
\hline$Y . \varepsilon$ & $1 \cdot .9$ & 179 & VV & $9 r$ & ضحايا التنمر \\
\hline$Y .7$ & $1 \cdot .1$ & IVY & $\sqrt{V Y}$ & $9 V$ & الضحايا المتنمرون \\
\hline$Y . V$ & $1 \cdot .9$ & IV. & Vo & 90 & العاديون \\
\hline Y. & $1 \cdot .9$ & $r \leqslant Y$ & $10 \%$ & 119 & العينة الكلية \\
\hline
\end{tabular}

ثانياً: أدوات الدراسة:

استخدمت الباحثة الأدوات الآتية:

(1) استمارة البيانات الأولية: (إعداد الباحثة)

تتضمن هذه الاستمارة بيانات خاصة بالطقل مثل العمر والجنس، والظروف الأسرية (تواجد الأب والأم - طلاق - هجر- سفر للخارج - انفصال) ومحل الإقامة، ودرجة تعليم ولئين الأب والأم ومهنة كل منهما، والأمراض الجسيمة إن وجلت، وغيرها من البيانات التي استخدمتها الباحثة بهدف اختيار العينة وضبطها. (Y) مقياس المتنمر / الضحية: (إعداد الباحثة) والأي أعد لتحديد الأطفال ضحايا التنمر، الضحايا المتنمرين، غير الضحايا من التلاميذ الذين يعانون من صعوبات التعلم في المرحلة العمرية من (9- r r l) عاماً.

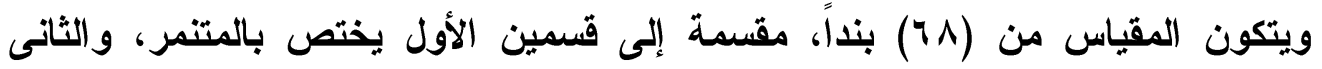
يختص بضحايا التنمر، ويتكون من سنة أبعاد أو جواتب لرصد سلوكيات التنمر التي قام

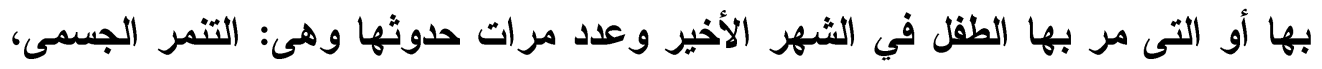

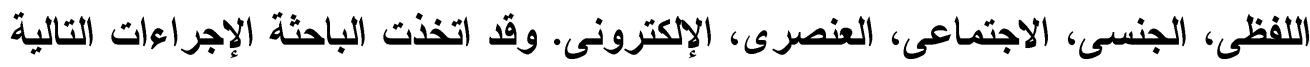
في سبيل إعداد هذا المقياس:

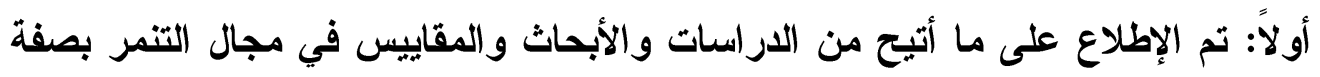

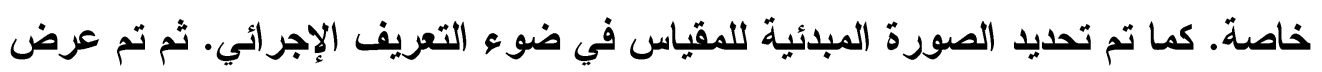




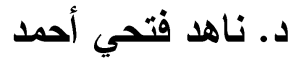

بنود المقياس على عدد من المتخصصين في مجال علم النفس والتربية الخاصة وفي ضوء ذلك قامت الباحثة بالتعديل والتغيير والحذف والإضافة لبنود المقياس. كما تم تطبيق هذا المقياس على عينة الثبات والصدق المكونة من (ه૦) من الأطفال ذوى

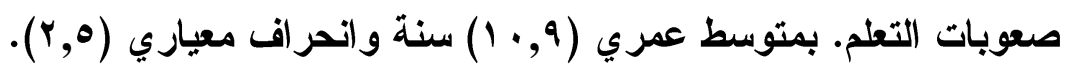
ثانياً: الصدق: تم التحقق من صدق المقياس بطريقتين كما يلي:

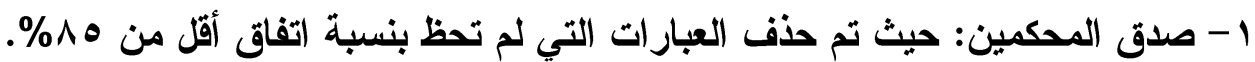
r- الصدق العاملي: قامت الباحثة باستخدام أسلوب التحليل العاملى للوقوف على البنية

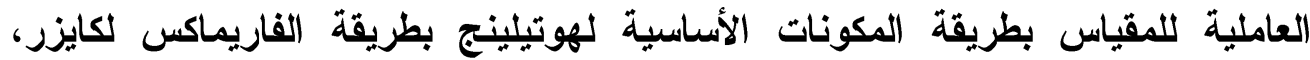

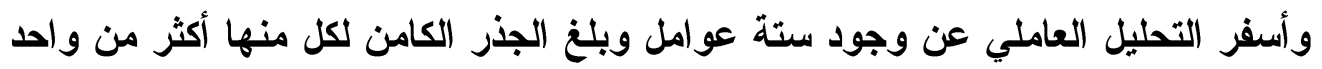

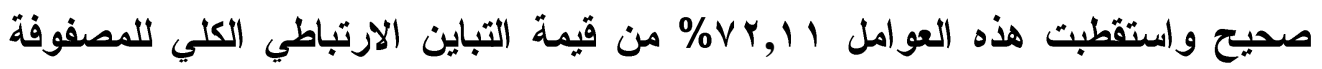

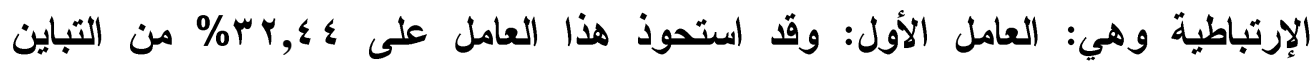

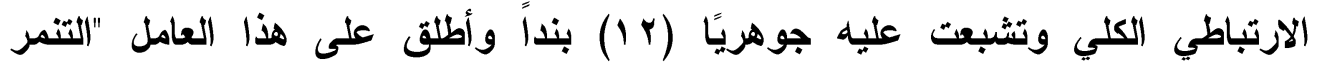

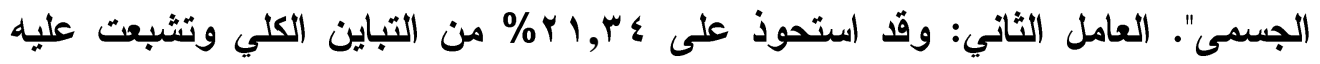

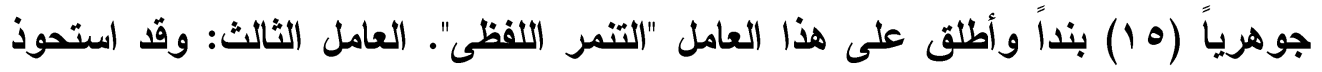

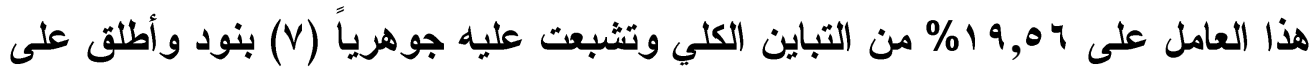

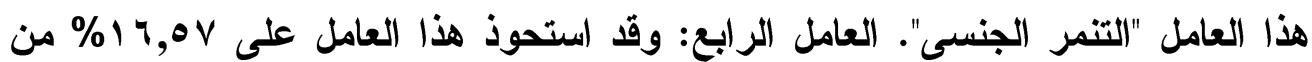
التباين الكلي وتثبعت عليه جوهرياً (17) بنداً وأطلق على هذا لهاء العامل "التنمر الاجتماعى". العامل الخامس: وقد استحوذ هذا العامل على بآ,11\% 1ه من التباين الكلي وتثبعت عليه جوهرياً (†) بنود وأطلق على هذا العامل "التنمر العنصرى". العامل السادس: وقد استحوذ هذا العامل على ، †,\% من التباين الكلي وتثبعت عليه جوهرياً

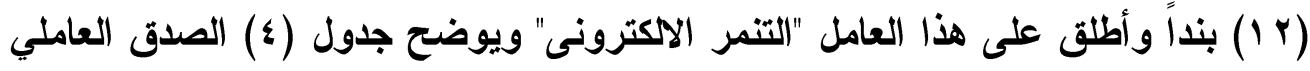
لبنود المقياس. 
ضحايا التنمر من الأطفال ذوي صعوبات التعلم "دراسة لأهم المشكلات النفسية والاجتماعية فى ضوء بعض المتغيرات النفسية" -

$$
\text { (r) جدول }
$$

الصدق العاملي لبنود المقياس وتثبعاتها العاملية بعد التدوير ع ع ع ع ع ع ع ع ع ع ع ع ع ع ع ع ع ع ع ع ع ع ع ع

\begin{tabular}{|c|c|c|c|c|c|c|c|c|c|c|c|c|c|}
\hline $\begin{array}{c}\varepsilon \\
\text { (1) }\end{array}$ & $\begin{array}{c}\varepsilon \\
(0)\end{array}$ & $\begin{array}{c}\varepsilon \\
(\mathfrak{\xi})\end{array}$ & $\begin{array}{c}\varepsilon \\
(\stackrel{r}{)})\end{array}$ & $\begin{array}{c}\varepsilon \\
(\mathbb{r})\end{array}$ & $\begin{array}{l}\varepsilon \\
(1)\end{array}$ & البنود & $\begin{array}{l}\varepsilon \\
(7) \\
\text { (1) }\end{array}$ & $\begin{array}{l}\varepsilon \\
(0)\end{array}$ & $\begin{array}{c}\varepsilon \\
(\xi) \\
(\varepsilon)\end{array}$ & $\begin{array}{l}\varepsilon \\
(\widetilde{v})\end{array}$ & $\begin{array}{c}\varepsilon \\
(r)\end{array}$ & $\begin{array}{c}\varepsilon \\
\text { (1) }\end{array}$ & البنود \\
\hline & & & & & $\cdot, 0$ & ro & & & & & & 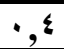 & $T$ \\
\hline & & & $\cdot, \xi$ & & & rq & & & & & $\cdot 0$ & & Y \\
\hline \multirow[t]{2}{*}{$\cdot, 0$} & & & & & & $r v$ & & & & & & $\cdot, 7$ & $r$ \\
\hline & & & & $\cdot, 7$ & & $r \wedge$ & & & & & $\cdot, \mathrm{V}$ & & $\xi$ \\
\hline \multirow[t]{4}{*}{$\cdot, \mathrm{v}$} & & & & & & rq & $\cdot, 0$ & & & & & & 0 \\
\hline & & & $\cdot, 0$ & & & $\varepsilon$ & & & & & $\cdot, 7$ & & 7 \\
\hline & & $\cdot, 7$ & & & & $\leqslant 1$ & & & & & & $\because, 0$ & $v$ \\
\hline & $\cdot 0$ & & & & & $\leqslant Y$ & & & $\cdot, \mathrm{V}$ & & & & $\Lambda$ \\
\hline$\cdot, \xi$ & & & & & & $\varepsilon r$ & & & & & $\cdot, \wedge$ & & 9 \\
\hline \multirow[t]{2}{*}{$\cdot, 0$} & & & & & & \& & • & & & & & & 1. \\
\hline & & & & $\cdot, 0$ & & $\leqslant 0$ & & & & & & $\cdot 0$ & 11 \\
\hline \multirow[t]{4}{*}{$\cdot, 7$} & & & & & & $\leqslant 7$ & & & & $\cdot, \wedge$ & & & Ir \\
\hline & & $\cdot, 7$ & & & & $\leqslant V$ & & & $\cdot, 7$ & & & & 14 \\
\hline & $\cdot, \wedge$ & & & & & $\leqslant 1$ & & $\cdot, 0$ & & & & & $1 \varepsilon$ \\
\hline & & $\cdot, 0$ & & & & 29 & & & & & $\because, 0$ & & 10 \\
\hline \multirow[t]{10}{*}{$\cdot, 7$} & & & & & & 0. & 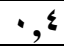 & & & & & & 17 \\
\hline & & & & $\cdot, 0$ & & 01 & & & & & & $\cdot \pi$ & IV \\
\hline & $\cdot, 7$ & & & & & $O Y$ & & & $\cdot, \wedge$ & & & & 11 \\
\hline & & & & $\cdot, \mathrm{V}$ & & or & & & & & & $\cdot 7$ & 19 \\
\hline & & $\cdot, 0$ & & & & 0\{ & & & & $\cdot,^{\circ}$ & & & $r$. \\
\hline & & & & $\cdot, \wedge$ & & 00 & & & & & & $\cdot, 7$ & ru \\
\hline & & $\cdot, \mathrm{V}$ & & & & 04 & & & 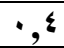 & & & & Yr \\
\hline & & & & & $\cdot, \mathrm{v}$ & OV & $\cdot, 0$ & & & & & & Yr \\
\hline & & & $\cdot, \xi$ & & & 01 & & & & & $\cdot, 7$ & & $Y \xi$ \\
\hline & & & & $\cdot, 0$ & & 09 & & & & & & $\because, 0$ & ro \\
\hline \multirow[t]{5}{*}{$\cdot, 0$} & & & & & & 7. & & & & & $\cdot$, \& & & ry \\
\hline & & & $\cdot, 7$ & & & 71 & & & $\cdot, 0$ & & & & $r V$ \\
\hline & $\cdot, \varepsilon$ & & & & & $T Y$ & & & & & & 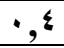 & $r \wedge$ \\
\hline & & $\cdot, 0$ & & & & 74 & & & $\cdot, \xi$ & & & & rq \\
\hline & & & $\cdot, 7$ & & & $7 \varepsilon$ & & $\cdot, 0$ & & & & & $r$. \\
\hline \multirow[t]{4}{*}{$\cdot, \mathrm{V}$} & & & & & & 70 & & & & & $\cdot, 0$ & & $r$ \\
\hline & & $\cdot, 7$ & & & & 74 & & & $\cdot, 7$ & & & & rr \\
\hline & $\cdot, \mathrm{V}$ & & & & & $7 V$ & & & $\cdot,^{\circ}$ & & & & $r r$ \\
\hline & & & & & $\cdot, 0$ & 71 & & & & & $\cdot, \mathrm{V}$ & & $r \varepsilon$ \\
\hline
\end{tabular}

ثالثاً: الثبــات: تحققت الباحثة من ثبات المقياس بثُلاث طرق: باستخدام معامل ثبات ألفا

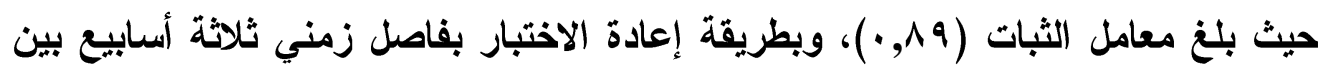


التطبيقين الأول والثاني وبلغ معامل الثبات (^^, •)، وبطريقة التجزئة النصفية بلغ معامل

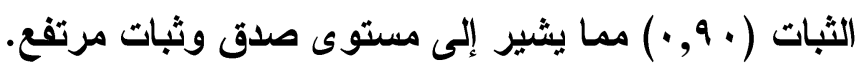

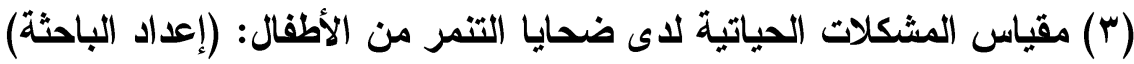

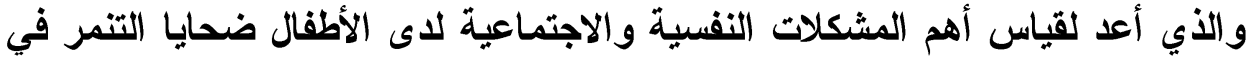

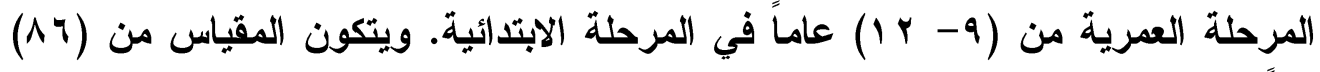

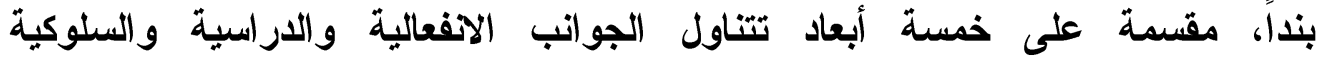

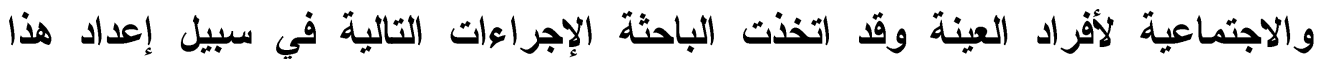
المقياس.

أولاً: تم الإطلاع على ما أتيح من الدارسات والأبحاث: التي تتناول بعض الجواتب

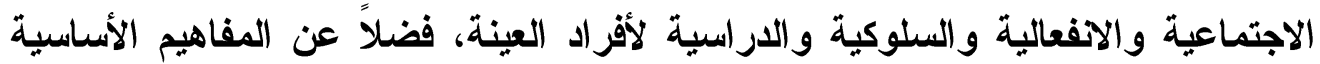

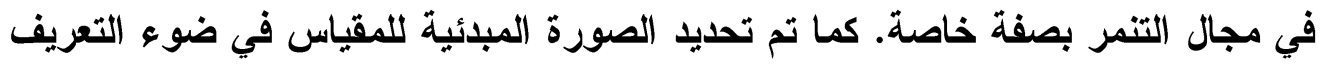

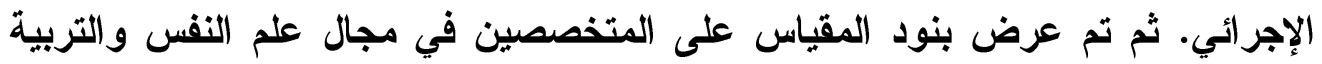

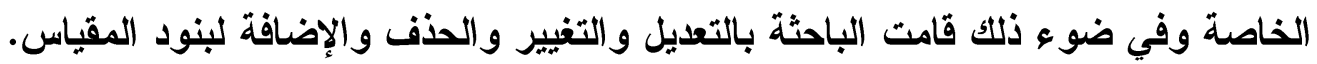

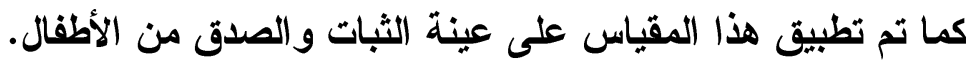

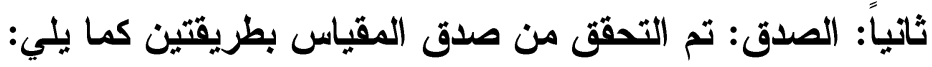

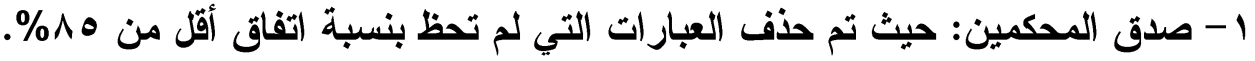
r- الصدق العاملي: قامت الباحثة باستخدام أسلوب التحليل العاملى للوقوف على على البنية

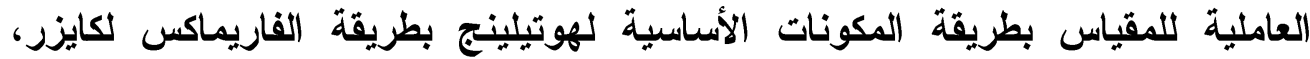

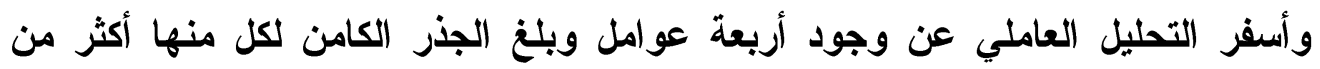

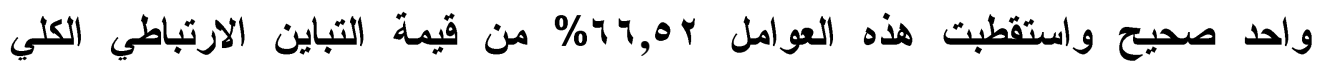

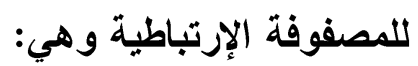

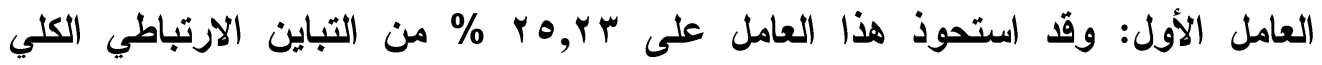

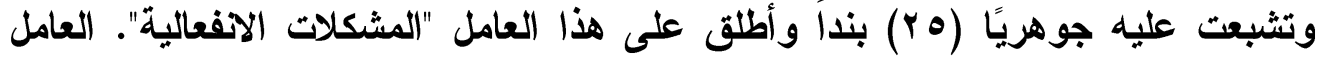

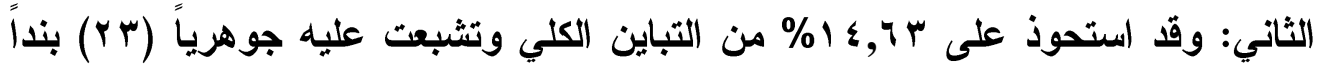

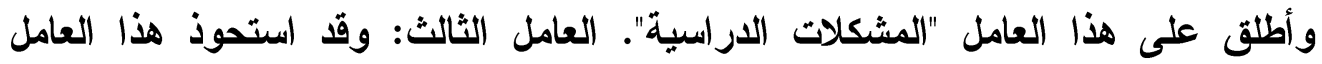

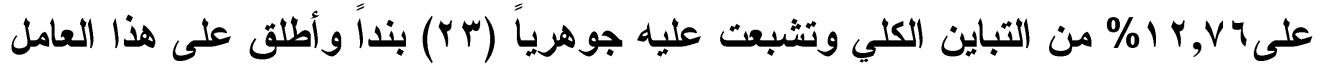

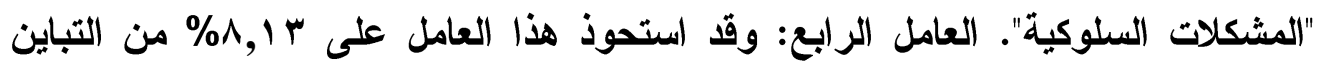
الكلي وتثبعت عليه جوهرياً (0 1 ) بنداً وأطلق على هذا العامل "المشكلات الاجتماعية". ويوضح جدول (؛) الصدق العاملي لبنود المقياس. 
ضحايا التنمر من الأطفال ذوي صعوبات التعلم "دراسة لأهم المشكلات النفسية والاجتماعية فى ضوء بعض المتغيرات النفسية" -

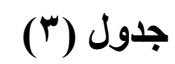

الصدق العاملي لبنود المقياس وتثبعاتها العاملية بعد التدوير ع ع ع ع ع ع ع ع ع ع ع ع ع

\begin{tabular}{|c|c|c|c|c|c|c|c|c|c|}
\hline $\begin{array}{l}\varepsilon \\
(\xi)\end{array}$ & $\mathcal{F}_{(\tilde{u})}$ & $\left(\begin{array}{l}\xi \\
(1)\end{array}\right.$ & (1) & البنويد & $\begin{array}{l}\xi \xi \\
(\xi)\end{array}$ & $\left(\begin{array}{l}\xi \\
(i)\end{array}\right.$ & $(\varepsilon)$ & (1) & البنود \\
\hline & & & $\because, 00$ & \& & & & $\cdot, 04$ & & $T$ \\
\hline & $\theta, \leqslant 0$ & & & $\leqslant 0$ & & & & $\cdot, 74$ & r \\
\hline & & & $\cdot, 174$ & $\leqslant 7$ & & $\cdot$, AT & & & $r$ \\
\hline & &,$\pi \mathrm{V}$ & & $\varepsilon V$ & & & & $\cdot, 7 \wedge$ & $\varepsilon$ \\
\hline \multirow[t]{3}{*}{$\cdot, \mathrm{V} \theta$} & & & & $\leqslant \Lambda$ & & & $\because, 09$ & & 0 \\
\hline & & 0,07 & & $\varepsilon 9$ & & & & $\cdot, \pi$ & 7 \\
\hline & & & $\theta, \leqslant 1$ & 0. & & $\because, \wedge$. & & & V \\
\hline \multirow[t]{7}{*}{$\cdot, 7 \mathrm{~V}$} & & & & 01 & & & & ? & $\Lambda$ \\
\hline & & $\because, 09$ & & Or & & $\because, 00$ & & & 9 \\
\hline &., 07 & & & Or & & & & 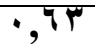 & 1. \\
\hline & & & $\because, 04$ & $0 \leqslant$ & & & $\theta, 0\}$ & & 11 \\
\hline & & $, 0\}$ & & 00 & & $\because, \lambda$ & & & Tr \\
\hline & $\because, 0 \mathrm{~V}$ & & & 07 & & & 0,70 & & $1 T$ \\
\hline & & & $\because, \wedge$. & OV & $\cdot, \leqslant 1$ & & & & $1 \leqslant$ \\
\hline \multirow{5}{*}{., 09} & & & & 01 & & & & $\cdot, 7 \leqslant$ & 10 \\
\hline & $\because, O \mathrm{~V}$ & & & 09 & & $\because, 19$ & & & 17 \\
\hline & & $\because, 01$ & & 9. & & & & $\cdot, 74$ & IV \\
\hline & & & $0, \leqslant 9$ & 71 & $\because, 01$ & & & & 11 \\
\hline & $0, \leqslant 7$ & & & 74 & & & $\theta, \mathrm{VN}$ & & 19 \\
\hline \multirow[t]{11}{*}{$\cdot, 79$} & & & & $7 \pi$ & $\because, 00$ & & & & T. \\
\hline & & 0,79 & & $7 \varepsilon$ & & & $\cdot, \lambda \Gamma$ & & Tा \\
\hline & & & $\because, 04$ & 70 & $\because, \mathrm{VV}$ & & & & YY \\
\hline & $\because, 0 \mathrm{~V}$ & & & 79 & & & & $\because, \mathrm{V} \theta$ & $T T$ \\
\hline & & $\because, 01$ & & $7 \mathrm{~V}$ & & $\because, \leqslant 9$ & & & Tद \\
\hline & & 0,07 & & 71 & & & $\because, 0 \leqslant$ & & To \\
\hline & & & $0, \leqslant 9$ & 79 & $\because, 01$ & & & & 17 \\
\hline &., 07 & & & V. & & & $\because, \infty 0$ & & TV \\
\hline & & $\because, \mathrm{V}_{0}$ & & VI & & & & $\cdot, 77$ & TA \\
\hline & $\because, 00$ & & & VY & & $\cdot, 70$ & & & rq \\
\hline & & &., 09 & $V N$ & & & & $\because, \mathrm{VV}$ & $r$. \\
\hline \multirow[t]{2}{*}{$\cdot, 70$} & & & & $V \varepsilon$ & $\because, 0 \mathrm{~V}$ & & & & TI \\
\hline & $\because, \mathrm{V}^{\circ}$ & & & Vo & & & 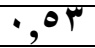 & & $r r$ \\
\hline \multirow[t]{11}{*}{., 09} & & & & 87 & $\cdot, \pi$ & & & & $r T$ \\
\hline & & $\because, \wedge \cdot$ & & $\begin{array}{l}V \\
\end{array}$ & & & & $\because, \leqslant \leqslant$ & $\Gamma \varepsilon$ \\
\hline & $\cdot, \mathrm{VN}$ & & & $\nabla \Lambda$ & & & 0,07 & & ro \\
\hline & & & $\because, \mathrm{VV}$ & 79 & & 9,70 & & & $r 4$ \\
\hline & & $\because, \leqslant 1$ & & $\Lambda \cdot$ & & $\because, \leqslant \mathrm{V}$ & & & TV \\
\hline & &., 07 & & $\Lambda 1$ & & & & $\because, 0 \mathrm{~V}$ & $r \lambda$ \\
\hline & & & $\because, 10$ & NY & $\because, \mathrm{V} 0$ & & & & 19 \\
\hline &, $7 \leqslant$ & & & $\Lambda T$ & & & & $\because, \wedge \wedge$ & $\varepsilon$ \\
\hline & & 0,07 & & $\Lambda \varepsilon$ & & $\cdot, 7 \leqslant$ & & & \&1 \\
\hline & $\because, 0 \leqslant$ & & & 10 & , OT & & & & $\varepsilon Y$ \\
\hline & & & $\cdot, \leqslant 9$ & 17 & & $\cdot, 79$ & & & $\varepsilon \Gamma$ \\
\hline
\end{tabular}


د. ناهد فتحي أحمد

ثالثاً: الثبات: تحققت الباحثة من ثبات المقياس بثلاث طرق: باستخدام معامل ثبات ألفا

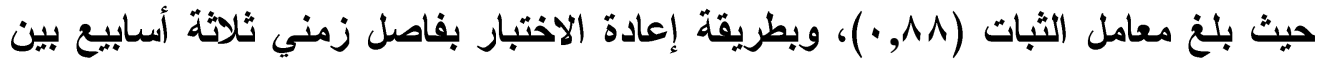

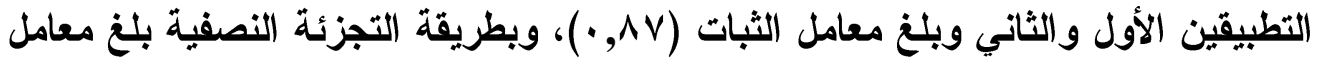

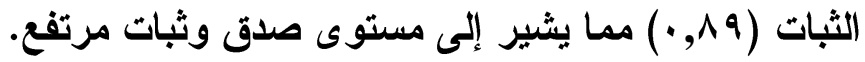

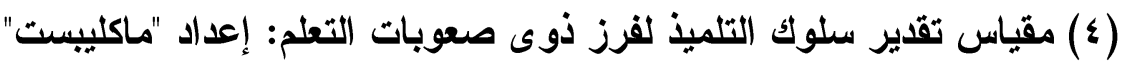

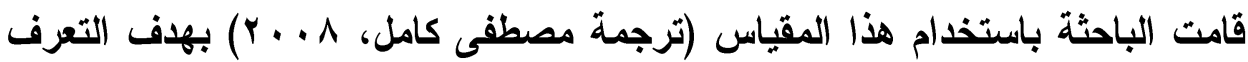

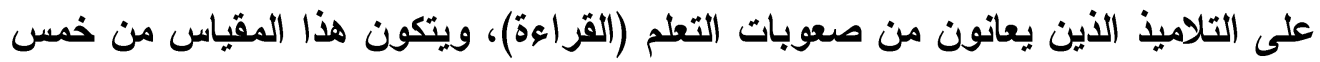

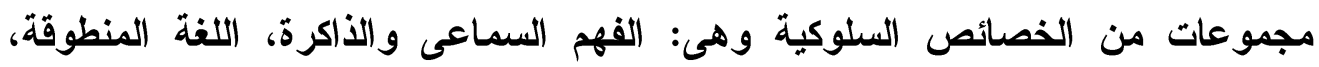

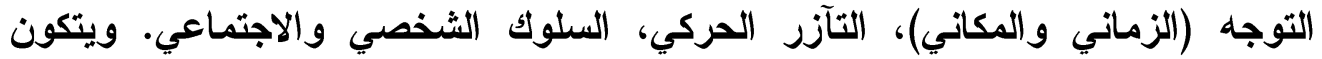
المقياس من أربع وعشرون فقرة، يتم تقدير التلميذ في كل منها على مقياس خماسي التئي

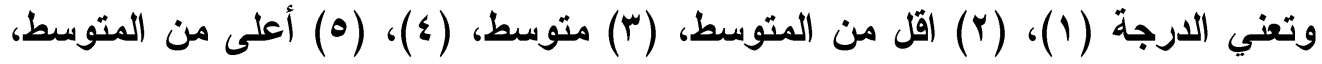

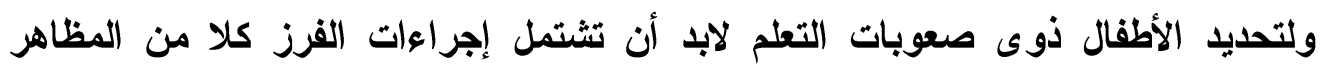
اللفظية وغير اللفظية للتعلم ويمكن أن يقوم بالتقدير كل من له معرفة وثيقة بالتبات التلميذ موضع التقدير كالمعلمين، الأخصائيين النفسيين. ولقد تحققت الباحثة من صدق وثبات المقياس كالأتى:

1- صدق المقياس: باستخدام الصدق العاملي حيث استخدمت الباحثة التحليل العاملي

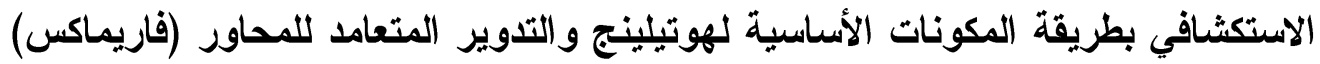
مع محك كايزر والتي أوضحت توافر الصدق العاملي للمقياس، وأسفر التحليل العاملي عن وجود خمسة عوامل أو أبعاد للمقياس هي: العامل الأول: الفهم السماعى والأكرة وقداً استحوذ هذا العامل على (· (1,1\%) من التباين الارتباطي الكلي وتثبعت عليه جوهرياً

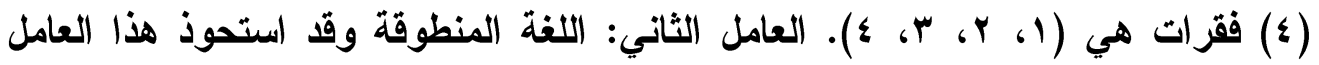

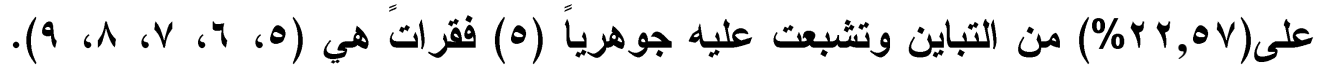

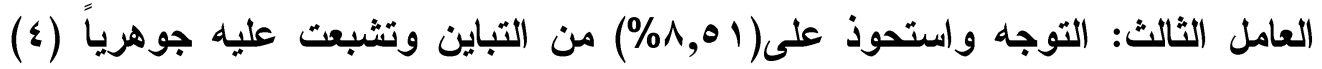

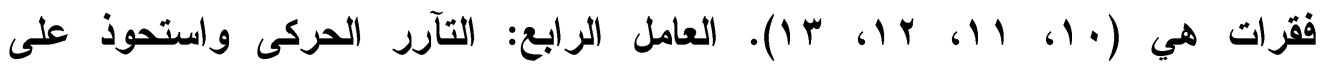

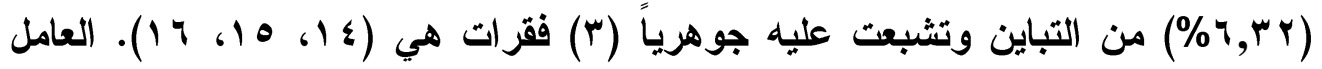

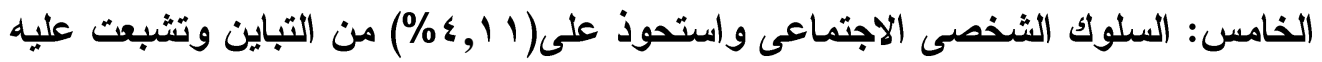

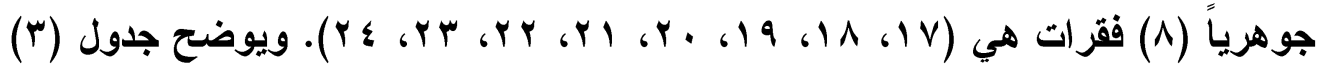
الصدق العاملي لفقرات مقياس تقدير سلوك التلميذ وتثبعاتها العاملية. 
ضحايا التنمر من الأطفال ذوي صعوبات التعلم "دراسة لأهم المثكلات النفسية والاجتماعية فى ضوء بعض المتغيرات النفسية" -

جدول (ع) بنود مقياس تقدير سلوك التلميذ وتشبعاتها العاملية بعد التدوير

\begin{tabular}{|c|c|c|c|c|c|c|}
\hline الخامس & الرابع & الثامل & الثاني & الأعلمل & البنـــــود & p \\
\hline & & & & $\cdot, 70$ & فهم معانى الكلمات. & 1 \\
\hline & & & & $\cdot, 00$ & تنفيذ التعليمات. & $r$ \\
\hline & & & & $\cdot, \leqslant 1$ & فهم المناقشات التى تذور فى الفصل. & $r$ \\
\hline & & & & $\cdot, \bullet \mathrm{V}$ & تذكر المعلومات. & $\varepsilon$ \\
\hline & & & $\cdot, \varepsilon r$ & & المحصول اللفظى. & 0 \\
\hline & & & $\cdot, \mu$ & & قواعد اللغة. & 7 \\
\hline & & & $\cdot, \leqslant Y$ & & ت تذكر الكلمات. & $\mathrm{V}$ \\
\hline & & & $\cdot, 0 \leq$ & & رواية القصص والربط بين الخبرات. & $\Lambda$ \\
\hline & & & $\cdot, r$ & & التعبير عن الأفكار. & 9 \\
\hline & & $\cdot, \varepsilon r$ & & & التعرف على الزمن. & 1. \\
\hline & & $\cdot, 74$ & & & التعرف على المكان. & 11 \\
\hline & & $\cdot, \leqslant \wedge$ & & & إدراك العلاقات. & Ir \\
\hline & &, 00 & & & معرفة الاتجاهات. & $1 T$ \\
\hline & $\cdot, \mathrm{r \Lambda}$ & & & & التآزر التام (المشى/ الجرى/ الوثب/ الققر/ الكتابة). & $1 \leqslant$ \\
\hline & $\cdot, \leqslant 0$ & & & & التوازن. & 10 \\
\hline & $\cdot, 00$ & & & & المهارة اليدوية. & 17 \\
\hline$\cdot, 7 \varepsilon$ & & & & & التعاون. & IV \\
\hline$\cdot, \mu_{0}$ & & & & & الانتباه. & 11 \\
\hline$\cdot, 0 \mathrm{~V}$ & & & & & التظيم. & 19 \\
\hline$\cdot, \varepsilon Y$ & & & & & المواقف الجديدة. & $r \cdot$ \\
\hline$\cdot, 71$ & & & & & التقبل الاجتماعى. & YI \\
\hline$\cdot, \leqslant 1$ & & & & & تحمل المسئولية. & rr \\
\hline$\cdot, \leqslant 7$ & & & & & إتمام المهام. & $r r$ \\
\hline$\cdot, 0 r$ & & & & & اللباقة (الذوق العام والحساسية). & $r \varepsilon$ \\
\hline
\end{tabular}

r- ثبات المقياس: من خلال ثلاث طرق باستخدام معامل ثبات ألفا حيث بلغ معامل الثبات (^^,^•)، وبطريقة إعادة الاختبار بفاصل زمني ب أسابيع بين التطبيقين الأول والثاني بلغ

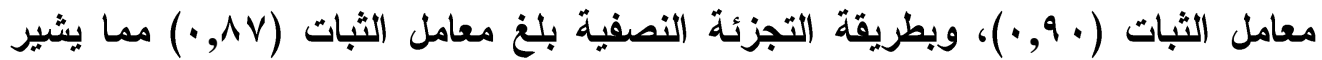
إلى تمتع المقياس بلرجة جيدة من الصدق والثبات. (0) مقياس التعامل مع السلوك التنمرى: (إعداد باريس وآخرون)

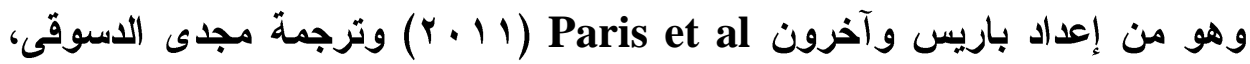
ويتكون المقياس من ( • ب) بنداً مقسمة على أربعة أبعاد تمثل أساليب التعامل مع السلوك التنمرى وهى: البحث عن المساندة، التجاهـل، لوم الأات، الدفاع عن النفس. وطريقة الإجابة على بنود المقياس تتطلب من التلميذ أن يجيب وفقاً لبدائل أربعة هى: أبداً، أحياناً، 
د. ناهد فتحي أحمد

غالباً، دائماً، وتم التأكد من قبل مترجم المقياس من صدق المقياس باستخدام الصدق التلازمى، الصدق التمييزى، الصدق العاملى. ومن ثبات المقياس باستخدام إعادة التطبيق،

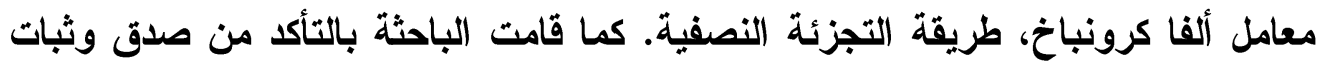

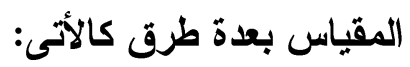
أسـولاً: صدق المقياس: باستخدام الصدق العاملى الاستكثافي بطريقة المكونات الأساسية

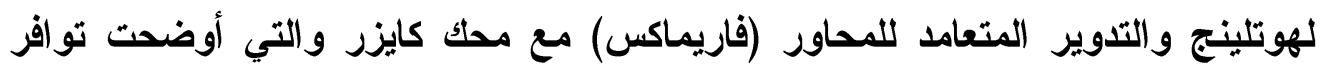
الصدق العاملى للمقياس، وأسفر التحليل العاملى عن وجود أربعة عوامل للمقياس هي:

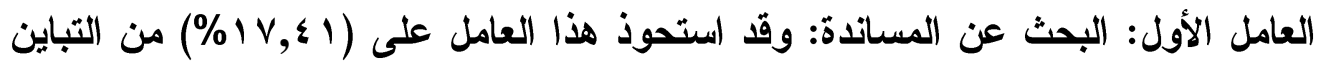

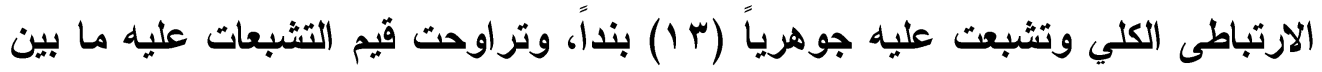

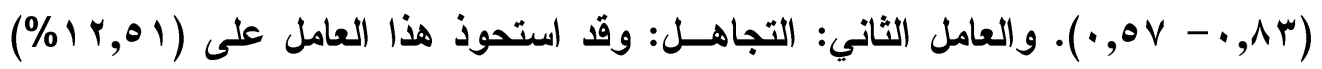
من التباين وتثبعت عليه جوهرياً (V) بنود، وتراوحت قيم التشبعات عليه ما بين

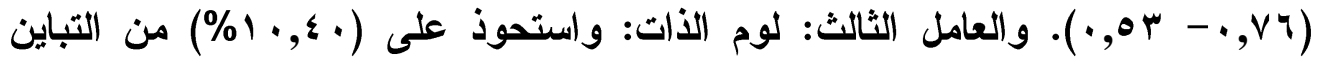

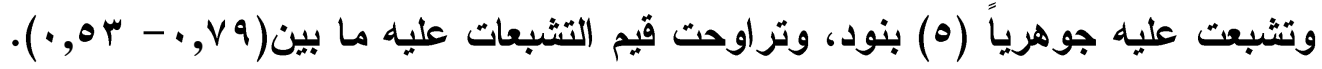

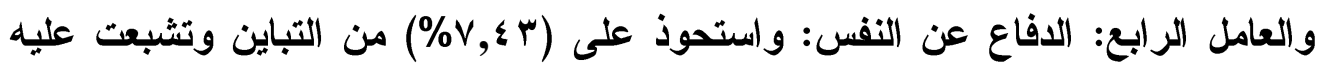

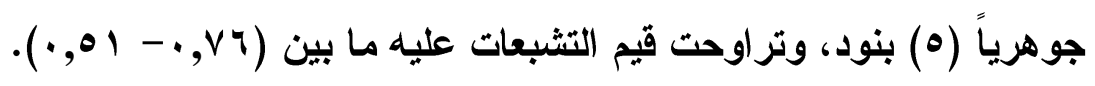

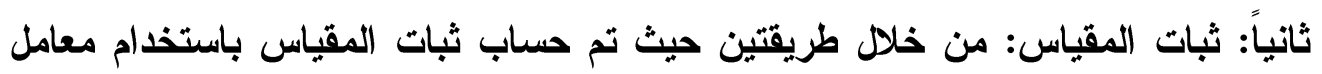

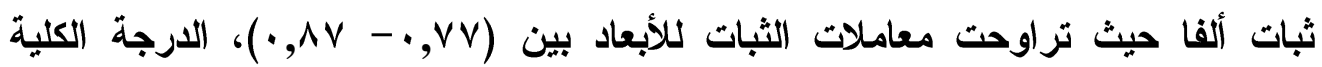
للمقياس (1 (1, •)، وبطريقة التجزئة النصفية حيث تراوحت معاملات الثبات للأبعاد بين

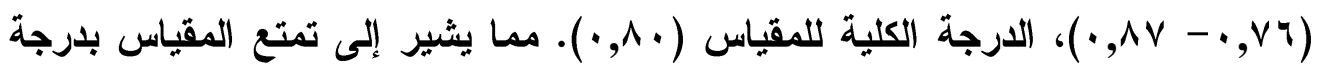
جيدة من الصدق والثبات.

(7) مقياس الضغط المدرسى: (تعديل الباحثة)

وهو من إعداد لطفى عبد الباسط، ويتكون المقياس من (هـ) بنداً مقسمة على تسعة أبعاد هى: طبيعة العلاقة بين التلميذ والزملاء، طبيعة العلاقة بين التلميذ والمدرس،

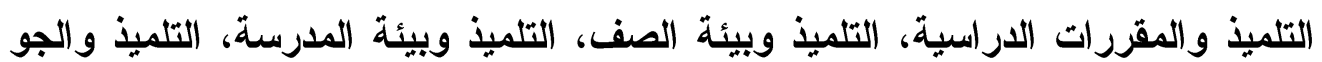
الأسرى، التلميذ والتفكير فى المستقبل، التلميذ والتأييد الاجتماعى. وقد قامت ولثيله الباحثة بإدخال بعض التعديلات من صياغة وإضافة بعض البنود وفى طريقة الإجابة على بنود 
ضحايا التنمر من الأطفال ذوي صعوبات التعلم "دراسة لأهم المشكلات النفسية والاجتماعية فى ضوء بعض المتغيرات النفسية" المقياس حيث أصبحت (نعم، لا) بدلاً من (موافق تماماً، موافق بصفة عامة، موافق إلى

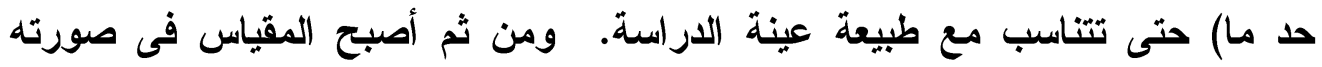
النهائية يتكون من (^ه) بنداً بعد التعديل، ثم قامت الباحثة بالتأكد من صدق وثبات

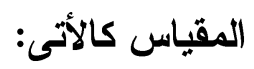

أولاً: صدق المقياس: تم التحقق من صدق المقياس من خلال:

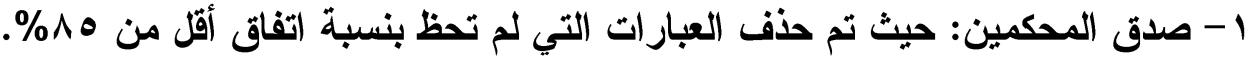
r- الصدق العاملي: حيث استخدمت الباحثة التحليل العاملى الاستكثافي بطريقة المكونات الأساسية لهوتلينج والتدوير المتعامد للمحاور (فاريماكس) مع محك كايزر والتي أوضحت توافر الصدق العاملى للمقياس، وأسفر التحليل العاملى عن وجود تسعة عوامل أو أبعاد للمقياس هي: العامل الأول: طبيعة العلاقة بين التلميذ والزملاء: وقا وهي

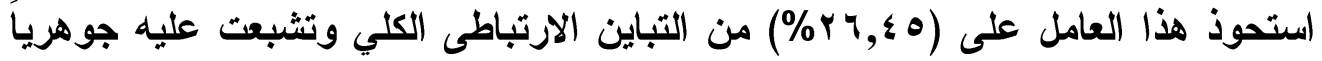

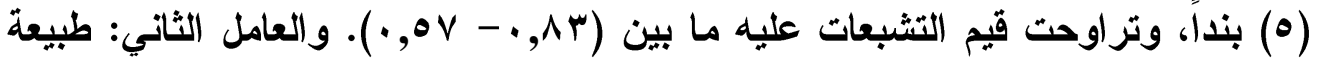
العلاقة بين التلميذ والمدرس: وقد استحوذ هذا العامل على (اب, اYr\%) من التباين

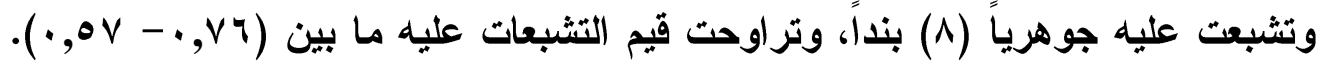

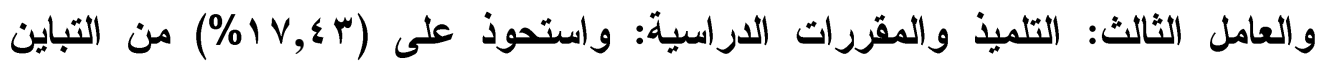

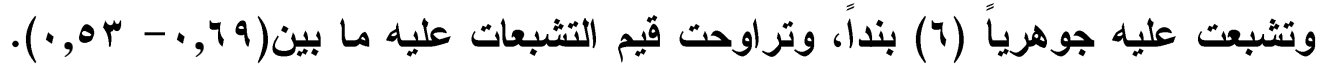

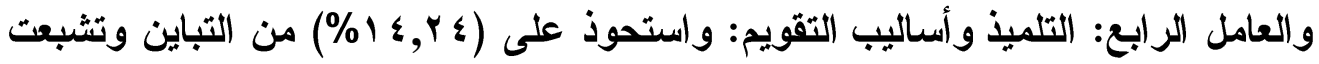

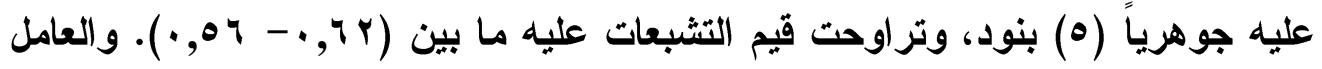

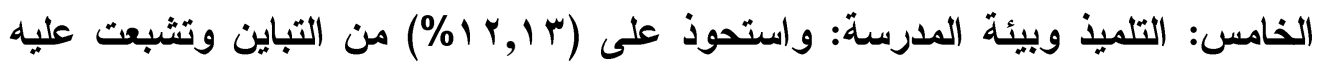
جوهرياً (V) بنود، وتراوحت قيم التثبعات عليه ما بين (V0,.-- . ه,.•). والعامل

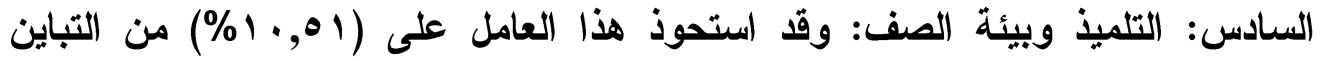

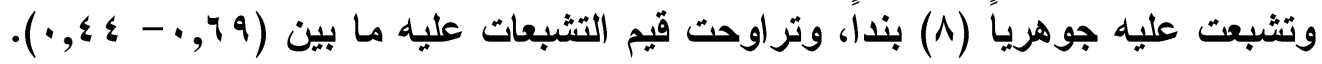

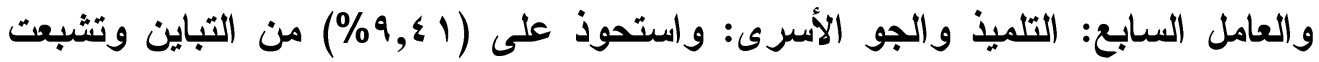

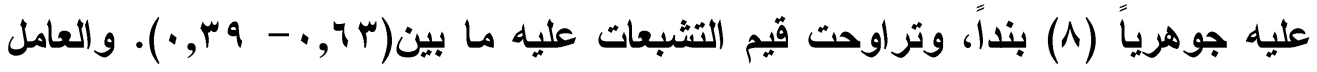

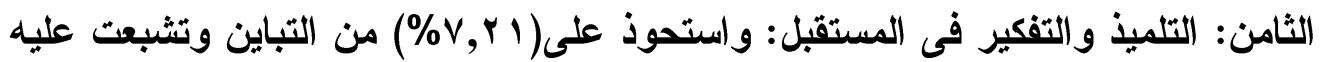

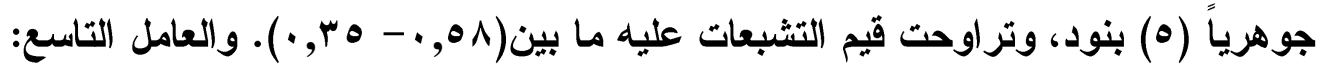


التلميذ والتأييد الاجتماعى: واستحوذ على (0 1,؛\%) من التباين ونثبعت عليه جوهرياً

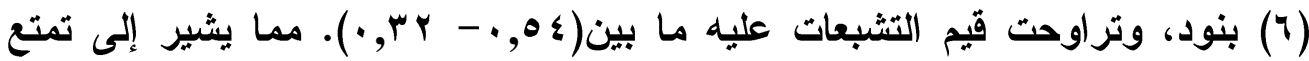
المقياس بلرجة جيدة من الصدق والثبات. ثانياً: ثبات المقياس: كما تم التحقق من ثبات المقياس من خلال طريقتين باستخدام معامل

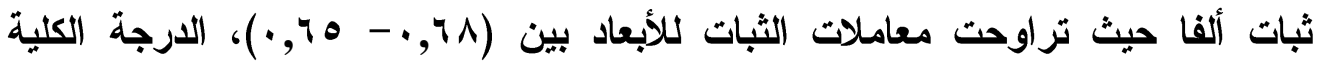
للمقياس (V9, ·). وبطريقة التجزئة النصفية بعد تصحيح الطول حيث تراوحت معاملات

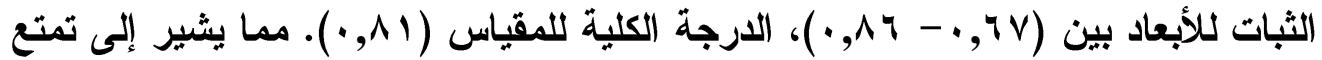
المقياس بدرجة جيدة من الصدق والثبات.

(V) مقياس أساليب المعاملة الوالدية اللاسوية كما يدركها الأبناء: (إعداد الباحثة)

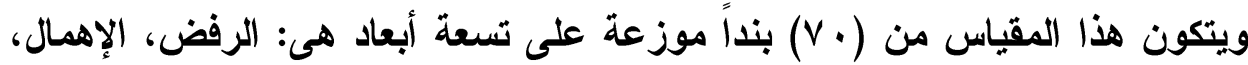
الحماية الزائدة، التسلط، القسوة، التفرقة، الخضوع، عدام الاتساق، إثارة الألم النفسى. ويتم الإجابة على كل بند من خلال خيارين (تنطبق/ لا تنطبق)، وتوضح اختيار الطفل

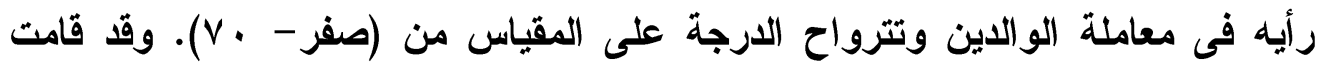
الباحثة بالتأكد من صدق وثبات المقياس بعدة طرق كالأتى:

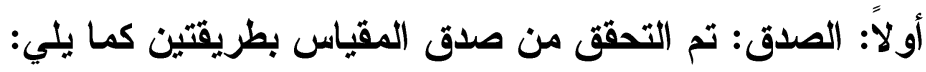

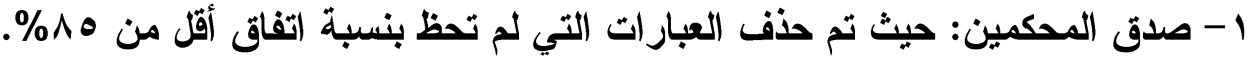
r- الصدق العاملي: قامت الباحثة باستخدام أسلوب التحليل العاملى للوقوف على البنية العاملية للمقياس بطريقة المكونات الأساسية لهوتيلينج بطريقة الفاريماكس لكايزر، وأسفر التحليل العاملي عن وجود أربعة عوامل وبلغ الجذر الكامن لكل منها أكثر من بطن واحد صحيح واستقطبت هذه العوامل rV,Ir\% من قيمة التباين الارتباطي الكلي

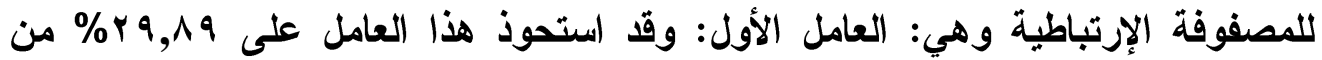
التباين الارتباطي الكلي وتثبعت عليه جوهريًا (· (1) بنود وأطلق على هذا العامل

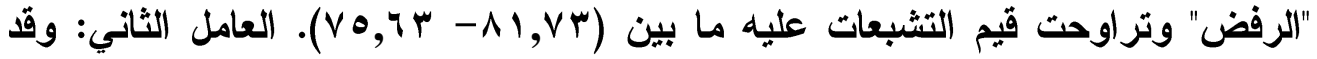

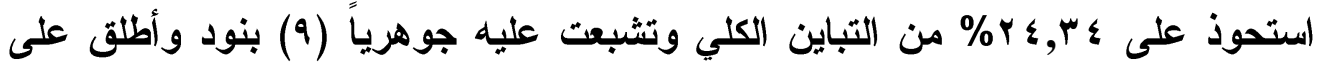

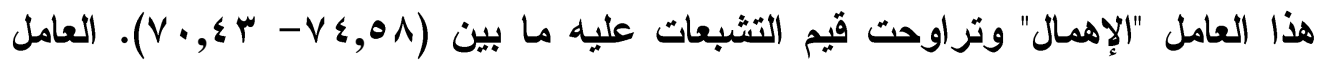

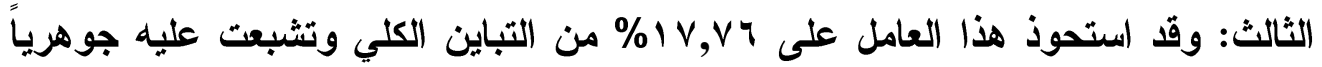


ضحايا التنمر من الأطفال ذوي صعوبات التعلم "دراسة لأهم المشكلات النفسية والاجتماعية فى ضوء بعض المتغيرات النفسية" (9) بنود وأطلق على هذا العامل "الحماية الزائدة" وتراوحت قيم التشبعات عليه ما بين

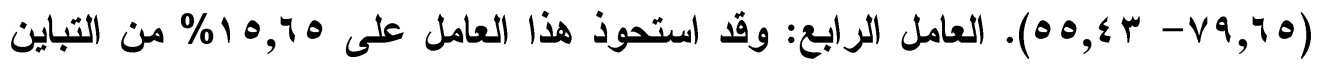
الكلي وتثبعت عليه جوهرياً (9) بنود وأطلق على هذا العامل "التسلط" وتراوحت قيم

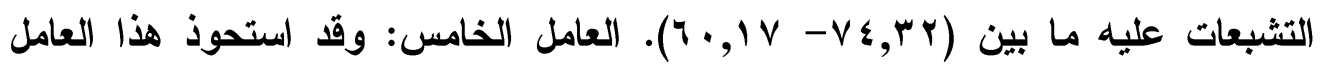

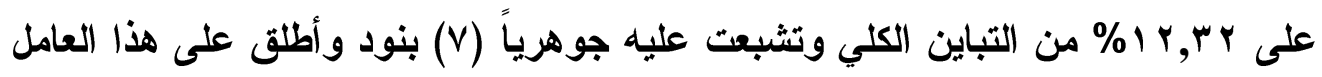

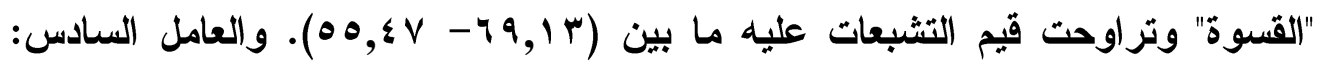

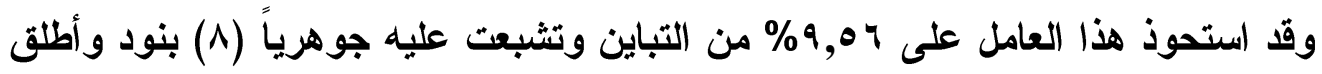

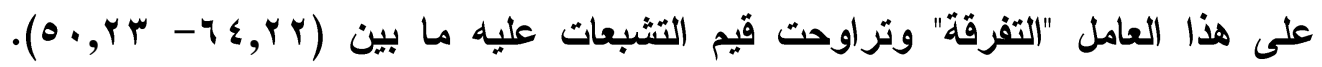

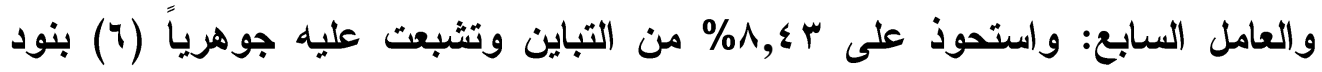

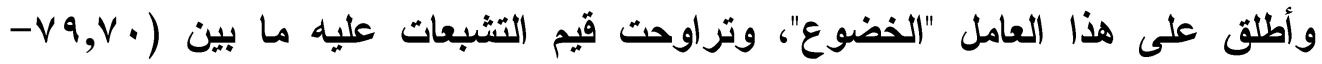

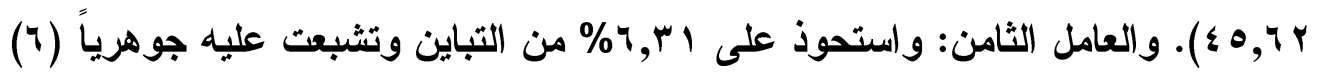
بنود وأطلق على هذا العامل "عدم الاتساق"، وتراوحت قيم التشبعات عليه ما بين

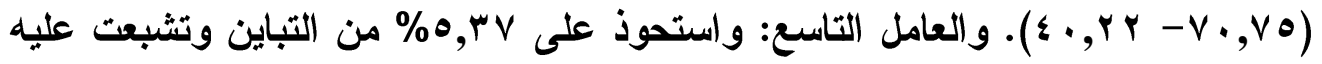

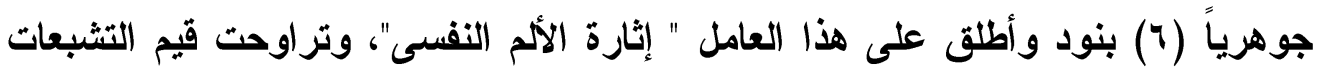

$$
\text { عليه ما بين ( }
$$

ثانياً: الثبات: كما تحققت الباحثة من ثبات المقياس باستخدام معامل ثبات ألفا حيث بلغ معامل الثبات († ^, ·)، وبطريقة إعادة الاختبار بفاصل زمني ثلاثة أسابيع بين التطبيقين

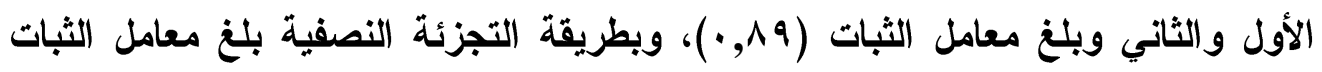

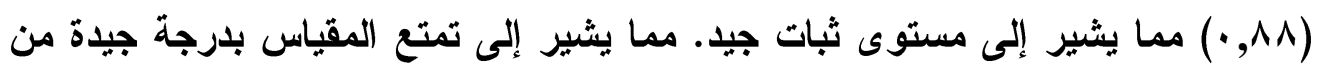

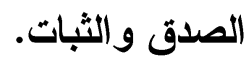
(^) اختبار المصفوفات المتتابعة الملون: أعده "رافن" لقياس ذكاء الأطفال، ويعد من أكثر مقاييس الأكاء شيوعاً المأو واستخداماً في قياس القدرات العقلية العامة. ويتضمن هذا الاختبار به مصفوفة أو شكل أحد أجزائه مقطوع، وعلى التلميذ اختيار الجزء المناسب من بين ستة بدائل معطاة، ويتكون من ثلاث

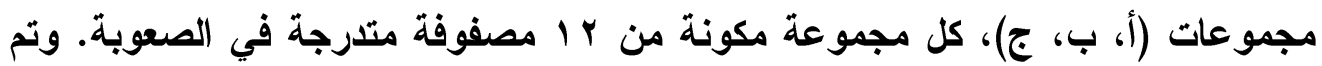
التأكد من صدق وثبات الاختبار من خلال العديد من الدراسات. 


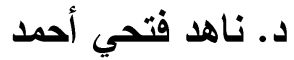

(9) استمارة المستوى الاجتماعي الاقتصادي: (إعداد الباحثة) أعدت الباحثة هذه الاستمارة لتتناسب مع التغيرات الحضارية الراهنة بهـف التحقق التقدي من التجانس بين أفراد العينة فى المستوى الاجتماعي الاقتصادي، حيث قامت بإعدادهادها بعد مراجعة بعض الاستمارات السابقة فى التراث البحثى، وتتكون الاستمارة من ثلاثة

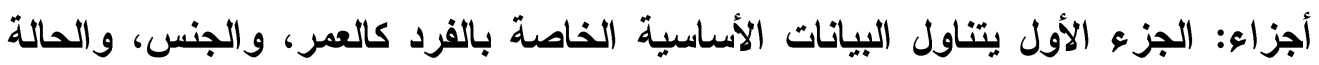

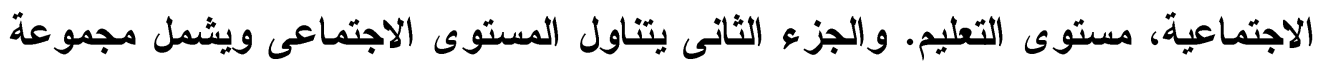
من البنود مثل مستوى الوسط الاجتماعى للأسرة، المستوى المهنى للوالدين، حجم

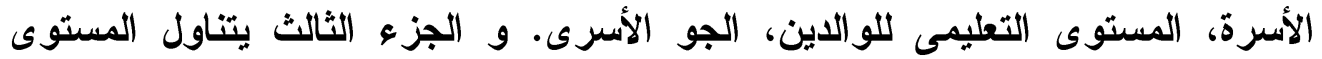

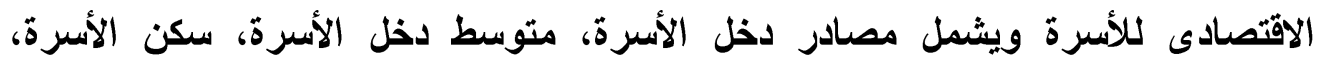

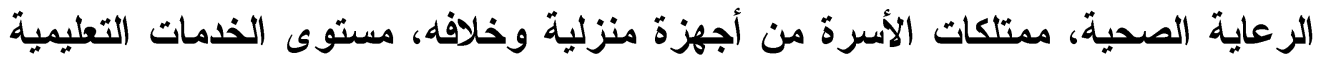
للأسرة، وسائل انتقال الأسرة، قضاء أوقات الفراغ، مستوى الترفيه فى الأسرة. خامساً: التحليلات الإحصائية: بعد أن تم تطبيق المقاييس واستخراج الارجات الخام، تم إجراء المعاملات الإحصائية وفقاً لكل فرض من فروض الدراسة الراهنة كل علي حدة وهى: تحليل التباين فى اتجاه واحد، اختبار شيفيه، الاتحدار المتعدد، معاملات ارتباط بيرسون، اختبار "ت"، التكرارات، النسب لرده المئوية.

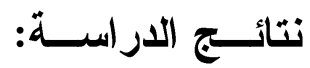
تعرض الباحثة وصفاً تفصيلياً لنتائج الاراسة، وذلك من أجل التحقق من صحة فروض الدراسة وأهدافها.

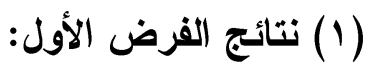
والذى يشير إلى انتشار وشيوع المشكلات النفسية والاجتماعية لاى الأطفال ذوى

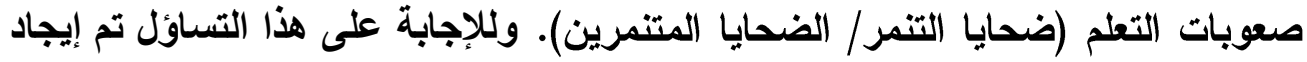
التكرارات والنسب المئوية وفقاً لمقياس المشكلات النفسية والاجتماعية التى يعانى منها هؤلاء الأطفال ذوى صعوبات التعلم كما هو موضح بالجدول رقم (•). 
ضحايا التنمر من الأطفال ذوي صعوبات التعلم "دراسة لأهم المثكلات النفسية والاجتماعية فى ضوء بعض المتغيرات النفسية" ـ

جدل (0) التكرارات والنسب المئوية للمشكلات النفسية والاجتماعية التى يعانى منها

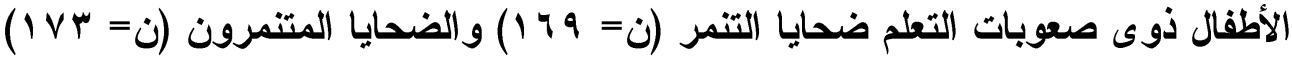

\begin{tabular}{|c|c|c|c|c|c|c|c|}
\hline \multicolumn{3}{|c|}{ الضحايا المتنمرون } & \multicolumn{3}{|c|}{ ضحايا التنمر } & \multirow{2}{*}{ المشكلات } & \multirow{2}{*}{ الأبعاد } \\
\hline$\%$ & ك5 & ت & $\%$ & ك5 & 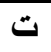 & & \\
\hline$\% 1 \ldots$ & IVr & 1 & $\% 1 \ldots$ & 179 & 1 & انخفاض تقدير الذات & \\
\hline$\% 79$ & ir. & $r$ & $\% 1 \ldots$ & 179 & r & 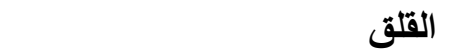 & \\
\hline$\% 1 \ldots$ & IVr & $r$ & $\% 1 \ldots$ & 179 & $r$ & الإحساس بعدم الأمان & \\
\hline$\% 7 \varepsilon$ & 111 & $\bullet$ & $\% 1 \cdots$ & 179 & $\varepsilon$ & تأة بالنفس & \\
\hline$\% \bullet \wedge$ & $1 \cdot 1$ & $\wedge$ & $\% \wedge 1$ & IrV & $\bullet$ & الأ & \\
\hline$\%$ & 11. & 7 & $\% \wedge$. & 1 Ho & 7 & ربالوحدة & \\
\hline$\%$ & $11 \mathrm{~V}$ & $\varepsilon$ & $\% \wedge \wedge$ & $|r|$ & V & ر بالاضطهاد & \\
\hline$\% 9 \leq, \varepsilon$ & 90 & 9 & $\% V_{1}, 0$ & 1.9 & $\Lambda$ & ماس بالإحباط & \\
\hline$\% \circ 0$ & $\Lambda r$ & 1 . & $\%$ & $1 \cdot v$ & 9 & اس بالكبت & \\
\hline$\% \circ 9$ & $1 \cdot r$ & 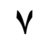 & $\%$ & 1.0 & 1 . & الإحساس بعدم السعادة & \\
\hline$\% 1 \ldots$ & IVT & 1 & $\% 1 \ldots$ & 179 & 1 & من المدرسة & \\
\hline$\% 1 \ldots$ & IVT & $r$ & $\% 1 \ldots$ & 179 & r & 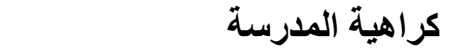 & \\
\hline$\% \circ r$ & 9. & 7 & $\% 9 r$ & 101 & $r$ & ثدرة على تكوين الصداقات & \\
\hline$\% \vee 7$ & | & $\varepsilon$ & $\% 9$. & lor & $\varepsilon$ & الإحساس بغياب دعم المدرس & ラ \\
\hline$\% 9 \leq$ & $19 r$ & $r$ & $\% \wedge 0$ & $1 \leq r$ & $\bullet$ & غ المستوى الاراسى & \\
\hline$\% \bullet \wedge$ & $1 \cdot 1$ & $\bullet$ & $\% \vee 7$ & $1 r q$ & 7 & الإحساس بغياب دعم الأقران & \\
\hline$\% 01$ & $\wedge q$ & $v$ & $\% \vee \varepsilon$ & Iro & 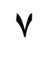 & الوندماج المد & \\
\hline$\%$ & $\Lambda V$ & $\Lambda$ & $\% \bullet V$ & $9 \vee$ & $\Lambda$ & 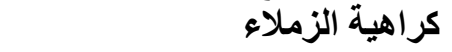 & \\
\hline$\% \cdot, r$ & $\bullet$ & 9 & $\% \cdot, 0$ & $\Lambda$ & 9 & تكرار الرسوب & \\
\hline$\% \vee r$ & IYV & $\varepsilon$ & $\% 1 \ldots$ & 179 & 1 & الخجل & \\
\hline$\% \leqslant r$ & V० & 9 & $\% 1 \cdots$ & 179 & r & ' و الانسحاب & \\
\hline$\% 1 \ldots$ & IVr & 1 & $\% 1 \cdots$ & 179 & $r$ & اضطر ابات النوم & \\
\hline$\% \bullet 0$ & 90 & $\Lambda$ & $\% \circ 9$ & $1 \cdots$ & $\varepsilon$ & الافتقار إلى القيادة & \\
\hline$\% 07$ & १V & V & $\% \bullet V$ & 97 & $\bullet$ & الحذر & 1 \\
\hline$\% 1 \ldots$ & IVT & r & $\%$ & $\Lambda \varepsilon$ & 7 & العنف & $y_{z}$ \\
\hline$\% 1 \ldots$ & IVT & $r$ & $\% \leqslant \Lambda$ & $\wedge 1$ & V & 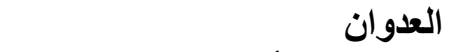 & \\
\hline$\% \vee 1$ & Irr & $\bullet$ & $\%$ rq & $\leqslant 9$ & $\Lambda$ & الميل إلى الثأر والإنتقام & \\
\hline$\% 79$ & ir. & 7 & $\% \cdot, \cdot 0$ & $\varepsilon$ & 9 & اللازمات العصبية & \\
\hline$\% \cdot, \cdot 1$ & r & 1. & $\% \cdot, r$ & $\mu$ & 1 . & التبول اللإر ادى & \\
\hline$\% 1 \ldots$ & IVT & 1 & $\% 1 \cdots$ & 179 & 1 & انخفاض التكيف الاجتماعى & $\overline{7}$ \\
\hline$\% 1 \ldots$ & IVT & r & $\% \vee q$ & ع & r & الإحساس بالة & 19 \\
\hline$\%$ & 11. & $\varepsilon$ & $\% \vee 7$ & $14 q$ & $r$ & الإحساس بالتهميش & पु \\
\hline$\% \vee V$ & Irr & $r$ & $\% \vee r$ & $|Y|$ & $\varepsilon$ & نقص المهارات الاجتماعية & : \\
\hline
\end{tabular}

يتضح من الجدول السابق انتشار أو شيوع العديد من المشكلات النفية النهاءية

والاجتماعية لاى الأطفال ذوى صعوبات التعلم (ضحايا التنمر/ الضحايا المتنمرين). 


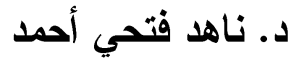

أ- فعلي المستوي العام للمشكلات: جاعت مشكلة انخفاض تقدير الذات، القلق، الإحساس بعدم الأمان، عدم الثقة بالنفس، الغياب من المدرسة، كراهية المدرسة، الخجل، العزلة

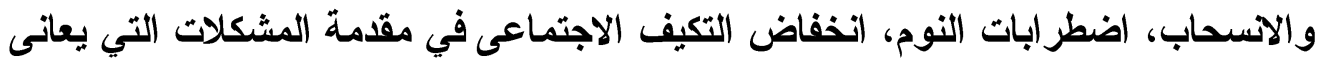
منها الأطفال فى مجموعة ضحايا التنمر حيث جاعت نسبة الاتفاق والاتتشار أو الثيوع بين الأطفال ( . (1\%)، فى حين جايت مشكلة الإحساس بعدم الأمان، كراهية المدرسة،

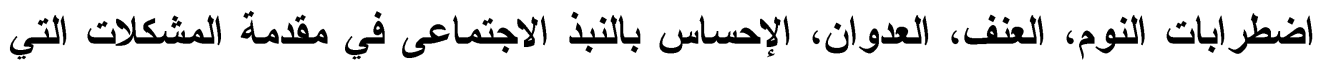
يعانى منها الأطفال فى مجموعة الضحايا المتنمرين حيث كانت نسبة الثيوع أو الانتثار بين الأطفال ( . . 1\%). ب- أما علي المستوي الفرعي: فبالنسبة للمشكلات الانفعالية: احتلت كل من مشكلة انخفاض تقدير الأات، الإحساس بعدم الأمان المرتبة الأولى لاي المجموعتين من الأطفال

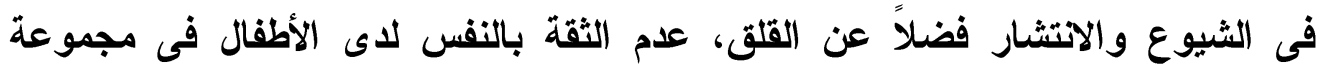

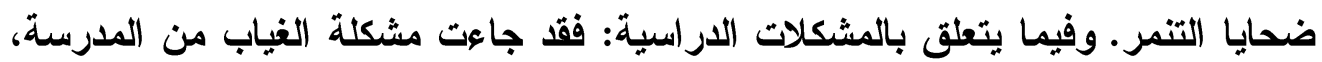
كراهية المدرسة في المقدمة لاي المجموعتين من الأطفال. وفيما يتعلق بالمشكلات السلوكية: فقد جاعت مشكلة اضطرابات النوم في المقدمة لاي المجموعتين من الأطفال

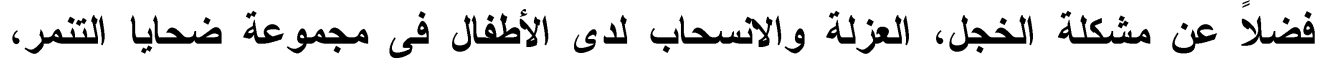

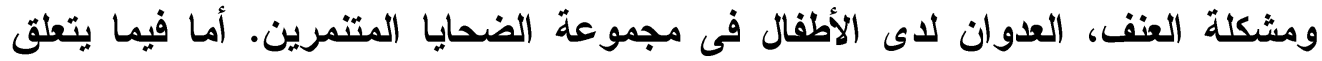
بالمشكلات الاجتماعية: فقد جاعت مشكلة انخفاض التكيف الاجتماعى في مقدمة المشكلات التي يعانى منها الأطفال فى المجموعتين، في حين جاءت مثكلة الإحساس بالنبذ الاجتماعى في مقدمة المثكلات التي يعانى منها الأطفال فى مجموعة الضحايا المتنمرين.

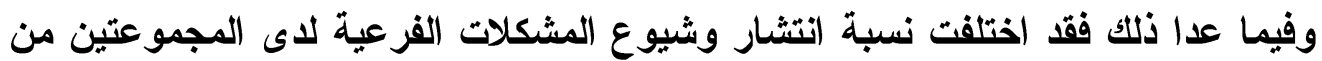
الأطفال ذوى صعوبات التعلم. (1) (1) نتائج الفرض الثوى الثانى:

والأى يشير إلى وجود فروق ذات دلالة إحصائية بين الأطفال ذوى صعوبات التعلم

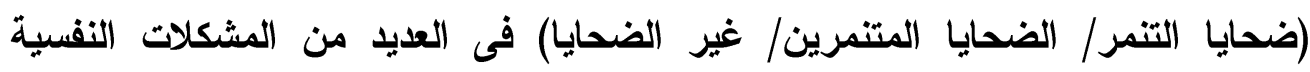
والاجتماعية. وللتحقق من صدق هذا الفرض تم استخدام تحليل التباين أحادي الاتجاه

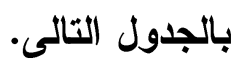


ضحايا التنمر من الأطفال ذوي صعوبات التعلم "دراسة لأهم المشكلات النفسية والاجتماعية فى ضوء بعض المتغيرات النفسية" جدول (†) الفروق في أهم المشكلات النفسية والاجتماعيةلدى الأطفال ذوى صعويات

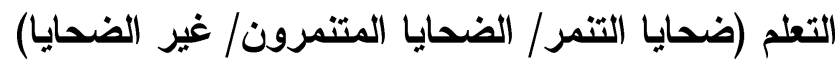

\begin{tabular}{|c|c|c|c|c|c|}
\hline ف & م.المربعات & د. الحرية & مجج. المربعات & مصدر التباين & المشكلات \\
\hline \multirow{2}{*}{$\begin{array}{r}r_{*}, \xi \\
\text {, }\end{array}$} & $|r \wedge, r|$ & $r$ & YY $\{, T \leqslant$ & بين المجموعات & \multirow{2}{*}{ الانفعالية } \\
\hline & 0,1 . & $r r q$ & $\varepsilon 7 V, 71$ & داخل المجموعات & \\
\hline \multirow{2}{*}{$\begin{array}{c}T V, \xi \\
*\end{array}$} & $1 r \varepsilon, 11$ & $\bar{r}$ & Yo,$I V$ & بين المجموعات & \multirow{2}{*}{ الاراسية } \\
\hline & $v, 01$ & rrq & $71 \%, 07$ & داخل المجموعات & \\
\hline \multirow{2}{*}{$\begin{array}{c}Y V, \xi \\
*\end{array}$} & $T r \cdot, r \Lambda$ & $\bar{r}$ & $71 \leqslant, 01$ & بين المجموعات & \multirow{2}{*}{ السلوكية } \\
\hline & $0, r^{9}$ & rrq & $Y \leqslant 7, V Y$ & داخل المجموعات & \\
\hline \multirow{2}{*}{$\begin{array}{c}17, r \\
*\end{array}$} & $9, \mathrm{Q1}$ & $\bar{r}$ & $1 V 1, \leqslant \Lambda$ & بين المجموعات & \multirow{2}{*}{ الاجتماعية } \\
\hline & 0,79 & $r r q$ & TrY,O & داخل المجموعات & \\
\hline \multirow{2}{*}{$\begin{array}{c}1 \wedge, \xi \\
*\end{array}$} & $\varepsilon 0 \wedge, Y \vee$ & r & $099, r \leqslant$ & بين المجموعات & \multirow{2}{*}{ لارجة الكلية } \\
\hline & $r r, 01$ & rrq & $q 0 \leqslant r, V Y$ & داخل المجموعات & \\
\hline
\end{tabular}

يتبين من الجدول السابق وجود فروق ذات دلالة إحصائية فى المشكلات (الانفعالية

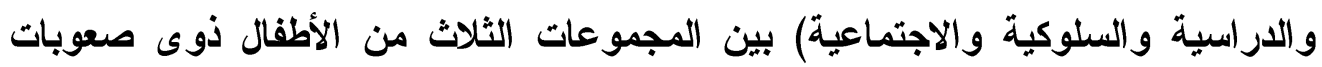

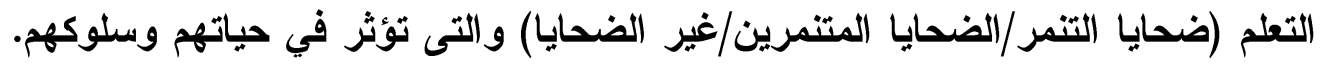

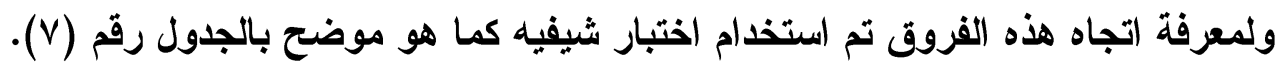

جدول (V) دلالة الفروق بين متوسط المجموعات الثلاث باستخدام اختبار شيفيه

\begin{tabular}{|c|c|c|c|c|}
\hline \multicolumn{2}{|c|}{ فروق المتوسطات والدلالة } & \multirow[b]{2}{*}{ e } & \multirow{2}{*}{ مجموعات المقارنة } & \multirow{2}{*}{ المشكلات } \\
\hline $\bar{r}$ & T & & & \\
\hline & - & 19,8 & 1- ضحايا التنمر & \multirow{3}{*}{ الانفعالية } \\
\hline & $* Y, \cdot 1$ & $I V, V$ & r- الضحايا المتنمرون & \\
\hline \multirow[t]{3}{*}{$* 1,91$} & $* * * \varepsilon, 9 \leqslant$ & 11,1 & rا ــ العاديون & \\
\hline & - & $r 1, V$ & 1 - ضحايا التنمر & \multirow{3}{*}{ الاراسية } \\
\hline & $* * * \mu, V V$ & $1 \mathrm{~V}, 1$ & r ــ الضحايا المتنمرون & \\
\hline \multirow[t]{3}{*}{$* * r, \wedge r$} & $* * * 0,1 \wedge$ & $1 r, q$ & "آــ العاديون & \\
\hline & - & $r q, 8$ & 1- ضحايا التنمر & \multirow{3}{*}{ السلوكية } \\
\hline & $* 1,9 V$ & $r V, 0$ & rـ الضحايا المتنمرون & \\
\hline \multirow[t]{3}{*}{$* * * \varepsilon, 0 r$} & $* * * 0,91$ & 19,9 & r- العاديون & \\
\hline & - & $1 \wedge, \xi$ & 1 - ضحايا التنمر & \multirow{3}{*}{ الاجتماعية } \\
\hline & $* 1,99$ & $17, \mathrm{~V}$ & rـ الضحايا المتنمرون & \\
\hline \multirow[t]{3}{*}{$* 1,9 \wedge$} & $* * * r, 9 V$ & $1 \leqslant, 0$ & r- العاديون & \\
\hline & - & YY,Y & 1 - ضحايا التنمر & \multirow{3}{*}{ الدرجة الكلية } \\
\hline & $* 1,99$ & 19,9 & זـ الضحايا المتنمرون & \\
\hline$* * * Y, Y Y$ & $* * * 4,01$ & $1 \leqslant, 1$ & r- العاديون & \\
\hline
\end{tabular}

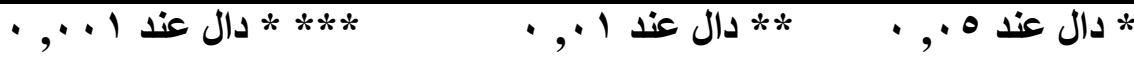


يتبين من الجدول السابق وجود فروق ذات دلالة إحصائية بين الأطفال ذوى صعوبات التعلم في المجموعات الثلاث (ضحايا التنمر/ الضحايا المتنمرين/ غير الضحايا) في جميع أبعاد المشكلات وفى الدرجة الكلية في اتجاه الأطفال ضحايا التنمر ثم الضحايا المتنمرين ثم غير الضحايا. (1) - (1) نتائج الفرض الثالث:

والذى يشير إلى وجود فروق ذات دلالة إحصائية فى الضغوط المدرسية وأساليب المعاملة الوالدية اللاسوية بين الأطفال ذوى صعوبات التعلم ضحايا التنمر والضحايا

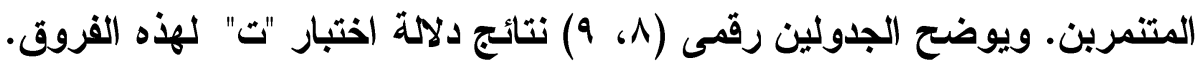

جدول (^)

اختبار "ت" لالالة الفروق بين الأطفال ذوى صعوبات التعلم ضحايا التنمر

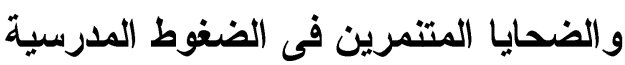

\begin{tabular}{|c|c|c|c|c|c|}
\hline \multirow{2}{*}{ ت ت } & \multicolumn{2}{|c|}{ الضحايا المتنمرون } & \multicolumn{2}{|c|}{ ضحايا التنمر } & \multirow{2}{*}{ الضغوط المدرسية } \\
\hline & $\varepsilon$ & b & $\varepsilon$ & 5 & \\
\hline$* * r, r$ & $7, r$ & $\Lambda \cdot, \Lambda$ & 7,7 & $\Lambda \vee, \mu$ & طبيعة العلاقة بين التلميذ والزملاء \\
\hline$* Y, \varepsilon$ & 7,1 & $\Lambda 9,7$ & 0,9 & $\Lambda \neg, 0$ & طبيعة العلاقة بين التلميذ والمدرس \\
\hline $1, \varepsilon$ & 7,8 & $\Lambda \cdot, 1$ & $7, Y$ & $\Lambda 1, \mu$ & التلميذ والمقررات الدراسبية \\
\hline 1,7 & $7, r$ & $\vee \wedge, \wedge$ & 7,8 & $v q, r$ & التلميذ وأساليب التقويم \\
\hline $1, \varepsilon$ & $0, r$ & $v 7, \wedge$ & 0,8 & $V V, 0$ & التلميذ وبيئة الصف \\
\hline$* Y, 0$ & 7,8 & $\Lambda \cdot, r$ & 7,0 & $\Lambda \leqslant, \varepsilon$ & التلميذ وبيئة المدرسة \\
\hline$* * Y, 7$ & $0, V$ & $\wedge 7,9$ & 0,7 & $\Lambda \leqslant, \mu$ & التلميذ والجو الأسرى \\
\hline$\cdot 9$ & $7, r$ & $\wedge 9, \wedge$ & $7, \mathrm{~V}$ & $9 \cdot r$ & التلميذ والتفكير في المستقبل \\
\hline 1,1 & $0, \varepsilon$ & $\Lambda \vee, \cdot$ & $0, \varepsilon$ & $\Lambda$ ^ , & التلميذ والتأييا الاجتماعى \\
\hline 1,1 & $7, r$ & $\Lambda 1, \varepsilon$ & 7,8 & $\Lambda r, \Lambda$ & الارجة الكلية \\
\hline
\end{tabular}

يتبين من الجدول السابق وجود فروق ذات دلالة إحصائية بين الأطفال ذوى صعوبات التعلم ضحايا التنمر والضحايا المتنمرين في أربع أبعاد فقط هى: طبيعة العلاقة بين التلميذ والزملاء، والتلميذ وبيئة المدرسة في اتجاه الأطفال ضحايا التنمر، وطبيعة العلاقة بين التلميذ والمدرس، والتلميذ والجو الأسرى في اتجاه الأطفال الضحايا المتنمرين. 
ضحايا التنمر من الأطفال ذوي صعوبات التعلم "دراسة لأهم المثكلات النفسية والاجتماعية فى ضوء بعض المتغيرات النفسية" -

جدول (9) اختبار "ت" لالالة الفروق بين الأطفال ذوى صعوبات التعلم ضحايا التنمر والضحايا المتنمرين فى أساليب المعاملة الوالدية اللاسوية

\begin{tabular}{|c|c|c|c|c|c|}
\hline \multirow{2}{*}{ ت } & \multicolumn{2}{|c|}{ الضحايا المتتمرون } & \multicolumn{2}{|c|}{ ضحايا التتمر } & \multirow{2}{*}{ أساليب المعاملة الوالدية اللاسوية } \\
\hline & $\varepsilon$ & b & $\varepsilon$ & b & \\
\hline 1,1 & $7, r$ & $\Lambda \cdot, \Lambda \mu$ & 7,0 & $\Lambda 1, \leqslant \mu$ & الرفض \\
\hline $1, r$ & $7, r$ & $\Lambda \bullet, \wedge \mu$ & $7, V$ & $\Lambda V, 1 \mu$ & الإهمال \\
\hline$* Y, Y O$ & 7,1 & $\Lambda \bullet, \bullet \varepsilon$ & $0, V$ & $9 \cdot, 7 V$ & الحماية الزائدة \\
\hline$* * 7,1$ & $0, r$ & $\wedge q, \wedge r$ & 0,0 & $\Lambda \cdot, 71$ & التسلط \\
\hline$* r, 1$ & $\bullet, \mu$ & $9 \cdot, 74$ & $0, V$ & $\Lambda V, \Lambda \mathrm{r}$ & القسوة \\
\hline$\cdot, 9 \vee$ & 0,9 & $\vee \wedge, \Lambda \mu$ & 0,1 & $\vee \wedge, \bullet \varepsilon$ & التفرقة \\
\hline $1, \mu$ & 7, & $\Lambda \bullet, \Lambda \mu$ & 0,9 & $\Lambda \varepsilon, \vee \uparrow$ & الخضوع \\
\hline$\cdot, 99$ & 0,9 & VY, . & 7, & $V 1, \varepsilon r$ & عدم الاتساق \\
\hline$* * \varepsilon, 1$ & $7, \mu$ & $\Lambda V, \mu \varepsilon$ & 7,1 & $V q, \varepsilon r$ & إثارة الألم التفسى \\
\hline $1, \mathrm{~V}$ & $7, \mu$ & $\Lambda \varepsilon, \cdot V$ & 0,0 & $\Lambda Y, \& Y$ & اللدرجة الكلية \\
\hline
\end{tabular}

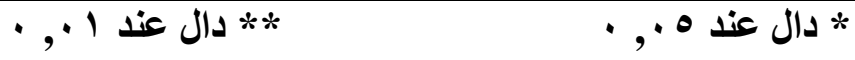

يتبين من الجدول السابق وجود فروق ذات دلالة إحصائية بين الأطفال ذوى صعوبات التعلم ضحايا التنمر والضحايا المتنمرين في أربعة أبعاد هى: التسلط، القسوة، إثارة الألم النفسى في اتجاه الأطفال الضحايا المتنمرين الأطفال، وفى الحماية الزائدة، في اتجاه الأطفال ضحايا التنمر. (1) نتائج الفرض الر ابع: والأى بعنى بالفزوق في المشكلات النفسية والاجتماعية بين الأطفال ذوى صعوبات التعلم ضحايا التنمر والضحايا المتنمرين وفقاً لارجات الضغوط المدرسية وأساليب المعاملة الوالدية اللاسوية. ويوضح جدول رقم ( • 1) نتائج دلالة اختبار "ت" لبيان تأثير كل متغير على المشكلات النفسية والاجتماعية لاى هؤلاء الأطفال. 


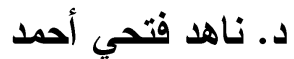

\section{جدول (1.)}

اختبار "ت" لالالة الفروق بين الأطفال ضحايا التنمر والضحايا المتنمرين في المشكلات

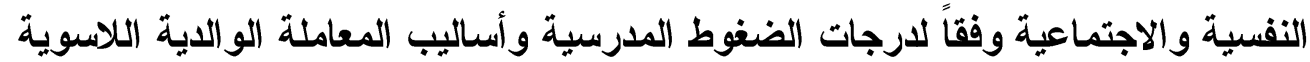

\begin{tabular}{|c|c|c|c|c|c|c|c|}
\hline \multicolumn{3}{|c|}{ أساليب المعاملة اللاسوية } & \multicolumn{3}{|c|}{ الضغوط المدرسية } & \multirow{2}{*}{ المجموعة } & \multirow{2}{*}{ المشكلات } \\
\hline 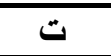 & $\varepsilon$ & م & $ت$ & $\varepsilon$ & م & & \\
\hline \multirow{2}{*}{$* * 4, \%$} & $\varepsilon, V$ & $\pi, \xi$ & \multirow{2}{*}{$* * 0, \leqslant$} & $0, \mu$ & $\varepsilon \vee, \wedge$ & 1 ــ ضحايا التنمر & \multirow{2}{*}{ الانفعالية } \\
\hline & $\varepsilon, \wedge$ & 09,8 & & $\varepsilon, \wedge$ & $\varepsilon 1, r$ & r ـ الضحايا المتنمرون & \\
\hline \multirow{2}{*}{$\cdot, 0$} & $\theta$, & $\Delta V, \Lambda$ & \multirow{2}{*}{$1, \xi$} & $\theta$, & $\varepsilon \cdot$, & | - ضحايا التتمر & \multirow{2}{*}{ الار اسية } \\
\hline & $\varepsilon, 9$ & $\theta v, r$ & & $\varepsilon, \wedge$ & $\leqslant 1,0$ & r - الضحايا المتنمرون & \\
\hline \multirow{2}{*}{1,1} & 0,1 & $7 \cdot, 1$ & \multirow{2}{*}{$1, \wedge$} & $\varepsilon, 9$ & $\varepsilon Y, T$ & 1ـ ضحايا التنمر & \multirow{2}{*}{ السلوكية } \\
\hline & 0,1 & $\pi r, \wedge$ & & $\varepsilon, 7$ & $\varepsilon r, Y$ & r ـ الضحايا المتنمرون & \\
\hline \multirow{2}{*}{$\cdot, 9$} & $\varepsilon, 9$ & $0 \wedge, \wedge$ & \multirow{2}{*}{$1, \cdot$} & 0,1 & $\varepsilon \cdot, 0$ & 1 - ضحايا التنمر & \multirow{2}{*}{ الاجتمـاعية } \\
\hline & $\varepsilon, \wedge$ & 09,9 & & $\theta$, & $\varepsilon 1, r$ & r ــ الضحايا المتنمرون & \\
\hline \multirow{2}{*}{$1, \varepsilon$} & 0,1 & $7 \cdot, 9$ & \multirow{2}{*}{1,7} & $0, r$ & $\varepsilon r, q$ & 1ـ ضحايا التنمر & \multirow{2}{*}{ الكلية } \\
\hline & $\varepsilon, \wedge$ & $09, \xi$ & & $\varepsilon, \wedge$ & $\varepsilon 1, r$ & r ـ الضحايا المتنمرون & \\
\hline
\end{tabular}

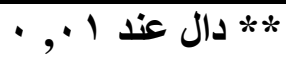

يتبين من الجدول السابق وجود فروق ذات دلالة إحصائية بين الأطفال ذوى صعوبات التعلم ضحايا التنمر والضحايا المتنمرين فقط في المشكلات الاتفعالية في اتجاه الأطفال ضحايا التنمر الأطفال، وفى المشكلات السلوكية في اتجاه الأطفال الضحايا المتنمرين وفقاً لارجات الضغوط المدرسية. ولم تكن هناك فروق ذات دلالة إحصائية فى المشكلات الار اسية والاجتماعية أو فى الارجة الكلية.

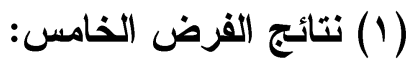

والأى يثير إلى عدم وجود فروق ذات دلالة إحصائية فى المشكلات النفسية

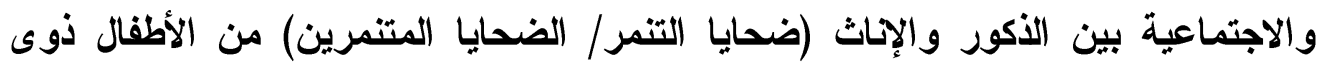

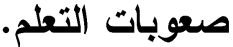


ضحايا التنمر من الأطفال ذوي صعوبات التعلم "دراسة لأهم المثكلات النفسية والاجتماعية فى ضوء بعض المتغيرات النفسية" -

$$
\text { جدول (11) }
$$

اختبار "ت" لالالة الفروق فى المشكلات النفسية والاجتماعية بين الأكور والإناث

(ضحايا التنمر/ الضحايا المتنمرين) من الأطفال ذوى صعوبات التعلم

\begin{tabular}{|c|c|c|c|c|c|c|}
\hline \multirow{2}{*}{ ت } & \multicolumn{2}{|c|}{ إناث } & \multicolumn{2}{|c|}{ ذكور } & \multirow{2}{*}{ المجموعة } & \multirow{2}{*}{ المثكلات } \\
\hline & $\varepsilon$ & م & $\varepsilon$ & م & & \\
\hline$* * \varepsilon, 7 \Lambda$ & $7, r$ & $99, \xi$ & $0, \xi$ & $91, r$ & 1 - ضحايا التنمر & \multirow{2}{*}{ الانفعالية } \\
\hline$* * r, \wedge \leqslant$ & $7, r$ & 99,0 & $0, \mathrm{~V}$ & $9 \cdot, v$ & r ـ الضحايا المتنمرون & \\
\hline$* * r, \wedge q$ & $0, r$ & $\Lambda \leqslant, q$ & $0, \varepsilon$ & $\wedge 9,1$ & 1 - ضحايا التنمر & \multirow{2}{*}{ الاراسية } \\
\hline$* * 4,0 V$ & $0, \xi$ & 11,9 & $0, \cdot$ & $\Lambda \cdot, 0$ & r- الضحايا المتنمرون & \\
\hline$* * 4,00$ & 7, & $\wedge r, \Lambda$ & 7,1 & $9 \leqslant, r$ & 1 - ضحايا التنمر & \multirow{2}{*}{ السلوكية } \\
\hline$* * 0, \leqslant 9$ & $0, \cdot$ & $\Lambda \cdot, 9$ & 0,1 & $\Lambda \Lambda, r$ & r- الضحايا المتنمرون & \\
\hline$* * \varepsilon, 70$ & 0,0 & $\Lambda \cdot, r$ & $0, \mathrm{~V}$ & $\Lambda v, \varepsilon$ & 1 - ضحايا التنمر & \multirow{2}{*}{ الاجتماعية } \\
\hline$* r, \cdots$ & $\bullet, \cdot$ & $\Lambda \cdot, 9$ & 0,4 & $\Lambda \Gamma, r$ & r ـ الضحايا المتنمرون & \\
\hline$* Y, \cdot 1$ & $0, \xi$ & $\Lambda \vee, 1$ & 0,0 & $9 \cdot, \cdot$ & 1 ـ ضحايا التنمر & \multirow{2}{*}{ الدرجة الكلية } \\
\hline$* 1,91$ & $0, r$ & $\Lambda 0,0$ & 0,4 & $\Lambda Y, Y$ & r - الضحايا المتنمرون & \\
\hline
\end{tabular}

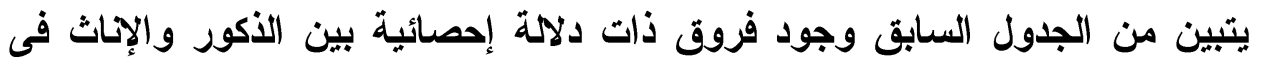

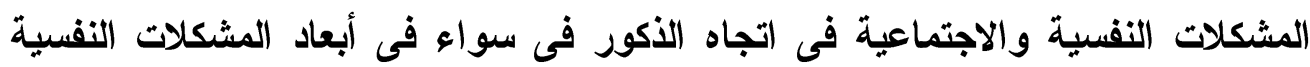
والاجتماعية أو فى الارجة الكلية لاى الأطفال ذوى صعوبات التعلم فى مجموعتى ضحايل فئاه التنمر والضحايا المتنمرين فيما عدا المشكلات الاففعالية حيث كانت الثروق في التهاه الإناث.

نتائج الفرض السادس:

والأى يشير إلى وجود العديد من أثكال التنمر السائدة التى يعانى منها الأطفال ضحايا التنمر والضحايا المتنمرين ذوى صعوبيات التعلم. 
جدول (Y Y) اختبار "ت" لالالة الفروق فى أثكال التنمر السائدة بين الأطفال (ضحايا التنمر/ الضحايا المتنمرين) ذوى صعوبات التعلم

\begin{tabular}{|c|c|c|c|c|c|}
\hline \multirow{2}{*}{ ت } & \multicolumn{2}{|c|}{ الضحايا المتنمرون } & \multicolumn{2}{|c|}{ ضحايا التنمر } & \multirow{2}{*}{ أشكال التثمر } \\
\hline & $\varepsilon$ & م & $\varepsilon$ & r & \\
\hline$* * \backslash \wedge, V$ & $\varepsilon, \varepsilon$ & $\$ 1,0$ & $\varepsilon, 1$ & $\pi Y, \varepsilon$ & ا ـ الجسدى \\
\hline$* * Y_{1}$, & $\varepsilon, 7$ & $q \cdot, r$ & $\varepsilon, Y$ & $\vee \wedge, 0$ & r ـ اللفظى \\
\hline$* * 19,9$ & $\varepsilon, 1$ & 17,1 & $\varepsilon, 0$ & 1,0 & "ا ــ الجنسى \\
\hline$* Y, \varepsilon$ & 0,1 & $\varepsilon V, \varepsilon$ & $0, \mu$ & $\varepsilon \Psi, \varepsilon$ & צ ـ الانفعالى \\
\hline$* * \varepsilon, 7$ & $0, \varepsilon$ & $\leqslant 1, \wedge$ & $0, \mu$ & $\varepsilon V, \varepsilon$ & 0ـ الاجتماعى \\
\hline$* * \mid \vee, r$ & $\varepsilon, 0$ & $r \cdot, r$ & $\varepsilon, 1$ & $r r, 1$ & ד - عبر الانترنت \\
\hline$* * r, v$ & $0, Y$ & $r r, q$ & $\varepsilon, 9$ & $r q, \varepsilon$ & Vـ العنصرى \\
\hline$* * \varepsilon, 9$ & $0, \varepsilon$ & $\varepsilon r$, & $\varepsilon, \wedge$ & $\leqslant 9,7$ & الارجة الكلية \\
\hline
\end{tabular}

جدول (r I) اختبار "ت" لالالة الفروق فى أشكال التنمر السائدة بين الأطفال الأكور والإناث (ضحايا التنمر/ الضحايا المتنمرين) ذوى صعوبات التعلم

\begin{tabular}{|c|c|c|c|c|c|c|}
\hline \multirow[t]{2}{*}{ ت } & \multicolumn{2}{|c|}{ إناث } & \multicolumn{2}{|c|}{ ذكور } & \multirow{2}{*}{ المجموعة } & \multirow{2}{*}{ أشكال التنمر } \\
\hline & $\varepsilon$ & b & $\varepsilon$ & r & & \\
\hline$* * 10,0$ & $\varepsilon, 0$ & $\varepsilon \cdot, \varepsilon$ & $\varepsilon, \mu$ & $7 \cdot, 0$ & 1 - ضحايا التنمر & \multirow{2}{*}{ الجسدى } \\
\hline$* * r r, r$ & $\varepsilon, \wedge$ & $\leqslant 0,0$ & $\varepsilon, V$ & $79, V$ & r ـ الضحايا المتنمرون & \\
\hline$* * r \cdot, \varepsilon$ & $\varepsilon, r$ & 91,9 & $\varepsilon, \varepsilon$ & $v 9,8$ & 1 - ضحايا التنمر & \multirow{2}{*}{ اللفظى } \\
\hline$* * 1 \wedge, 9$ & $\varepsilon, V$ & $99, \wedge$ & $\varepsilon, 7$ & $\Lambda \cdot, \varepsilon$ & r ـ الضحايا المتنمرون & \\
\hline$* * 10, \mathrm{~V}$ & $\varepsilon$, & 10,1 & $\varepsilon, 1$ & $r \cdot, 1$ & ا ـ ضحايا التنمر & \multirow{2}{*}{ الجنسى } \\
\hline$* * 19, r$ & 0,9 & $r 1,9$ & $0, Y$ & $r \wedge, \varepsilon$ & r ـ الضحايا المتنمرون & \\
\hline$* Y, r$ & $0, \varepsilon$ & $\varepsilon \leqslant, \varepsilon$ & $0, V$ & $\varepsilon 1, r$ & 1 - ضحايا التنمر & \multirow{2}{*}{ الانفعالى } \\
\hline$* Y, 0$ & 0,1 & $\leqslant 9,9$ & $\varepsilon, 9$ & $\varepsilon 0,0$ & r ـ الضحايا المتثمرون & \\
\hline$* Y, 0$ & $0, r$ & $\varepsilon Y, 0$ & 0,2 & $\leqslant 7,0$ & 1 ـ ضحايا التنمر & \multirow{2}{*}{ الاجتماعى } \\
\hline$* r$, & $0, r$ & $\varepsilon \wedge, q$ & 0,0 & $\Delta r, 0$ & r ـ الضحايا المتنمرون & \\
\hline$* * 1 \mathrm{~V}, \varepsilon$ & $\varepsilon$, & $r r, \Lambda$ & $\varepsilon, 1$ & $r \varepsilon, Y$ & 1 - ضحايا التنمر & \multirow{2}{*}{ عبر الانترنت } \\
\hline$* * r, 9$ & 0, & $\varepsilon \cdot, 9$ & $\varepsilon, 7$ & $\varepsilon q, r$ & r ـ الضحايا المتنمرون & \\
\hline$* * 0,0$ & 0,1 & $r, r$ & $\varepsilon, V$ & $r v, \varepsilon$ & 1 - ضحايا التنمر & \multirow{2}{*}{ العنصرى } \\
\hline$* * 0,1$ & $0, \cdot$ & $r r, V$ & $\varepsilon, \wedge$ & $r q, 7$ & r ـ الضحايا المتثمرون & \\
\hline$* * \varepsilon, \wedge$ & $0, r$ & $\varepsilon 1$, & $\varepsilon, 9$ & $\varepsilon V, 0$ & I - ضحايا التنمر & \multirow{2}{*}{ الدرجة الكلية } \\
\hline$* * 0, V$ & $0, \varepsilon$ & $\varepsilon V, \Lambda$ & $0, Y$ & $0 \leq, Y$ & r ـ الضحايا المتنمرون & \\
\hline
\end{tabular}


ضحايا التنمر من الأطفال ذوي صعوبات التعلم "دراسة لأهم المشكلات النفسية والاجتماعية فى ضوء بعض المتغيرات النفسية" يتبين من الجدولين السابقين أن التنمر اللفظى ثم التنمر الجسدى من أكثر أثنكال التنمر التى يتعرض لها هؤلاء الأطفال فى المجموعتين. كذلك وجد أن الأطفال فى هن الثين

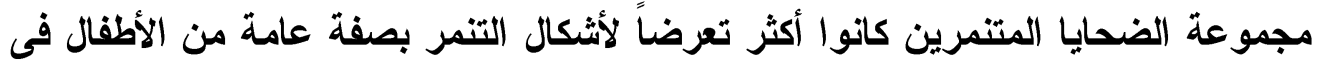
مجموعة ضحايا التنمر • وبثكل أكثر تفصيلاً وجدت فروق ذات دلالة إحصائية بين الأكور والإناث فى جميع أثكال التنمر التى يتعرض لها الأطفال ذوى صعوبات التعلم فى مجموعتى ضحايا التنمر والضحايا المتنمرين وفى الارجة الكلية فى اتجاه الذكور فيما عدا التنمر اللفظى والانفعالى فى اتجاه الإتاث. (V) والأى يثير إلى وجود فروق ذات دلالة إحصائية بين الأطفال ضحايا التنمر والضحايا

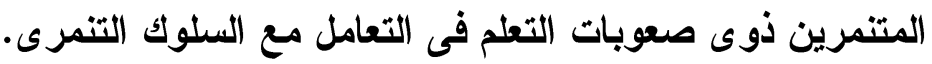

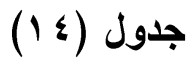

اختبار "ت" لالالة الفروق فى التعامل مع السلوك التنمرى بين الأطفال (ضحايا التنمر/ الضحايا المتنمرين) ذوى صعوبات التعلم

\begin{tabular}{|c|c|c|c|c|c|}
\hline \multirow{2}{*}{ ت } & \multicolumn{2}{|c|}{ الضحايا المتنمرون } & \multicolumn{2}{|c|}{ ضحايا التنمر } & \multirow{2}{*}{ المشكلات } \\
\hline & $\varepsilon$ & م & $\varepsilon$ & م & \\
\hline 1,71 & $7, r$ & $\Lambda V, \varepsilon$ & $7, \xi$ & $\Lambda \vee, r$ & البحث عن المساندة \\
\hline$* * 11, \wedge 9$ & 7,1 & $\Lambda V, q$ & $7, V$ & 99,1 & التجاهــــــل \\
\hline$* * 1,00$ & $7, r$ & $\wedge \wedge, 7$ & 7,1 & $V q, r$ & الدفاع عن النفس \\
\hline$* * 1 r, 70$ & 0,9 & $\Lambda v, r$ & $7, \cdot$ & $9 \wedge, \varepsilon$ & لــوم الأذات \\
\hline$* Y, r \varepsilon$ & 7,1 & $\wedge \wedge, 7$ & 7,1 & 91, & الارجة الكلية \\
\hline
\end{tabular}

يتبين من الجدول السابق وجود فروق ذات دلالة إحصائية بين ضحايا التنمر

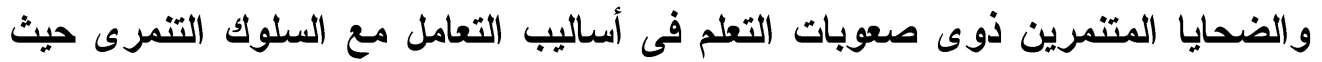
كاتت الفروق فى اتجاه ضحايا التنمر فى سلوك التجاهـلـل ولوم الأات وفى اتجاه الضحايا المتنمرين فى سلوك البحث عن المساندة والدفاع عن النفس وفى الدرجة الكلية. 


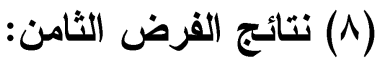

والذى يشير إلى إمكانية التنبؤ بالمشكلات النفسية والاجتماعية لاى الأطفال ذوى صعوبات التعلم ضحايا التنمر والضحايا المتنمرين من خلال متوسط الدرجات على كل من الضغوط المدرسية وأساليب المعاملة الوالدية اللاسوية ولفية.

$$
\text { جدول (10) }
$$

تحليل الاحدار المتعدد للمشكلات النفسية والاجتماعية كمتغير تابع والضغوط المدرسية وأساليب المعاملة الو الدية اللاسوية كمتغيرات مستقلة لاى الأطفال ذوى صعوبات التعلم

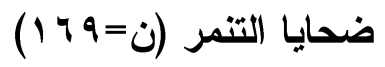

\begin{tabular}{|c|c|c|c|c|c|}
\hline نسبة التفسير & مستوى الالاية & قيمة & بيتّان & معامل الانحدار & المتغيرات المنبئة \\
\hline$\cdot, Y \varepsilon$ & $\cdot, \cdot 1$ & $0, V V$ &., 00 & 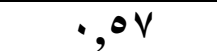 & الضغوط المدرسية \\
\hline \multirow[t]{4}{*}{ • } & $\bullet, \cdots 1$ & $9, \leqslant 9$ & $\cdot, V \vee$ & $\cdot, V \varepsilon$ & أللاسيوية المعاملة \\
\hline & & & & $77, \leqslant \leqslant$ & قيمة الثابت \\
\hline & $\cdot, \cdots 1$ & & & $19, \mu v$ & قيمة (ف) \\
\hline & & & & • & راب (R2) لجميع \\
\hline
\end{tabular}

$$
\text { جدول (17) }
$$

تحليل الاحدار المتعدد للمشكلات النفسية والاجتماعية كمتفير تابع والضغوط المدرسية

\begin{tabular}{|c|c|c|c|c|c|}
\hline $\begin{array}{c}\text { نسبة التفسير } \\
\text { (R2) }\end{array}$ & مستوى الدلالة & قيمة & $\begin{array}{l}\text { بيتّا } \\
\text { Beta }\end{array}$ & $\begin{array}{c}\text { معامل الانحدار } \\
\text { B }\end{array}$ & المتغيرات المنبئة \\
\hline$\cdot, 14$ & $\cdot, \cdots 1$ & 0,09 & $\cdot, 09$ & $\cdot, 74$ & الضغوط المدرسية \\
\hline \multirow[t]{4}{*}{$\cdot, r q$} & $\cdot, \cdots 1$ & $\wedge, 91$ & $\cdot, \mathrm{v} 0$ &,, $\mathrm{~V}^{\circ}$ & أسلاليب المعاملة \\
\hline & & & & $V \wedge, Y Y$ & قيمة الثابت \\
\hline &,$+\cdots 1$ & & & $I V, Y \varepsilon$ & قيمة (ف) \\
\hline & & & & & المتغيرات (R2) لجميع \\
\hline
\end{tabular}
وأساليب المعاملة الو الدية اللاسوية كمتغيرات مستقلة لاى الأطفال ذوى صعوبات التعلم

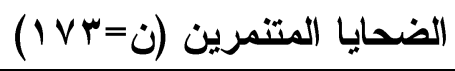


ضحايا التنمر من الأطفال ذوي صعوبات التعلم "دراسة لأهم المشكلات النفسية والاجتماعية فى ضوء بعض المتغيرات النفسية" يتضح من نتائج تحليل الاتحدار المتعدد الواردة بالجدولين السابقين أن كل من الضغوط المدرسية وأساليب المعاملة الوالدية اللاسوية قادران على التبؤ بالمشكلات النفسية والاجتماعية لدى الأطفال ذوى صعوبات التعلم ضحايا التنمر والضحايا المتنمرين عند مستويات دلالة مرتفعة (1 (.,.). حيث جاء إسهام أساليب المعاملة الوالدية

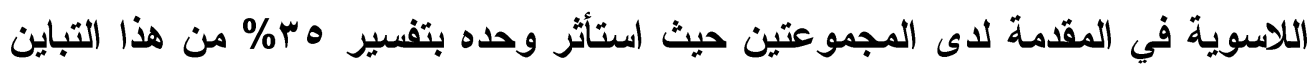

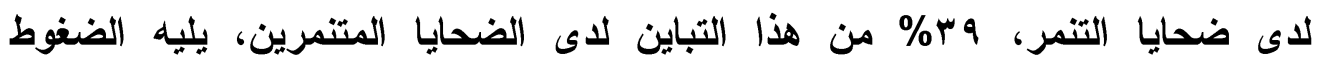

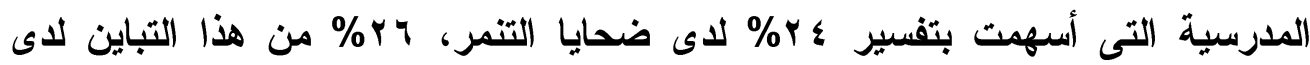
الضحايا المتنمرين.ومن ثم تثبير النتائج إلى المعادلتين التنبؤتين كالتالي:

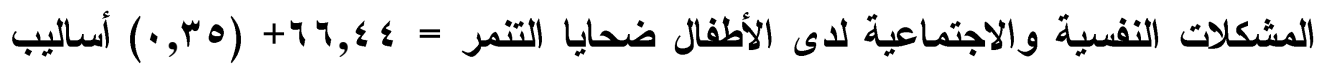

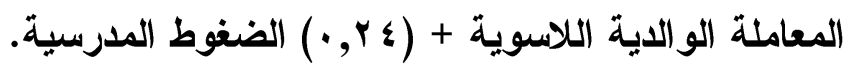
المشكلات النفسية والاجتماعية لاى الأطفال الضحايا المتنمرين =

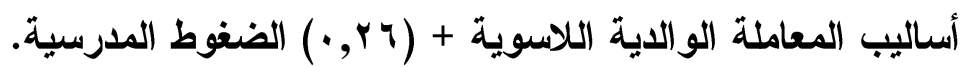

مناقشة النتائج: سوف يتم مناقشة نتائج الاراسة بنفس التسلسل الأي انتظمت به فروض الاراسة مع بيان مدي اتفاق أو اختلاف النتائج مع الدراسات السابقة من ناحية والاستعانة بالإطار النظري لتوضيح دلالتها النفسية و التطبيقية.

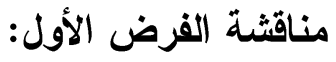

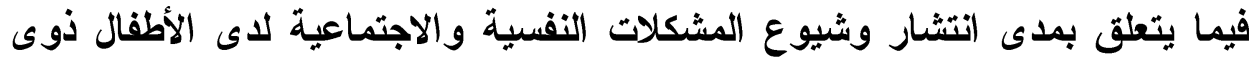

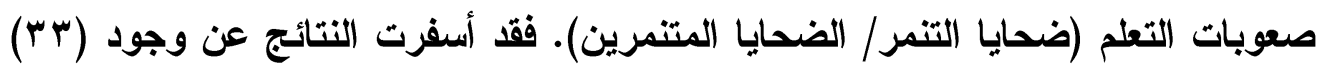

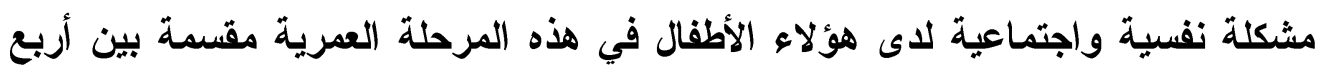

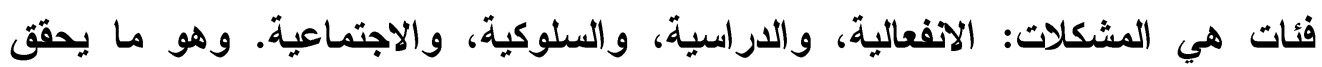

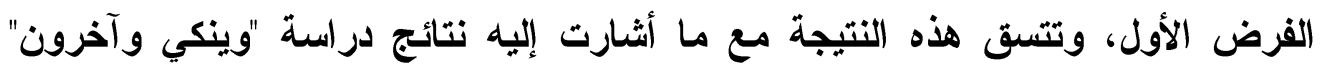
(Wienke et al., 2009) معدلات التنمر لاى ذوي صعوبات التعلم (المتنمرين، والضحايا، والمتنمر/ الضحية). وارتباطه إيجابياً بالمشكلات النفسية والتحصيلية لايهم. كما يعانى هؤلاء الأطفال أيضاً

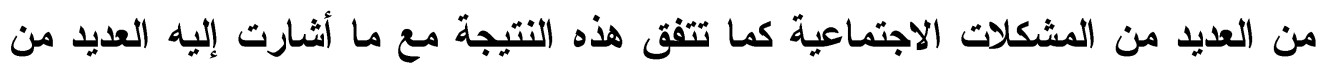


الاراسات كدراسة "سبادى" (Spade, 2007) التى وجدت علاقة سلبية بين التنمر وتقدير Juvonen et al., ) الأت لاى المتنمرين وضحاياهم. ودراسة "جيوفونن وآخرون 2003) التى توصلت إلى أن الطلبة ضحايا التنمر يعانون ألماً عاطفياً ونبذاً اجتماعياً

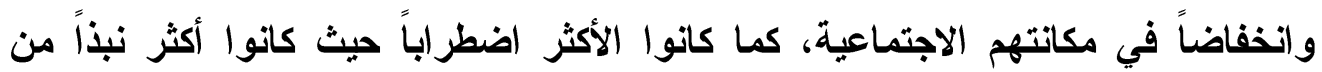
أقر انهم، وأكثرهم ميلاً لإظهار المشكلات السلوكية ويعانون مستويات مرتفعة من الاكتئاب والوحدة النفسية. كما تثفق هذه النتيجة مع ما أثثارت إليه نتائج دراسة "ثثوارتز وآخرون" (Schwartz et al., 2002) من أن التعرض للتنمر يرتبط بانخفاض السلوك الاجتماعي والإحساس بالوحدة و العدوانية والانعز الية. وربما يفسر التشابه في نسبة انتشار وشيوع بعض المشكلات النفسية والاجتماعية

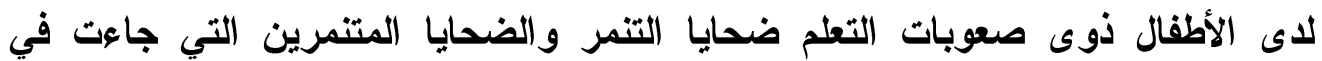
المقدمة في ضوء أهمية هذه المشكلات (انخفاض تقدير الأات، الإحساس بعدم الأمان، مشكلة الغياب من المدرسة، كراهية المدرسة، اضطرابات النوم، انخفاض التكيف

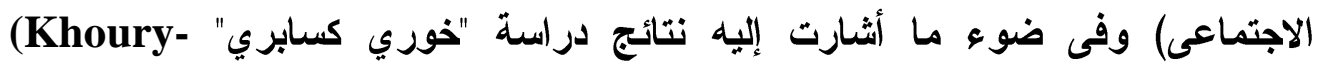
Kassabri, 2009) لسوء المعاملة النفسية والجسدية والعاطفية من جانب موظفى المدرسة أكثر من تعرضهم

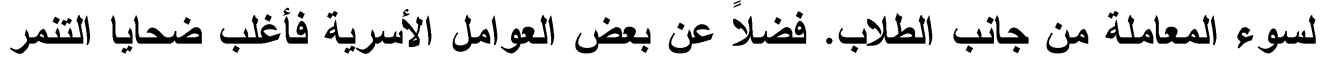
يأتون من بيوت بها علاقات سلبية مع الوالدين، وبالتالي لا تساعد في تطوير المهارات

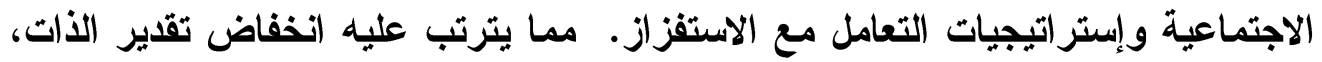

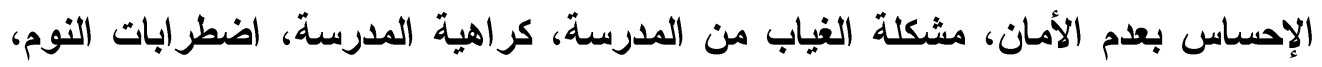
انخفاض التكيف الاجتماعى وغيرها من المشكلات. ومن الملاحظ أن هذه المشكلات تتعلق بالذات وبالمدرسة وهو مؤشر لأهمية العلاقة بين البيئة الأسرية والمدرسية المدية السلبية وبين هذه المشكلات.

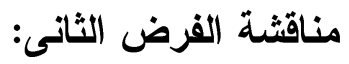
وفيما يتعلق بوجود فروق ذات دلالة إحصائية بين الأطفال ذوى صعوبات التعلم في

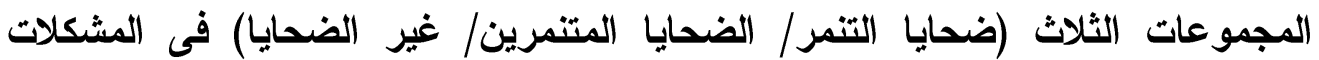
(الاففعالية والاراسية والسلوكية والاجتماعية) و الدرجة الكلية في اتجاه الأطفال ضحايا 
ضحايا التنمر من الأطفال ذوي صعوبات التعلم "دراسة لأهم المشكلات النفسية والاجتماعية فى ضوء بعض المتغيرات النفسية" ـ التنمر ثم الضحايا المتنمرين ثم غير الضحايا. يبدو مجمل النتائج محققاً للفرض الثالث كما تبدو هذه النتائج بهذا الثكل متسقة مع نتائج الاراسات السابقة كدراسة "ميثنا" (Mishna, 2009)(التى أثارت إلى أن الأطفال ضحايا التنمر ذوي صعوبات التعلم

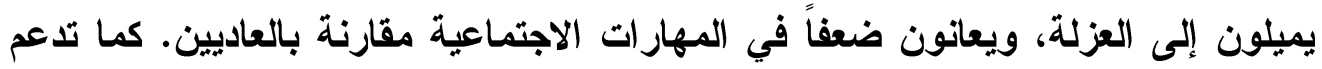

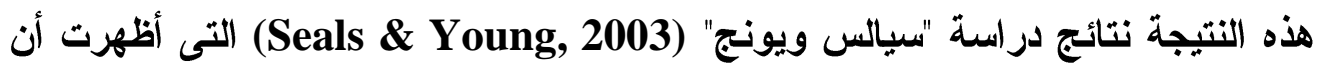
المتنمرين والضحايا حصلوا على درجات أعلى على مقياس الإحباط مقارنة بالعاديين. وكنلك دراسة "وودز" (Woods et al., 2009) التى توصلت إلى أن الضحايا كانوا أقل بل الفئات في تمييز عواطفهم ومشاعرهم السلبية؛ كالغضب والخوف في المواجهات، كما لوحظ أن الأطفال الذين تعرضوا للتنمر كانوا أضعف في فهم المعلومات الوجدانية من المتنمرين والأطفال غير المشاركين. وما أثارت إليه دراسة "ثاين" (Shin, 2010) من وجود فروق كبيرة في القلق الاجتماعي والثعور بالوحدة النفسية بين مجموعات الارساسة

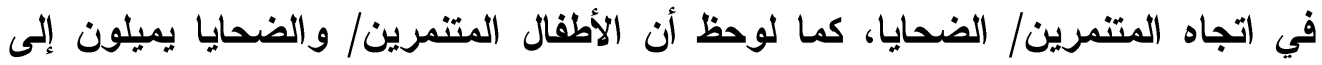
إقامة علاقات صداقة ضعيفة، كما تبين أن الضحايا السلبيين لا يعدون أصدقائهم مصدرا

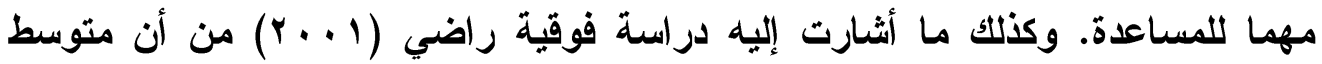
درجات التلاميذ ضحايا التنمر أقل من نظرائهم في تقدير الأت في حين كاتت درجاتهم أعلى في الاكتئاب والوحدة النفسية وما توصل إليه كلا من "أمور وكيرفام" ئل \& Kirkham, 2001) في العمر نفسه والذين لا يصنفون ضمن فئة المتنمرين والضحايا. كما كان الضحايا جميعهم أقل شعبية وجاذبية وأكثر اضطر اباً وقلقاً من غير الضحائا. وربما يفسر ذلك ما أثشار إليه "بلاش وجاكسون" (Black \& Jackson, 2007) من أن للتنمر وخاصة التنمر المدرسي العديد من الآثار السلبية على الصحة النفسية سواء كان متنمراً أو ضحية للتمر . وما أثشار إليه أيضاً "ديلفابرو وآخرون" DelFabro et al., 2006) لخطر حدوث مشاكل بعيدة المدى في أوقات لاحقة. ومن ثم يعانون من ارتفاع معدلات النفور الاجتماعى وهم أكثر عزوفاً عن العملية التعليمية وأقل تقبلاً للذات وللأخرين. 
مناقثة الفرضين الثالث و الر ابع: وفيما يتعلق بوجود فروق ذات دلالة إحصائية بين الأطفال ذوى صعوبات التعلم ضحايا التنمر والضحايا المتنمرين في أربع أبعاد فقط هى: طبيعة العلاقة بين التلميذ و الزملاء، والتلميذ وبيئة المدرسة في اتجاه الأطفال ضحايا التنمر، وطبيعة العلاقة بين التلميذ والمدرس، والتلميذ والجو الأسرى في اتجاه الأطفال الضحايا المتنمرين. كما ولائه وجدت فروق ذات دلالة إحصائية بين الأطفال ذوى صعوبات التعلم ضحايا التنمر والضحايا المتنمرين في أربعة أبعاد هى: التسلط، القسوة، إثارة الألم النفسى في اتجاه الأطفال الضحايا المتنمرين الأطفال، وفى الحماية الزائدة، في اتجاه الأطفال ضحايا التنمر . وتبدو هذه النتيجة محققة لهذا الفرض إلى حـ ما. وتتفق هذه النتيجة ميع ما أثشارت إليه نتائج دراسة "ثاين" (Shin, 2010) من أن الأطفال الضحايا يميلون إلى إقامة علاقات صداقة ضعيفة، كما تبين أن الضحايا السلبيين (ضحايا التنمر) لا بعدون أصدقائهم مصدراً مهماً للمساعدة. وبالتالي يكون من السهل وقوعهم فريسة للتنمر، كما أنهم يشعرون بعدم لهان الأمن ويهاجمون باستمرار، ويفثلون في الدفاع عن أنفسهم، ويستجيب هؤلاء الضحايا

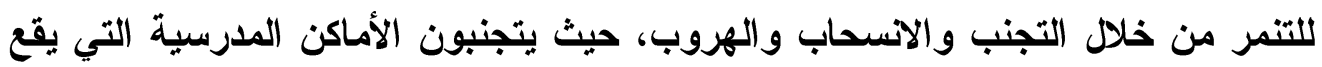
فيها التنمر، ويتجنبون الأنشة المدرسية. لذا كانت درجاتهم أعلى على الضغوط التى

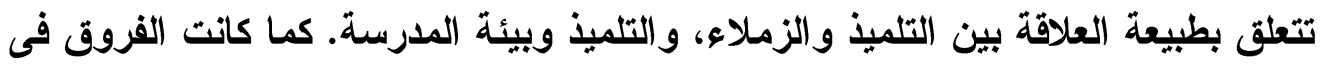
طبيعة العلاقة بين التلميذ والمدرس، والتلميذ والجو الأسرى في اتجاه الأطفال الضحايا

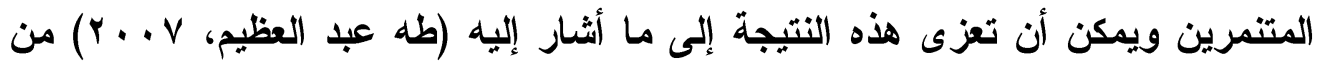

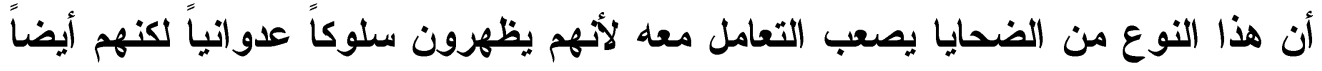

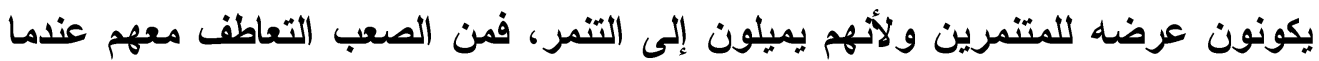

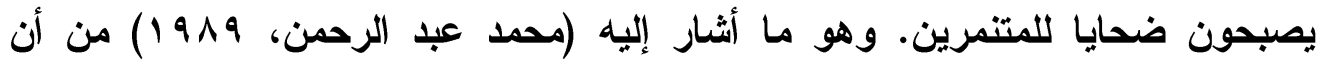
الطلبة المتنمرين، والضحايا المتنمرين قد حصلوا على دعم اجتماعي أقل من قبل المعلمين ومن قبل الوالدين. لذا كانت درجاتهم أعلى على الضغوط التى تتعلق بطبيعة العلاقة بين التلميذ والمدرس، والتلميذ والجو الأسرى. كما كان الطلبة المتنمرون يتعرضون لنمط رعاية والاية متسلطة أكثر من العاديين والضحايا كما أثنارت نتائج دراسة "أحمد وبرايثوايت" (Ahmed \& Braithwaite, 2004). كما وجدت دراسة ولة 
ضحايا التنمر من الأطفال ذوي صعوبات التعلم "دراسة لأهم المشكلات النفسية والاجتماعية فى ضوء بعض المتغيرات النفسية" ـ "هولت وآخرون" (Holt, Kaufman \& Finkelhor, 2009) أن منازل المتنمرين وصفت بسوء معاملة الطفل وتعرضه للعنف المنزلي. كذلك أثشارت نتائج دراسة "]تجيورو" (Georgiou, 2008) أطفال ضحايا للتنمر . لذا حصلوا على درجات أعلى فى الحماية الزائدة. ويخصوص وجود فروق ذات دلالة إحصائية بين الأطفال ذوى صعوبات التعلم ضحايا

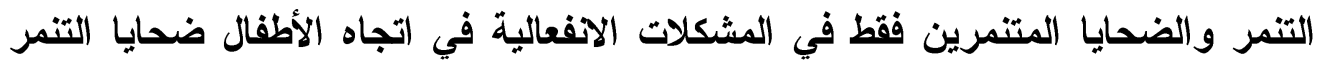
الأطفال، وفى المشكلات السلوكية في اتجاه الأطفال الضحايا المتنمرين وفقاً لارجات الضغوط المدرسية وأساليب المعاملة الوالدية اللاسوية. ولم تكن هنايك فروق ذات الجاه دلالة إحصائية فى المشكلات الدراسية والاجتماعية أو فى الارجة الكلية. تبدو هذه النهابة النتيجة أيضاً محققة لهذا الفرض فئَ إلى حد ما وربما تعزو هذه النتيجة إلى:

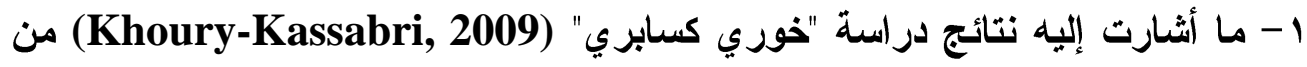
أن الطلاب المتنمرين، والضحايا، والضحايا المتنمرين تعرضوا لسوء المعاملة النفسية والجسدية والعاطفية من جانب موظفى المدرسة أكثر من تعرضهم لسوء المعاملة من لمن

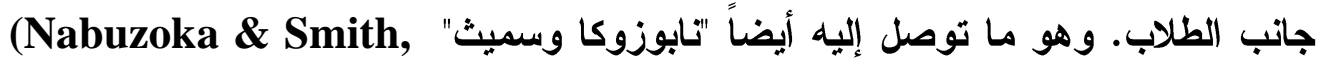
(1993 من أن العديد من معلمي الأطفال ذوي صعوبات التعلم والعاديين لم يقدموا

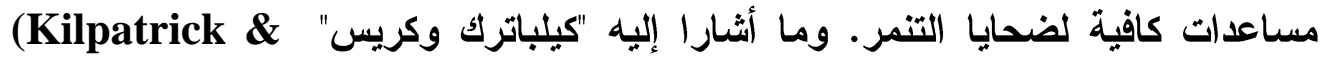
Kerres, 2003) اجتماعي أقل من قبل المعلمين والأقران من الطلاب العاديين غير المشاركين في التنمر (العاديين) ومجموعة الضحايا.

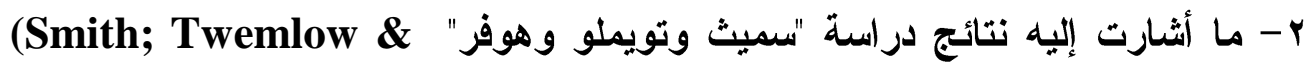
Hoover, 1999) غير المرغوب فيها هي السائدة مع أحد أو كلا الو الدين.

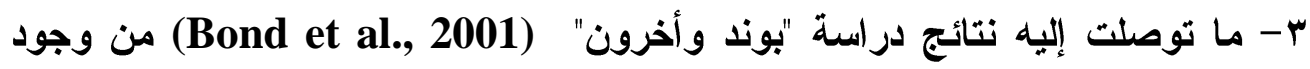

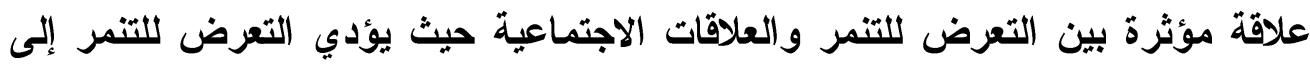
ظهور أعراض القلق والاكتئاب مما يؤثر سلباً على العلاقات الاجتماعية للطلبة الذين 


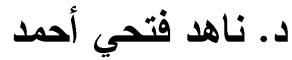

يتعرضون للتنمر • ولذا لم تكن هناك فروق ذات دلالة إحصائية فى المشكلات الدراسية أو الاجتماعية.

ع - ما أسفرت عنه نتائج دراسة "جيوفونن" وآخرين ( Juvonen, Graham \&) Schuster, 2003) أكثر الذين ينبذهم أقرانهم، وأكثرهم ميلاً لإظهار المشكلات السلوكية. فى حين تبين وفقاً لارسة "وودز وآخرون" (Woods et al., 2009) أن الضحايا كانو أكثر الفئات ضعفاً في تمييز عواطفهم ومشاعرهم السلبية؛ كالغضب والخوف في المواجهات. لذا كاتت الفروق في المشكلات الاففعالية في اتجاه الأطفال ضحايا التنمر الأطفال وفى المشكلات السلوكية في اتجاه الأطفال الضحايا المتنمرين. مناقثة الفرض الخامس: وفيما يتعلق بوجود فروق ذات دلالة إحصائية بين الذكور والإناث فى المشكلات النفسية والاجتماعية فى اتجاه الأكور فى سواء فى أبعاد المثكلات النفسية والاجتماعية أو فى الدرجة الكلية لاى الأطفال ذوى صعوبات التعلم فى مجموعتى ضحايا التنمر و الضحايا المتنمرين فيما عدا المشكلات الانفعالية حيث كاتت الفروق فى اتجاه الإناث. يبدو مجمل النتائج محققاً للفرض الخامس كما تبدو هذه النتائج بهذا الثكل متسقة مع نتائج الدراسات السابقة كدراسة "بولاستري وآخرون" : Pollastri, Cardmil. \& التى أسفرت عن وجود علاقة بين تقدير الأات المنففض والتنمر O'Donnell, 2010) لاى الإناث في حين لم يتبين أي ارتباط بين تقدير الذات وسلوك التنمر لاى الأكور. ويمكن تفسير هذه النتيجة من خلال الأتي:

ا - ما أثــارت إليه بعض الدراســات من وجود اختلافات بين الجنسين في مستويات التعرض لسلوك التنمر كلراسة "فون وبيترمانن" (Von \& Petermann, 2010) التى أثنارت إلى أن الذكور المتنمرين والضحايا/ المتنمرين أكثر من الإناث. وأن الأكور هم الأكثر فى التعرض المباشر لسلوك التنمر وأكثر استخداما لهذا السلوك. ودراسة "فايدنج وآخرون" (Viding et al., 2009) التى أثثارت أيضاً إلى أن الأكور أكثر مشاركة في سلوك التنمر المباشر فى حين كاتت الإناث أكثر مشاركة في 
ضحايا التنمر من الأطفال ذوي صعوبات التعلم "دراسة لأهم المشكلات النفسية والاجتماعية فى ضوء بعض المتغيرات النفسية" ـ

سلوك التنمر غير المباشر • ودراسة "دوماك" (Dilmac, 2009) التى توصلت إلى أن الأكور أقروا بعدد مرات تعرضهم لسلوك التنمر أكثر من الإناث. r- ما أثشار إليه نيوكومر (Newcomer; Barenbaum \& Pearson, 1995) من أن الإناث أكثر تعبيراً عما يعانين من اضطر ابات انفعالية مقارنة بالذكور في مرحتي الطقولة والمراهقة الذين يظهرون أساليب سلوكية. مناقثة الفرض السادس: أولاً: فيما يتعلق بأثكال التنمر السائدة وجد أن التنمر اللفظى ثم التنمر الجسدى من أكثر أثكال التنمر التى يتعرض لها هؤلاء الأطفال فى المجموعتين. وتتفق هذه التهان النتيجة

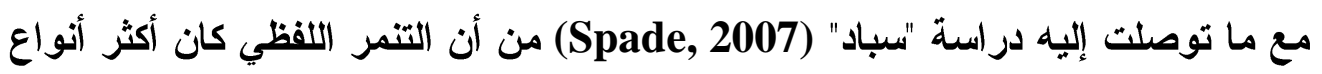

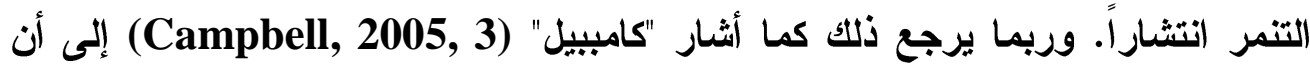
التنمر اللفظي ربما يكون من أكثر التأثيرات السلبية الممتدة الأثر على الضحية.

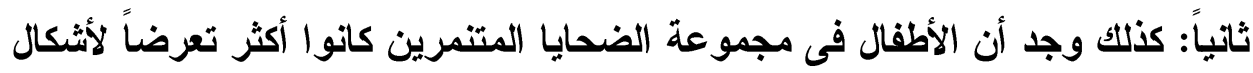

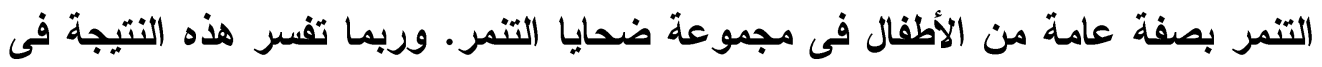

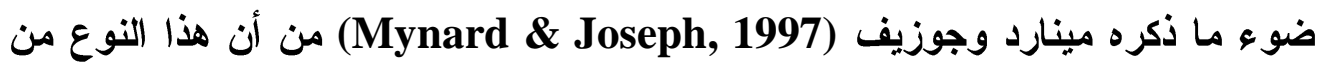
الضحايا يتسم بالعدوان والنشاط الزائد، وهو ما يستفز زملاءهم في الفصل ويجعله يعتدون عليهج. وما أثشارت إليه "كيلباترك وكريس" (Kilpatrick \& Kerres, 2003) من أن الطلبة المتنمرون والضحايا المتنمرون حصلوا على دعم اجتماعي أقل من الطلاب العاديين غير المشاركين في التنمر. ثالثاً: وبشكل أكثر تفصيلاً داخل كل مجموعة وجدت فئ فروق ذات دالئة إحصائية بين

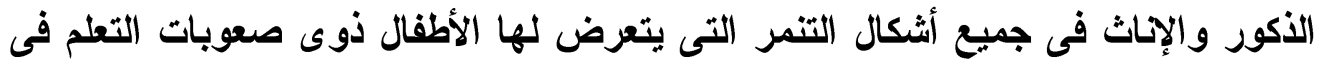
مجموعتى ضحايا التنمر والضحايا المتنمرين وفى الارجة الكلية فى اتجاه الأكور فيما

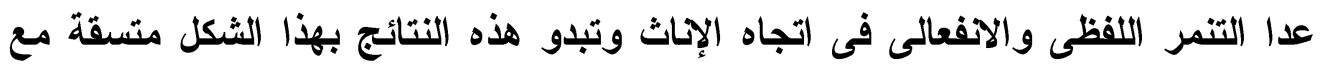

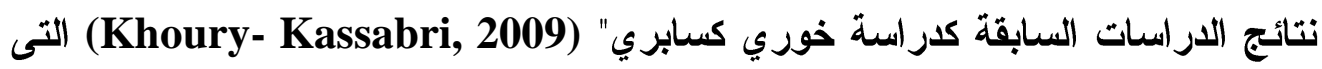
أثشارت إلى أن الفروق في أثكال التنمر تختلف باختلاف نوع الجنس، والانتماء الوطني،

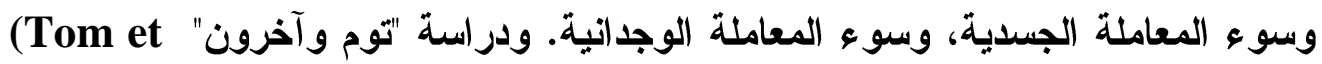

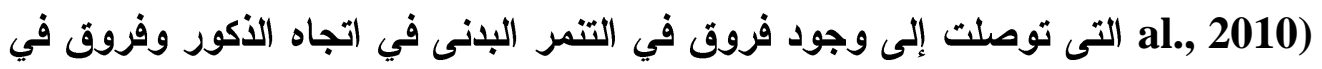


د. ناهد فتحي أحمد

(Pollastri; التنمر اللفظي والعاطفي في اتجاه البنات. ودراسة "بولاستري وآخرون التى أسفرت عن وجود فروق دالة إحصائياً بين

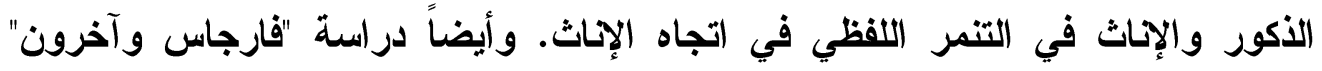
(Varjas; Henrich \& Meyers, 2009) ضحايا للتنمر البذني أكثر من التنمر اللفظي. وكذلك دراسة "منتون" (Minton, 2010) التى توصلت إلى أن الفروق بين الجنسين كانت أكثر وضوحاً فالأكور كانوا أكثر تعرضاً واستهدافاً للأشكال المباشرة من السلوك العدواني (التنمر)، بينما كانت الإناث أكثر

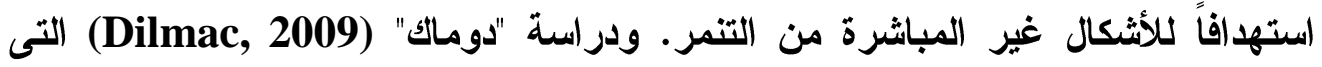

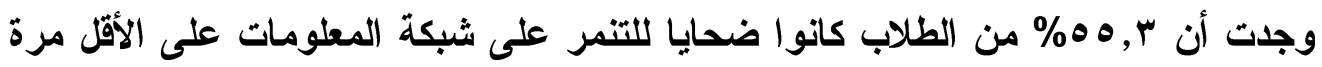
واحدة في حياتهم. وأن الأكور أقروا بعدد مرات تعرضهم لسلوك التنمر أكثر من الإناث.

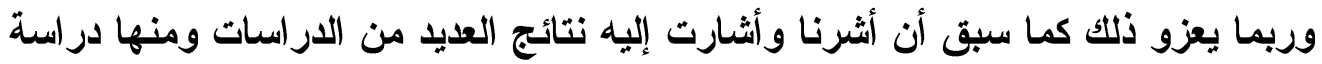
(Viding et ودراسة (Don \& Petermann, 2010) al., 2009) من أن الذكور هم الأكثر فى التعرض المباشر لسلوك التنمر وأكثر استخداما لهذا السلوك. ومن ثم يبدو مجمل النتائج محققاً للفرض السادس.

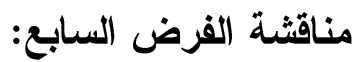
وفيما يتعلق بوجود فروق ذات دلالة إحصائية بين ضحايا التنمر والضحايا المتنمرين ذوى صعوبات التعلم فى أساليب التعامل مع السلوك التنمرى يبدو مجمل النتائج محقةًا

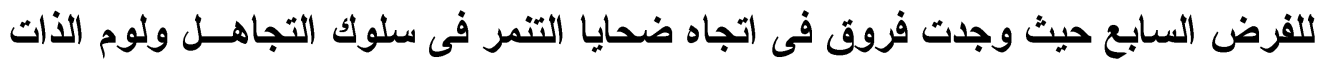
وفى الارجة الكلية وفى اتجاه الضحايا المتنمرين فى سلوك البحث عن فئ المساندة الدفاع عن النفس ولم تكن هناك فروق فى سلوك البحث عن المساندة. وتبدو هذه النتائج بهذا

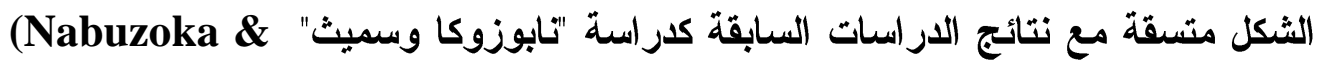

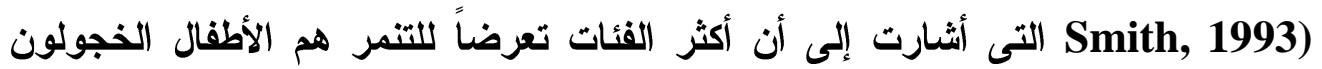
ذوو صعوبات التعلم ، كما كان ذوو صعوبات التعلم أكثر طلباً للمساعدة مقارنة بالعاديين. ودراسة "ميشنا" (Mishna, 2009) التى توصلت إلى أن المتنمرين يميلون إلى النشاط الزائد، كما يميل الضحايا إلى العزلة. ومن ثم التجاهل. 
ضحايا التنمر من الأطفال ذوي صعوبات التعلم "دراسة لأهم المشكلات النفسية والاجتماعية فى ضوء بعض المتغيرات النفسية" ـ هذا ويفسر عدم وجود فروق فى سلوك البحث عن المساندة بين المجموعتين وتفوق المجموعة الأولى فى سلوك التجاهـل ولوم الذات و وتفوق المجموعة الثانية فى سلوك

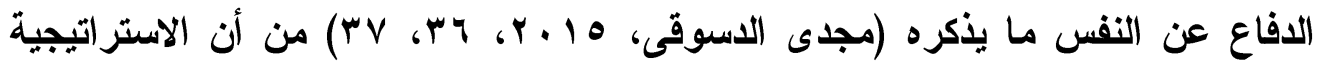

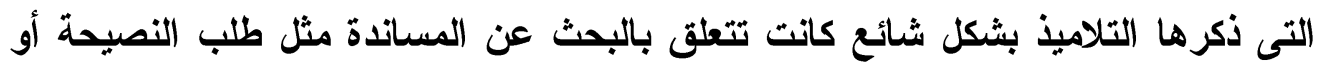
التثجيع من الو الدين والمعلمين والأصدقاء و الاستراتيجيات الإضافية للتعامل مع التنمر تضمنت حل المشكلات مثل وضع خطة وتقليل التوتر (على سبيل المثال الصياح وتهئئة الأت)، والابتعاد مثل التجاهل والأصراف بعيداً عن مصدر القلق والتوتر، وإعادة التركيب المعرفى مثل التركيز على الجوانب الإيجابية والسلوكيات الخارجية مثل لوم ولهئ الأات. كما أوضح عدد كبير من الباحثين أن إدراثك الثخص بمدى الثجى التحكم أو السيطرة التى لايه فى الموقف يؤثر على أى استر اتيجيات يمكن أن يستخدمها. مناقشة الفرض الثامن: - مانه

أما ما يتعلق بمدى إسهام كل من الضغوط المدرسية وأساليب المعاملة الوالدية اللاسوية فى التنبؤ بالمشكلات النفسية والاجتماعية. فبالرغم من اختلاف إسهام هذان

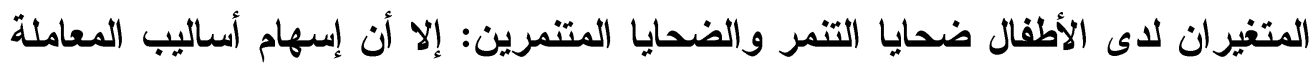
الوالدية اللاسوية في التنبؤ بالمشكلات النفسية والاجتماعية جاء في المقدمة لاى الى

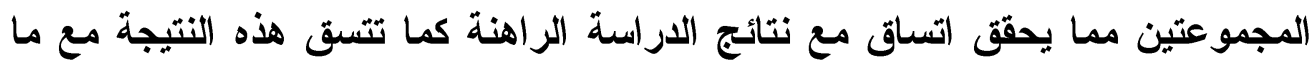
يذكره "كرستين" (Cristine, 2009, 140) من أن للسلوك الأسرى أثر بالغ على ظهور

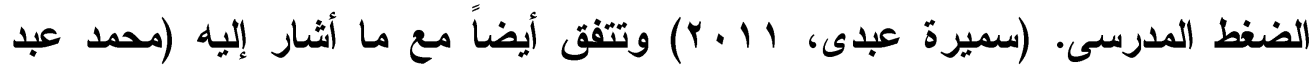

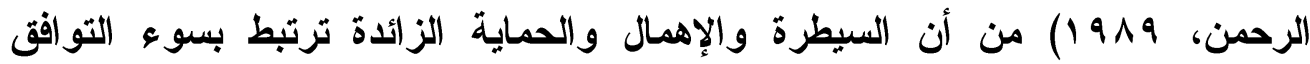

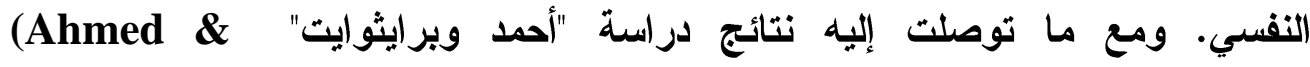
Braithwaite, 2004) وأن أسر الطلبة الضحايا كانت أكثر تفكاً. كما يفسره ما يذكره "سميث وتويملو وهوفر" (Smith; Twemlow \& Hoover, 1999) ذكروا أن العلاقات السلبية أو غير المرغوب فيها هي السائدة مع أحد أو كلا الوالدين. وعن دور الضغوط المدرسية جاء إسهام هذا المتغير فى التنبؤ بالمشكلات النفسية

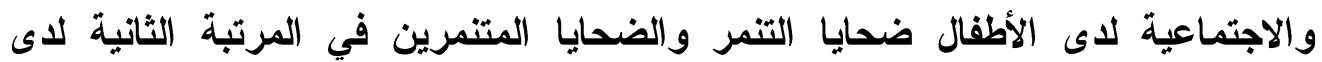




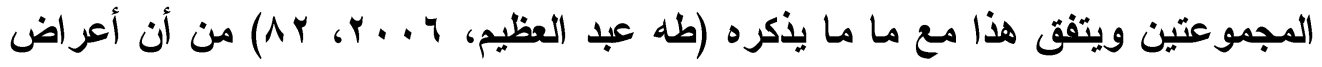
الضغوط المدرسية عديدة ومتنوعة منها النفسية: كالوساوس، وانخفاض تقدير الذات، ونقص الثقة بالنفس، والغضب. ومنها السلوكية: وتتمثل فى العدوانية مع الهروب من

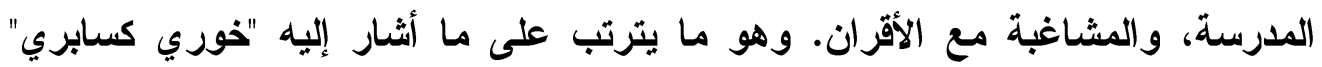
(Khoury-Kassabri, 2009) المتنمرين يتعرضوا لسوء المعاملة النفسية والجسدية والعاطفية من جانب موظفى

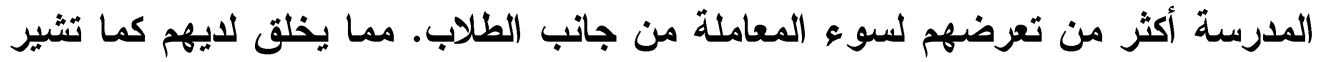
"تاديا" (Nadia, 2009, 15) توتر واضطر ابات نفسية تؤثر فى أدائهم وصحتهم النفسية

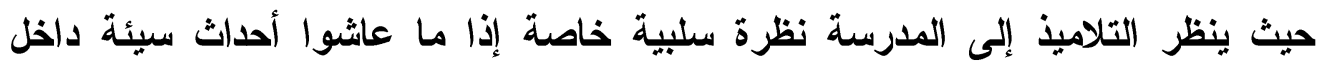

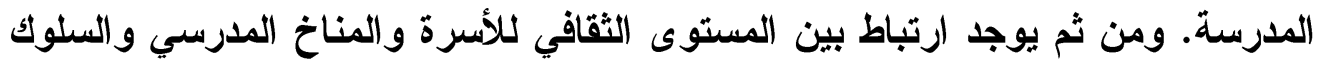
التنمري كما يرتبط التنمر ببغض الاضطر ابات النفسية الأخرى كالقلق والاكتئاب وغيرها. (Hilton; Anngela-Cole \& Wakita, 2010) و المدرسين قد يخفف من آثار التنمر على جودة حياة الضحايا ومشكلاتهم. Flaspohler) et al., 2009)

$$
\text { تلقروض إلى حد كبير. }
$$

فى ضوء ما أسفرت عنه نتائج الدراسة الراهنة توصى الباحثة وترى أنه لابد من

تفعيل دور كل من الأسرة والمدرسة والأخصائى النفسى للحد من هذه الظاهرة وهو النها

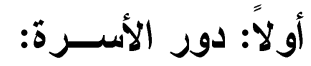

ا - فتح حوار هادئ مع الآبناء للتعرف على ما يحدث لهم.

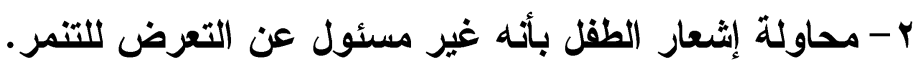

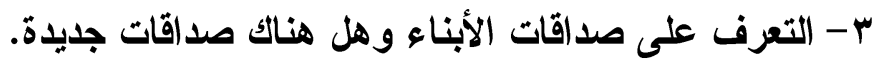
ع - محاولة جعل الطقل فى حالة تأهب لإمكان حدوث التنمر لله، من خلاكل سرد السلوكيات

$$
\text { التنمرية التى يمكن أن يتعرض لهار الها. }
$$

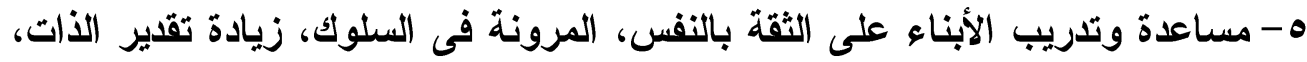

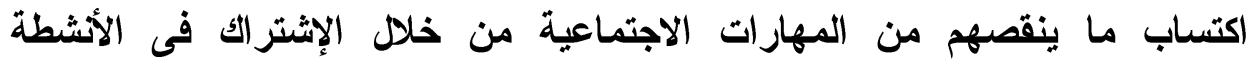

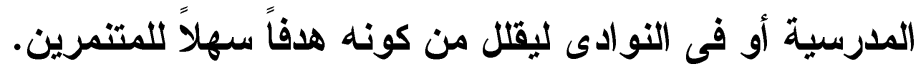


ضحايا التنمر من الأطفال ذوي صعوبات التعلم "دراسة لأهم المثكلات النفسية والاجتماعية فى ضوء بعض المتغيرات النفسية" -

$$
\text { ૧ - مساعد الأبناء على التفوق الدراسى. }
$$

V- تعليم الأبناء مهارات الإحساس بالأمان كاللجوء إلى طلب المساعدة من القائمين على

$$
\text { رعايتهم: الوالدين، المدرس، الأخصائى النفسى وغيرهم. }
$$

1- تعليم الأبناء على استخدام الأساليب الابلوماسية المناسبة للتخلص من الأوضاع الحرجة.

9- التواصل المنتظم مع المدرسة والمدرسين للوقوف على مدى إمكانية الحد من هذه المشكلة وما تثمر عنه من آثار سلبية، ومساعدة الطقل الضحية من خلال الإستفادة

$$
\text { التوجيه والإرشاد للضحية وللأسرة. }
$$

• - قـ يصبح الأطفال الأين تعرضوا للتنمر متنمرين (من كثرة الإحساس بالظلم والإحباط) على أطفال أخرين، ومن ثم يجب إخضاعه لبرامج تعديل لهذا السلوك

المشكل من قبل المعالجين النفسيين.

$$
\text { ثانياً: دور المدرسة: }
$$

ا-دعم التواصل المباشر بين المدرسة والآباء لتوفير مناخ مدرسى وأسرى مناسب

$$
\text { لكلأبناء لاحتواء الأبناء. }
$$

ץ- اشر الك الأطفال ضحايا التنمر فى الأنشطة المدرسية والاجتماعية التى تناسب ميولهم واهتماماتهم حيث من شأن ذلك أن يزيد من الثقة بالنفس وتقدير الذات والمهارات الاجتماعية لايهمث.

ب- عقد مجلس للآباء مع المدرسين وإدارة المدرسة والإخصائى النفسى لطرح مشكلة التنمر وأبعادها وكيفية مقاومتها وآثارها السلبية على المتنمر والضحية، وتوعية الآباء بدورهم بتوعية أبنائهم حتى لا تحدث، وما يتم اتخاذه من تدابيز إزاء حدوث

$$
\text { هذه المشكلة لأبنائهم المتنمرين والضحايا. }
$$

ع - تدريب الأطفال ضحايا التنمر على اكتساب ما ينقصه من المهارات الاجتماعية مثل: ممارسة الاستجابات التوكيدية، والمبادأة، والثقة بالنفس والمرونة من خلال الأشطة القتية والتربوية ومن خلال السيكودراما وآداء الاور، وفنيات العلاج النفسى من قبل الأخصائى النقسى. ه- تزويد المدرسين الطلاب بمعلومات واضحة داخل الفصل عن مشكلة التنمر، ومناقشتها فى إطار المنهج الاراسى (أو فى إطار حصص الإرشاد الأكاديمى) مع الإستعانة ببعض نماذج من الأفلام المتصلة بهذه المشكلة من خلال الفيديو بهدف 


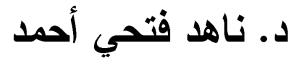

توضيح مدى رفض المجتمع والأسر والأفراد لسلوك التنمر وأنه سلوك غير مقبول اجتماعياً.

؟- القيام بإجراءات عقابية محددة وواضحة ضد المتنمرين على مرأى من أقرانه ومن

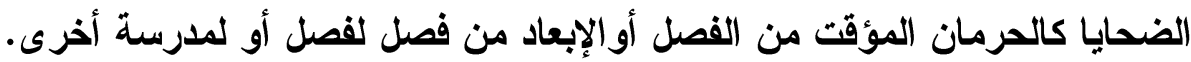

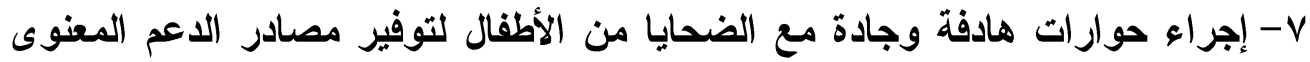
و المساندة الاجتماعية. ^- ازدياد تخاذ كافة إجراءات المراقبة والإثراف على سلوك الأطفال داخل المدرسة وخاصة الأماكن التى يتوقع حدوث سلوك التنمر بأرجائها مثل: الحمامات، فناء المدرسة، الملاعب، الطرق المؤدية من المدرسة وإليها (ولذا يجب تنظيم الذهاب الأبات

$$
\text { والإياب مع أحد أفراد الأسرة الأكبر سناً). }
$$

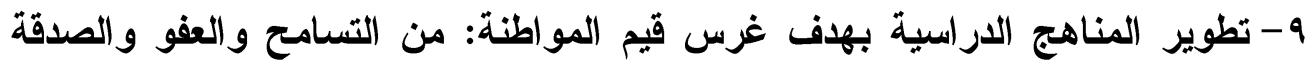
بين والتواصل بين الأقران وبين المدرسين وبين إدارة المدرسة. • 1 - تعزيز السلوكيات الإيجابية والاجتماعية التى تصدر من قبل الطلاب.

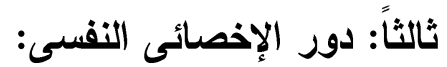
1- تشخيص الحالات من خلال تطبيق الاختبار ات والمقاييس، ومتابعة هذه الحالات. r- القيام بعمل برامج سلوكية تساعده فى حل مشكلات الأطفال، و التحكم فى أنفسهر.

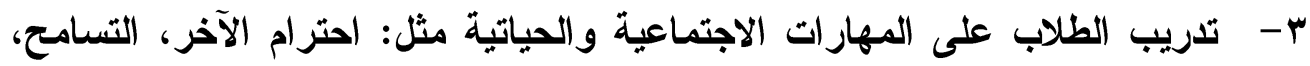

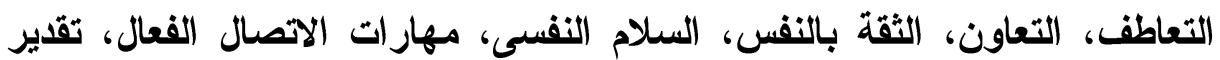
الأتات للسيطرة على الصر اعات بين النتنمر والضحية.

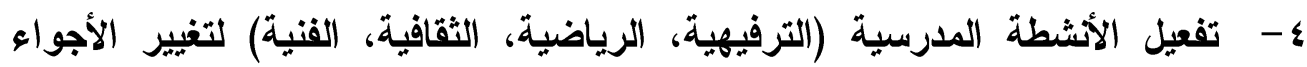
العامة للمدرسة و إثراك الطلاب لتفريغ الطاقة السلبية والمكبوتة لايهم وتحويلها لهنها لطاقة إيجابية. ه- تتح حوار هادئ مع الطلاب والاهتمام بالثكاوى المقدمة من الطلاب والآباء من أجل دعم اكتساب الطلاب سلوك طلب المساعدة. צ- معاملة الطلاب على قم المساواة دون تمييز. -V - القيام بعل ندوات للطلاب والآباء للتعرف على كيفية التعامل مع الأطفال المتنمرين وضحايا التنمر · 
ضحايا التتمر من الأطفال ذوي صعوبات التطلم "دراسة لأهم المشكلات النفسية والاجتماعية فى ضوء بعض المتغيرات النفسية" ^- تثكيل فريق للصحة النفسية يقوم بالإشاد والتوجيه والوقاية وإثراتك الطقل

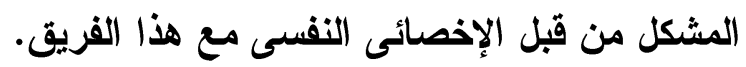
9- - تشجيع السلوك الإيجابى من قبل الأطفال.

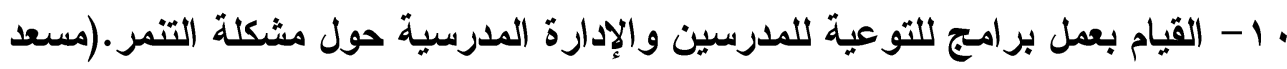

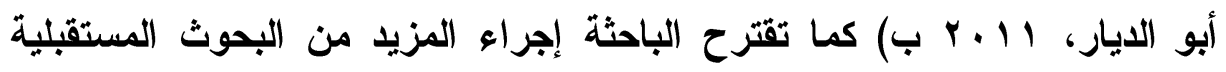
حول دراسة: - العلاقة بين التعرض للتنمر والتسرب المدرسى للى ضحايا التنمر "دراسة عبر حضارية".

- دراسة للخصائص الثخصية والنفسية للمتنمر والضحية والمشاهدين لسلوك - التنمر

- دور الانشطة المدرسية وتعلم المهارات الاجتماعية فى مواجهة التنمر. - الكفاعة المهنية للإخصائى النفسى كمدخل للحد من معدل التنمر المدرسى. - فاعلية برنامج معرفى سلوكى للد من الأثار النفسية لاع ضحايا التنمر . 
د. ناهد فتحي أحمد

$$
\text { المر اجع: }
$$

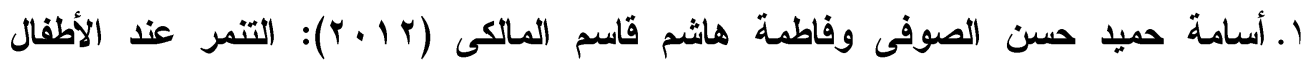

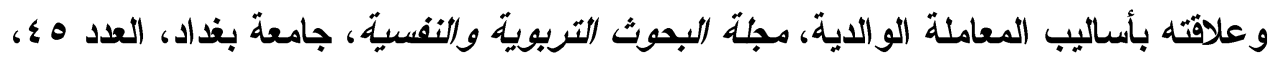

$$
.1 \wedge \wedge-1 \leqslant 4
$$

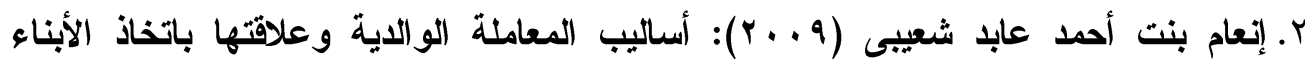

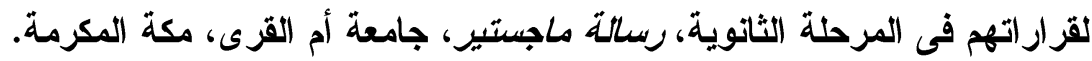

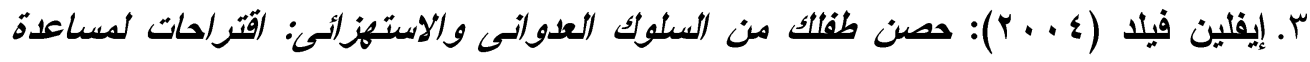

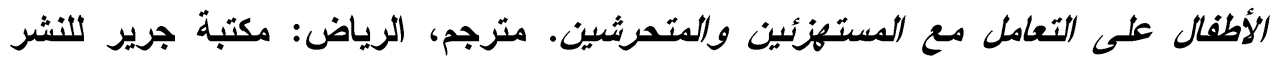

$$
\text { و التوزيع. }
$$

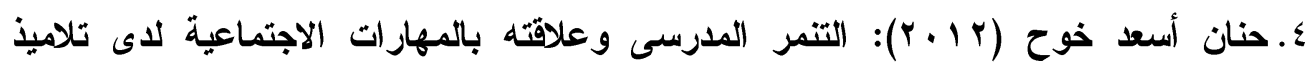

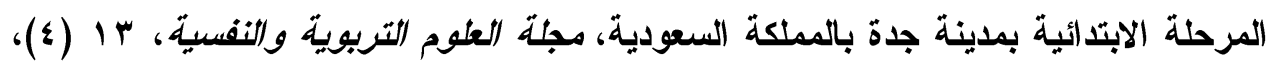

$$
\text { . } 1 \wedge-1 \wedge \Lambda
$$

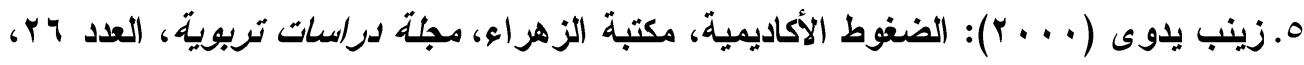

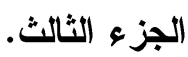

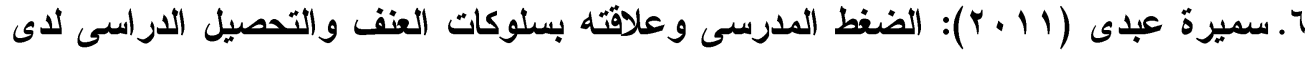

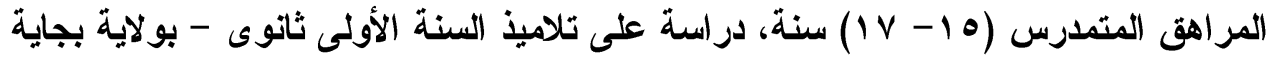
نموذجاً - رسالة ماجستير، وزارة التعليم العالى والبحث العلمى، كلية العلوم الإسنانية

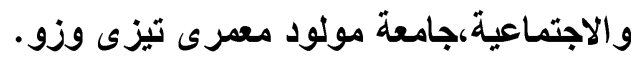

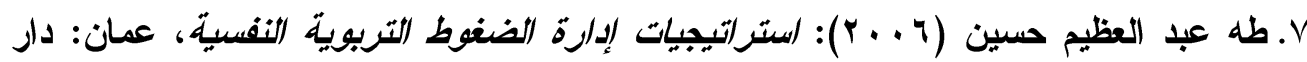
الفكر . (2)

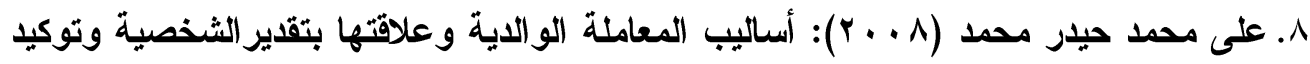

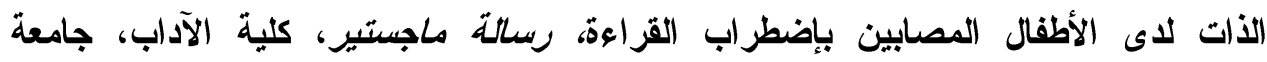

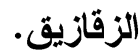

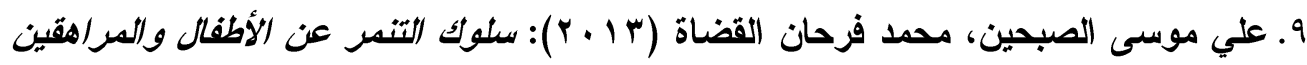

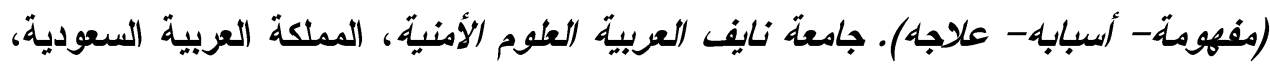

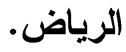

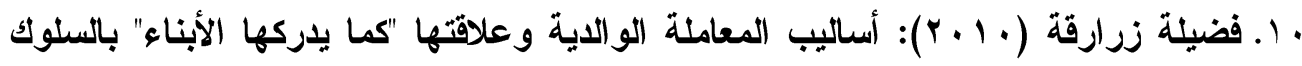

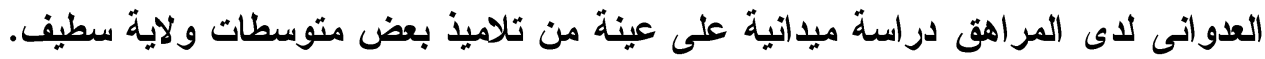

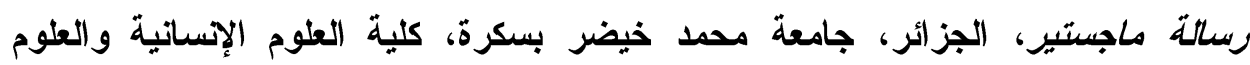

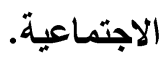


ضحايا التنمر من الأطفال ذوي صعوبات التعلم "دراسة لأهم المثكلات النفسية والاجتماعية فى ضوء بعض المتغيرات النفسية" -

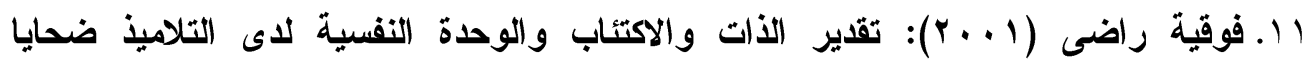

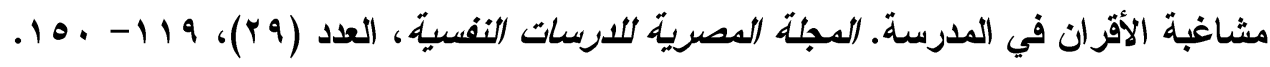

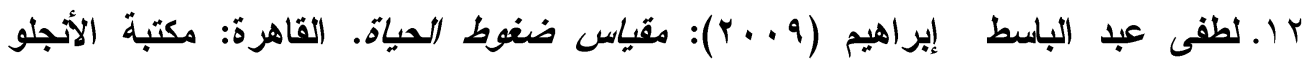
المصرية.

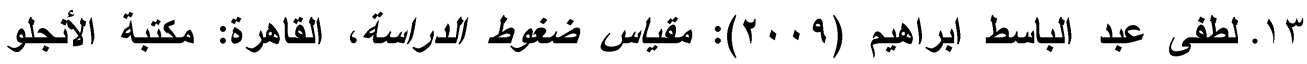
المصرية.

ـ ا ـ اللين بين (ه . . ب): الصف النالحي من الطلاب المستغوين أكثر من مئة فكرة وإستراتيجية لمعلمي الصفوف من الروضة للثانسي المتوسط ترجة مدارسي الظهران الأهلية. الامام: دار الكتاب التربوي للنشر والتوزيع (تاريخ النشر الأصلي 999 ( ) ).

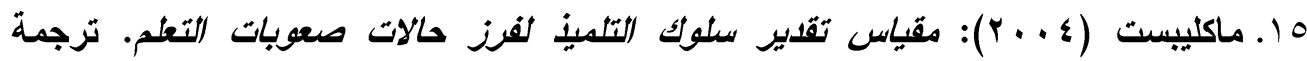
مصطفى محمد كامل، القاهرة: مكتبة الأجلو المصرية، الطبعة الر ابعة. ا ا. مجدى محمد الاسوقى (10 • r): مقياس التعامل مع السلوك التتمرى، القاهرة: مكتبة الأنجلو المصرية. V . محمد عبد الرحمن ( 919 1): أساليب المعاملة الوالاية كما يدركها العصابيون والأهانيون

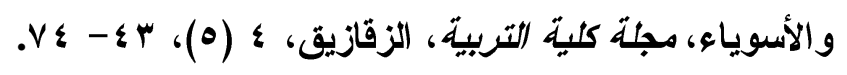

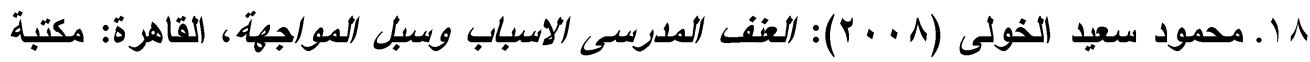
الأنجلو المصرية. 9 1. مسعد نجاح أبو الايار (11 ـ r أ): سيكولوجية التنمر بين النظرية والعلاج، الكويت: مكتبة الكويت الوطنية.

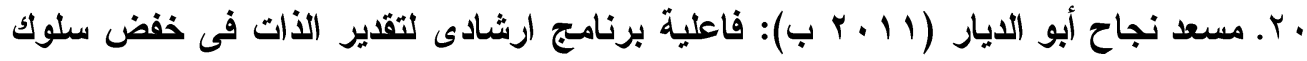
التنمر لاى الأطفال ذوى اضطراب الاتتباه المصحوب بفرط الحركة، مجلة مركز البحوث واللدراسات النفسية ، جامعة/القاهرة، عدد فبر اير الاطري

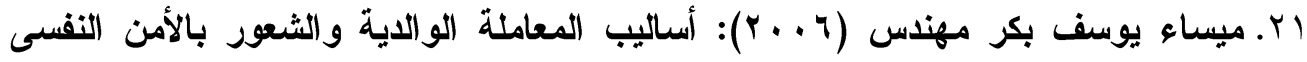
و القلق لاى عينة من طالبات المرحلة المتوسطة بمدينة جدة، رسالة ماجستبر غير منشورة،

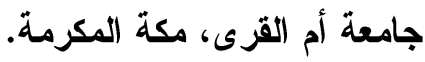

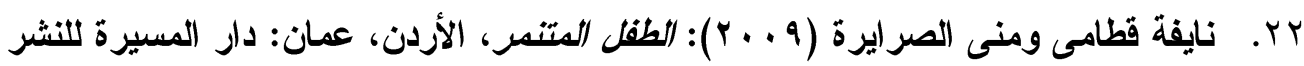
و التوزيع و الطباعة.

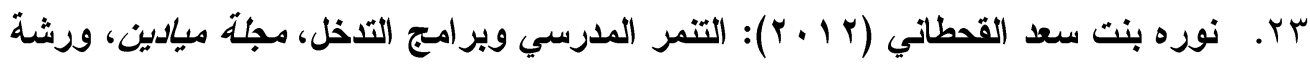

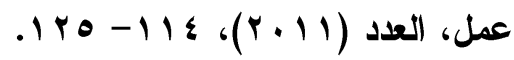




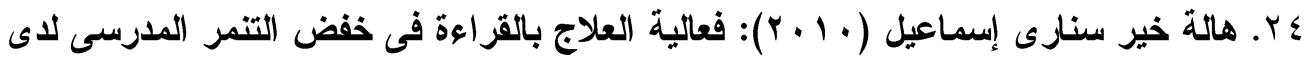

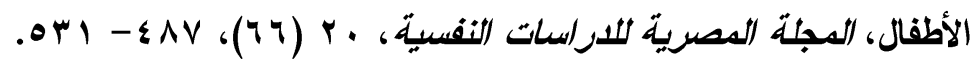

25. Academic correlates of Bullying and victimization in middle school, Journal of Adolescence, 32 (2), 193- 211.

26. Adams, J. (2006): What makes a bully tick?. Science World, 63 (4), 10-13.

27. Adamski, A. L \& Ryan, M. E. (2008): Minimizing female bullying in middle school students through anti- bullying programs. An Action Research Project Submitted to the Graduate Faculty of the School of Education in Partial Fulfillment of the Requirement for the Degree of Master of Arts in Teaching and Leadership, Saint Xavier University. Chicago, Illinois

28. Ahmed, E \& Braithwite, V (2004): Bullying and victimization: Causc for concern for both families and schools. Social psychology of education. 7, 35-45.

29. Andreou, E; Bonoti, F, (2010): Children's Bullying Experiences Expressed through Drawings and Self-Reports, School psychology International, 31 (2), 164- 177.

30. Ballard M., Argus T., and Rempley T. P. (1999): Bullying and School Violence: A proposed Prevention Program, NASSP Bulletin, 2, 38- 47.

31. Beane, A. L. (1999): Bully free classroom. Minneapolis, MN: Free Spirit Publishing, Inc.

32. Beane, A. L. (2008): Protect Your Child from Bullying: Expert Advice to Help You Recognize, Prevent, and Stop Bullying Before Your Child Gets Hurt, San Francisco: Jossey-Bass, A Wiley imprint, United States Of America.

33. Bear, G. G.; Mantz, L. S.; Glutting, J. J. \& Yang C. (2015): Differences in Bullying Victimization Between Students With and Without Disabilities, School Psychology Review, 44 (1), 98 - 116.

34. Black, S. A., \& Jackson, E. (2007): Using bullying incident density to evaluate the Olweus Bullying Prevention Programme. School Psychology International, 28, 623- 638.

35. Bond,L; Carlin, J; Rubin; K, \& Patton, G. (2001): Dose Bullying Cause Emotional Problems; S Prospective Atudy OF Yong Teenagers. British Medical Journal, 323, 480 - 483.

36. Cammack-Barry, T. (2005): Long-term impact of elementary school bullying victimization on adolescents. Dissertation Abstrats International: The Sciences and Engineering, 65, (9-B), 4819- 4854.

37. Campbell, M, A. (2005): Cyber bullying: An old problem in a new guise?. Australian Journal of Guidance and Counselling, 15 (1), 68- 76.

38. Carlson, E; Flannery, M; \& Kral, M. (2005): Differences in bully/victim problems between early adolescents with learning 
ضحايا التنمر من الأطفال ذوي صعوبات التعلم "دراسة لأهم المثكلات النفسية والاجتماعية فى ضوء بعض المتغيرات النفسية" -

disabilities and their non-disabled peers. Online submission, (ERIC Document reproduction service no. ED490374) Retrievedjuly l, 2007, from ERIC database.

39. Carroll-Lind, J; Kearney, A. (2004): Bullying: What Do Students Say?. Kairaranga, 5 (2), 19 - 24.

40. Conners-Burrow, N, A.; Johnson, D I.; Whiteside-Mansell. I.;

Mckelvey L.; Gargus, R. A, (2009): Adults matter: protection children from the negative impacts of bullying. Psychology in the schools, 46, (7), 593 - 604.

41. Crothers, M \& Levinson, E. (2004): Assessment of Bullying: A Review of Methods and Instruments. Journal of Counseling \& Development, 82 (4), 496- 503.

42. Delfabbro, P; Winefield, T; Trannor, S; Dollard, M; Anderson, S; Metzer, J. \& Hammarwtorm, A (2006): Peer and teacher bullying/ victimization of south australin secondary school students: prevalence and psychosocial profiles. British journal of educational psychology, 76, $71-90$.

43. Dilmac, B. (2009): Psychological Needs as a Predictor of Cyber Bullying: A Preliminary Report on College Students: Theory and Practice Educational Sciences, 9 (3), 1307 - 1325.

44. Eslea, M. Menesini, E. Morita, Y. Omoore, M. Mora-Merchan, J. Pereita, B. \& Smith, P. (2003): Friendship and loneliness among bullies and victims: Datat from seven countries. Aggressive behavior, 30, 71-83.

45. Farmer, T. W., Petrin, R., Brooks, D. S., Hamm, J. V., Lambert, K., \& Gravelle, M. (2010): Bullying in- volvement and the school adjustment of rural students with and without disabilities. Journal of Emotional and Behavioral Disorders, 20, 19 - 37.

46. Flaspohler, P. D., Elfstrom, J. L., Vanderzee, K. L., Sink, H. E., \& Birchmeier, Z. (2009): Stand by me: the effects of peer and teacher support in mitigating the impact of bullying onquality of life. Psychology, 46, 636 - 649.

47. Georgiou, S. (2008): Bullying and victimization at school: The role of mothers. British Journal of Educational Psychology, 78 (1), 109 125.

48. Gladden, R. M., Vivolo-Kantor, A. M., Hamburger, M. E., \& Lumpkin, C. D. (2014): Bullying surveillance among youths: Uniform definitions for public health and recommended data elements, version 1.0. Atlanta, GA: National Center for Injury Prevention and Control Centers for Disease Control and Prevention and US Department of Education

49. Grills, A. F. \& Ollendick, T. (2002): Peer victimization, global selfworth, and anxiety in middle school children. Journal of Clinical Child and Adolescent Psychology, 3 (1), 59 - 68. 
50. Health, M. A; Dyches, T. T. \& Prater, M. A. (2013): Classroom bullying prevention, pre-k 4 th grade children's books, lesson plants, and activities santa barbara, California: Linworth.

51. Hillsbereg, c \& Spak, H. (2006): Young adult literaturece of as the centerpiece of an anti-bullyingprogram in middle school. Middle school Journal, 38 (2), 23 - 28.

52. Hilton, J.; Anngela-Cole, L. \& Wakita, J. (2010): A cross- cultural comparison of factors associated with school bullying in Japan and the united states. family journal: Counseling and therapy for couples and familles, 18 (4), 413 - 422.

53. Holt, M. K; Kantor, G. K \& Finkelhor, D. (2009): Parent/child concordance about bullying involvement and family characteristics related to bullying and peer victimization, Journal Of School Violence, 8, 42- 63.

54. Ingesson. S. \& Gunnel. D (2007): Growing up with dyslexia: interviews with teenagers and young adults, International, 28 (5), 574591.

55. James, R. (2010): Trajectories of parents' experiences in discovering, reporting, and living with the aftermath of middle school bullying. Ph.D. Faculty of the University Graduate School: Indiana University.

56. Juvonen, J \& Graham, S. (2014): Bullying in schools: The power of bullies and plight of victims. Annual Review of Psychology, 65, 159185.

57. Juvonen, J. Graham, S. \& Schuser, M. (2003): Bullying among young adolescents: the strong, the weak, and the troubled. Pediatrics, $12(6), 1231$ - 1237.

58. Kerryn, P. (2001): Does bullying cause emotional Problems? A Prospective Study on Young Teenagers. British Medical Journal, 323 (73), 1 - 13.

59. Khoury-Kassabri, M. (2009): The relationship between staff maltreatment of students and bully-victim group membership, child abuse \& neglect the international journal, 33 (12), 914 - 923.

60. Kilpatrick. D \& Kerres, M. (2003): Perceptions of the frequency and importance of social support by students classified as victims. Bullies, and bully victims in an urban middle school, psychology Review, 32 (3).

61. Klomek, A, B; Kopelman-Rubin, D; Al-Yagon, M. ; Berkowitz, R. ; Apter, A. M. \& Mikulincer, M. (2015): Victimization by Bullying and Attachment to Parents and Teachers Among Student Who Report Learning Disorders and/or Attention Deficit Hyperactivity Disorder, Learning Disability Quarterly, 23, 1 - 9. 
ضحايا التنمر من الأطفال ذوي صعوبات التعل "دراسة لأهم المثكلات النفسية والاجتماعية فى ضوء بعض المتغيرات النفسية" ـ

62. Kokkinos, O. M. \& Panayiotou, G. (2004): Predicting Bullying and Victimization Among Early Adolescents: Associations With Disruptive Behavior Disorders, Aggressive Beahavior, 30, 520 - 533.

63. Kristensen, s \& Smith, P. (2003): The Use of Coping Strategies by Danish children classed as a Bullies, Victims, Bully Victims, and Not Involved in Response to Different (Hypothetical) Types of Bullying. Scandinavian Journal of Psychology, 44, 479 - 488.

64. Kuakiainen, A. Salmivalli, C. Lagerspetz, K. Tamminen, M. Vauras, M. Maki, H. \& Poskiparta, E. (2002): Learning difficulties, social intelligence, and self-concept: connections to bully-victim problems. Scandinavian, journal of psychology, 43, 269 - 268

65. Levinson, J. (2003): The effects of treatment of dyslexia children on self - esteem and behavior, Dissertation Abstracts international, 64 (5B), 2393.

66. Lindsay,G; Dockrell, J \& Mackie, C. (2008): Vulnerability to bullying in children with a history of specific speech and language difficulties, European journal of special needs education, 23 (1), 1 - 16.

67. Litz, E. (2005). A an analysis of bullying behaviors at E. B. Stanley, middle school in Abingdon. Virginia, published doctoral dissertation, east Tennessee state university.

68. Luciano, S \& Savage, R. (2007): Bullying risk in children with learning difficulties in inclusive educational settings, Canadian, Journal of school psychology, 22 (1), 14 - 31.

69. Marsh, H. W., Nagengast, B., Morin, A. J. S., Parada, R. H., Craven, R. G., \& Hamilton, L. R. (2011). Construct validity of the multidimensional structure of bullying and victimization: An application of exploratory structural equation modeling. Journal of Educational Psychology, 103, 701 - 732.

70. Martlew, M \& Hodson. J. (1991): Children with mild learning difficulties in at integrated and in a special school: comparisons of behavior, teasing and teachers' attitudes, British journal of educational psychology , 61 (3), 355 - 369.

71. McNamara, J; Vervaeke, S. \& Willoughby, T (2008): Learning disabilities and risk-taking behavior in adolescents: a comparison of those with and without comorbid attention-deficit/hyperactivity disorder, Journal of learning disabilities, 41 (6), 561- 574.

72. Minton, S, J. (2010): Students' experiences of aggressive behaviour and bully victim problems in irish schools, Irish Educational Studies, 29 (2), 131 - 132

73. Mishna. F. (2009): Learning disabilities and bully in faculty of social work. university of Toronto, 246 bloor street west. Toronto. Ontario, m551a1 f.mishna@utoronto.ca 
74. Mynard, H \& Joseph, S. (1997): Bully/victim problems and their association with Eysenck's personality dimensions in 8 to 13 year-olds. British Journal of Educational Psychology, 67 (1), 51 - 54.

75. Nabuzoka. D \& Smith. P. (1993): Sociometric status and social behavior of children with and without learning difficulties, Journal $O f$ Child Psychology and Psychiatry, 34 (8), 1435 -1448.

76. Nabuzoka. D. (2003): Teacher ratings and peer nominations of bullying and other behavior of children with and without learning difficulties, Educational Psychology, 23 (3), 307.

77. Nadia, R. (2009): Students' experiences of aggressive behaviour, Augustin, 4ed Canada.

78. Nansel, T. R., Overpeck, M. D., Haynie, D. L., Ruan, W. J., \& Scheidt, P. C. (2003): Relationships between bullying and violence among youth. Archives of Pediatrics \& Adolescent Medicine, 157, 348 353.

79. Nansel, T; Overpeck, M; Pilla, R; Ruan, W; Simmons-Morton, B \& Scheidt, P. (2001): Bullying behaviors among US youth: prevalence and association with psychosocial adjustment. Journal of the American Medical Association, 285 (16), 2094 - 2100.

80. National children's burea (NCB) (2007): Bullying and disability, Spotlight briefing, London, www.anti-bullying.ncb org uk

81. Newcomer, p: Barenbaum, E \& Pearson, N. (1995): Depression and Anxiety among children and adolescents with Learning disabilities, conduct disorder and disabilities. Journal of Emotion and Behavior Disorders, 3, 27 - 29.

82. Nikiforou, M., Georgiou, S. N., \& Stavrinides, P. (2013): Attachment to parents and peers as a parameter of bullying and victimization. Journal of Criminology, volume 2013, Article ID 484871, 9 pages. http://dx.doi.org/10.1155/2013/484871

83. Norwrich, B; Kelly, N (2004): Pupils' views on inclusion: moderate learning difficulties and bullying in mainstream and special schools, British Educational Research Journal, 30 (1), 43 - 65.

84. O'Brennan, L. M.; Bradshaw, CP.; Sawyer, AL. (2009): Examining development differences in the social emotional problems among frequent bullies victims, and bully/ victims, Psychology in the Schools, 46 (2), 100 - 115.

85. Olweus, D. (1993): Bullying at school. Oxford, UK; Blackwell publishing company.

86. Olweus, D. (1999): Norway. In P.K. Smith, R.Catalano \& P. Slee (eds.) The nature of school bullying : A cross - national perspective (pp. 28-48). London Rutledge.

87. Olweus, D. (2013): School bullying: Development and some important challenges. Annual Review of Clinical Psychology, 9, 751 780 . 
ضحايا التنمر من الأطفال ذوي صعوبات التعل "دراسة لأهم المثكلات النفسية والاجتماعية فى ضوء بعض المتغيرات النفسية" ـ

88. O'moore, A, M, M \& Kirkham C. (2001): Self-esteem and its relationship to bullying behavior. Aggressive Behavior, 27, 269 - 283

89. Pellegrini, A. D \& Long, J. D. (2002): A longitudinal study of bullying, dominance, and victimization during the transition from primary school through secondary school. The British Psychological Society. British Journal of Developmental Psychology, 20 (2), 259 - 280.

90. Pollastri, AR; \& Cardemil, EV \& O'Donnell, E. (2010): Self-esteem in pure bullies and bully/victims: a longitudinal analysis, Journal of interpersonal violence, 25 (8), 1489 - 1502.

91. Quiroz, H; Arnette, J., \& Stephens, R. (2006): Bullying in schools fighting the bully Battle. Eribaum: National School Safety Center, NJ.

92. Reid, P; Monsen, J \& Rivers,I (2004): Psychology's Contribution to Understanding and Managing Bullying within Schools, Educational Psychology in Practice, 20 (3).

93. Righby, K; Slee, P \& Cunningham, R. (1999): Effects of parenting on the peer relations of Australian adolescents. The journal of social psychology, 139 (3), 387 - 388.

94. Rose, C. A.; Espelage, D. L. \& Monda-Amaya, L. E. (2009): Bullying and victimization rates among students in general and special education: A comparative analysis. Educational Psychology, 29, 761 776.

95. Rose, C. A., Monda-Amaya, L. E., \& Espelage, D. L. (2011): Bullying perpetration and victimization in spe cial education: A review of the literature. Remedial and Special Education, 32, 114 - 130.

96. Ruble, D. (1978): sex differences in personality and abilities in J, Frieze, J parsons, P. Johson D puble \& G Zeuman (Eds) women \& sex Roles. A social psychological perspective. New York, WW Norton on Company.

97. Sarazen, J. A. (2002): Bullies and their victims: identification and interventions. A research paper. University of Wisconsin- stout.

98. Schwartz, D; Farcer, J; Change, L \& Lee-shin, Y. (2002): Victimization in South Korean children's peer groups. Journal of abnormal child psychology, 30, 113 -125.

99. Seals, D \& Young J. (2003): Bullying and victimization: Prevalence and relationship to gender, grade level, ethnicity, self- esteem, and depression. Adolescence, 38, 735-747.

100. Shaw, D. ; Dooley, J. ;Cross, D. ;Zubrick, S. \& Waters, S. (2013): The forms of Bullying scale (FBS): Validity and reliability estimates for a measure of Bullying victimization and perpetration in adolescence. Psychological Assessment, 25 (4), 1045 - 1057.

101. Shin. Y, (2010): Psychosocial and friendship characteristics of bully/victim subgroups in dorean primary shool chikdren, School Psychology International, 31 (4), 372 - 388. 
102. Smith, J. Twemlow, S \& Hoover, D. (1999): Victims and bystanders: a method or in school intervention and possible parental contributions. Child intermational, 31 (4), 372- 288.

103. Smith, P. K.; Mahdavi, J.; Carvalho, M.; Fisher, S.; Russell, S. \& Tippett, N. (2008): Cyberbullying: Its nature and impact in secondary school pupils. Journal of Child Psychology and Psychiatry, 49, 376-385.

104. Smith, S. (2001): Kids hurting kids: Bullies in the Schoolyard. Mothering Magazine, 7 (12), 43 - 59.

105. Smorti, A., Ortega, J., \& Ortega, R. (2006): Discrepant Story Task (DST): An instrument used to explore narrative strategies in bullying. Electronic Journal of Research in Educational Psychology, 9 (2), 397 426.

106. Spade J. A. (2007): The relationship between student bullying behaviors and self-esteem. Published doctoral dissertation, college of bowling green, state university.

107. Tom, R; Schwartz, D; chang, L; farver, J; Xu, Y. (2010): Correlates of victimization in Hong Kong Children's peer groups, Journal of Applied developmental psychology, 31 (1), 27 - 37.

108. Turner, H. A., Vanderminden, J., Finkelhor, D., Hamby, S., \& Shattuck, A. (2011). Disability and victimization in a national sample of children and youth. Child Maltreatment, 16, 275 - 286.

109. Turner, M. G., Exum, M. L., Brame, R., \& Holt, T. J. (2013): Bullying victimization and adolescent mental health: General and typological effects across sex. Journal of Criminal Justice, 41, 53 - 59.

110. Unnever, J. (2005): Bullies, Aggressive Victims, And Victims: are they distinct group?, Aggressive behavior, 31, 153 - 171.

111. Varjas, K; Henrich, Ch; Meyers, J. (2009): Urban Middle school student's perceptions of Bullying, cyber bullying, and school safety, Journal of School Violence, 8 (2), 159 - 176

112. Vervoort, M; Scholte, R \& Overbeek, G. (2010): Bullying and victimization among adolescents: The role of ethnicity and ethnic composition of school class. Journal of youth and adolescence, 39 (1), 111.

113. Viding, E ; Simmonds, E; Simmonds, E; Petrides, K; Frederickson, N. (2009): The contribution of callous-Unemotional Traits and Conduct problems to Bullying in Early Adolescene, Journal of child Psychology and Psychiatry, 50 (4), 471 - 481.

114. Von, M ; Petermann, f. (2010): Bullying in german Primary schools ; gender Differences, Age Trends and influence of parents ' Migration and Educational Backgrounds, School psychology International, 31 (2), 178-198.

115. Wiener, T. M; Green, A ; Karver, M \& Gesten, E. (2009): Multiple Informants in the Assessment of Psychological, Behavioral, and 
ضحايا التنمر من الأطفال ذوي صعوبات التعل "دراسة لأهم المثكلات النفسية والاجتماعية فى ضوء بعض المتغيرات النفسية" ـ

Academic correlates of Bullying and victimization in middle school, Journal of Adolescence, 32 (2), 193 - 211.

116. Wolke, D ; Sarah, W ; Stanford, K \& Schulzs. (2002): Bullying and Victimization of Primary School Children in England and German: Prevalence and School Factors. British Journal of Psychology, 92, 673 . 696.

117. Woods, S ; Wolke ,D. (2003): Does the content of Anti-Bullying policies inform us About the prevalence of Direct and Relational Bullying behavior in primary schools ?, Educational Psychology, 23. (4).

118. Woods, S ; wolke ,D; Nowicki, S; hall, L. (2009): Emotion Recognition Abilities and Empathy of Victims of bullying, child Abuse \& neglect, The International Journal, 33 (5), 307 - 311.

119. Wright, J. (2004): Preventing Classroom Bullying: What Teacher Can Do? Retrieved October 20, from http://www. interventioncentral.org

120. Yang, S. kim, J. kim, s. shin. I. \& yoon, J. (2006): Bullying And Victimization Behaviors in Boys And Girls At south Korean Primary schools. Journal Of American Academy Of Child \& Adolescent Psychiatry, 45 (1), 69 - 77.

121. Young, E. L; Heath, M. A ; Ashbaker, B. Y; smith, B. (2008): Sexual Harassment among students with Educational Disabilities; Perspectives of special Educators, Remedial and special Education, 45 (4), 1308-1316.

122. Young, J; Ne'eman, A \& Gelser, S. (2011): Bullying and students with disabilities. Briefing paper from the National Council on Disability, Washington, DC.

123. Zacchili, L.T. \& Valerio, C.Y. (2011): The knowledge and prevalence of cyberbullying in a college sample. Journal of Scientific Psychology. Journal of Scientific Psychology, 21, March, Retrieved prevalence_in_a-college_sample.pdf.

The victims of bullying of children with learning difficulties "Study of the most important psychological and social problems in the light of some Psychological variables"

Nahed Fathey Ahmed, Ph. D.

Objectives: The current study aimed to identify the most important psychological and social problems of children victims and bullyvictims with learning difficulties, discovering of differences between in school pressures and abnormal styles of parental socialization, and discovering differences between two groups according to gender on the one hand. Forms of bullying prevailing that experienced by those children, and Methods of dealing they have with the bullying behavior 
on the other. Additionally, identify the role school pressures and abnormal styles of parental socialization as predictor of most important psychological and social problems of children victims and bully- victims with learning difficulties. Method and Procedures: A sample consisted of (342) child from male and female with a mean of $10.9(\mathrm{SD}=2.6)$ divided into three sub-groups: The First consisted of (169) of children victims, The second consisted of (173) of children bully- victims, and other group consisted of (170) of Children who have not bullying with learning difficulties. Study tools: The study used nine tools are: The basic data questionnaire, Bully/victim scale, the problems of life scale, The Pupil Rating Scale, Methods of dealing with bullying behavior scale, school pressures scale, abnormal styles of parental socialization scale, color Progressive matrices scale and social economic scale. Results: have shown: significant statistical differences between in most important psychological and social problems of children victims and bully- victims with learning difficulties, There were differences in school pressures, abnormal styles of parental socialization, Forms of bullying prevailing and Methods of dealing with bullying behavior. Finally, school pressures, abnormal styles of parental socialization were significant predictor of most important psychological and social problems of children victims and bullyvictims with learning difficulties. 